\title{
Breeding strategies for sustainable intensification of developing smallholder dairy cattle production systems
}

Charles M. Kariuki 


\section{Thesis committee}

\section{Promotors}

Prof. Dr J. Komen

Personal chair at the Animal Breeding and Genomics Group

Wageningen University \& Research

Prof. Dr J.A.M. van Arendonk

Professor of Animal Breeding and Genomics

Wageningen University \& Research

\section{Thesis co-promotor}

Prof. Dr A.K. Kahi

Professor of Animal Breeding and Genetics

Egerton University, Kenya

\section{Other members}

Prof. Dr A.G.J.M. Oude Lansink, Wageningen University \& Research

Prof. Dr E.H. Bulte, Wageningen University \& Research

Prof. R.A. Mrode, International Livestock Research Institute, Nairobi, Kenya

Dr P. Berg, Aarhus University, Denmark

This research was conducted under the auspices of the Graduate School of Wageningen Institute of Animal Sciences (WIAS). 


\section{Breeding strategies for sustainable intensification of developing smallholder dairy cattle production systems}

Charles Mbogo Kariuki

\section{Thesis}

submitted in fulfillment of the requirements for the degree of doctor

at Wageningen University

by the authority of the Rector Magnificus,

$$
\begin{gathered}
\text { Prof. Dr A.P.J. Mol, } \\
\text { in the presence of the }
\end{gathered}
$$

Thesis Committee appointed by the Academic Board

to be defended in public

on Monday 1 May 2017

at 1.30 p.m. in the Aula. 
Kariuki, C.M.

Breeding strategies for sustainable intensification of developing smallholder dairy cattle production systems,

134 pages.

PhD thesis, Wageningen University, Wageningen, the Netherlands (2017)

With references, with summary in English

ISBN 978-94-6343-095-1

DOI: http://dx.doi.org/10.18174/405836 


\section{Abstract}

Kariuki, C.M. (2017). Breeding strategies for sustainable intensification of developing smallholder dairy cattle production systems. PhD thesis, Wageningen University, the Netherlands

Smallholder dairy cattle production systems in Africa are intensifying production through importation of germplasm from breeding programs conducted in temperate regions to improve commercial cow populations. Presence of genotype by environment interaction results in unfavorable correlated responses. The aim this thesis was to develop strategies for breeding programs in developing countries that can support sustainable intensification of these systems. Specific objectives were (a) to determine desired gains for breeding objective traits, (b) compare progeny testing (PT) and genomic selection (GS) selection strategies, (c) evaluate the economic performance of PT and GS selection strategies and (d) compare genetic gains for economic and non-economic breeding objectives; the Kenya dairy cattle sector was used as a working example. To account for the limited pedigree and performance recording, a five-trait breeding objective and small-sized breeding program were studied. Breeding objective traits, determined based on producer preferences, were milk yield (MY), production lifetime (PLT), calving interval (Cl), fat yield (FY) and mature body weight (MBW). Producers were categorized into high intensive group, who placed highest preference on PLT and MY, and low intensity group that placed highest preferences on $\mathrm{Cl}$ and PLT. MY and FY were the most important traits for processors. Consensus desired gains, based on weighted goal programming, were 2.51, 2.42, 0.22, 0.87 and $0.15 \%$ for PLT, MY, Cl, FY and MBW, respectively. Comparison of breeding schemes shows that GS schemes had lower accuracies but gave higher responses per year due to shorter generation intervals. Besides genetic gains, economic performance underpins the adoption of selection strategies. GS schemes had between 3.2 and 5.2-fold higher cumulated genetic gain in the commercial cow population and higher gross margins compared to PT schemes. Semen storage made PT schemes more profitable but less so than GS schemes. Functional traits can increase the sustainability of resource poor smallholder systems under harsh environments. Economic breeding objectives yielded undesirable responses in functional traits. Breeding objectives based on desired gains or non-market objectives improved response in functional traits but at a monetary cost. It is concluded that sustainable productivity of smallholder systems can be improved by implementation of local breeding program based on $\mathrm{GS}$, but this requires more emphasis on functional traits, which can be achieved by use of non-economic objectives. 



\section{Contents}

5 Abstract

$9 \quad 1-$ General introduction

202 - Multiple criteria decision making process to derive consensus desired gains for a dairy cattle breeding objective for diverse production systems

463 -Optimizing the design of small sized nucleus breeding programs for dairy cattle with minimal performance recording

674 - Economic evaluation of progeny testing and genomic selection for smallsized nucleus dairy cattle breeding programs in developing countries

905 - Incorporating sustainability in breeding objectives for developing smallholder dairy cattle production systems

1076 -General discussion

122 Summary

127 Training and Supervision Plan

130 Curriculum Vitae

131 Acknowledgements 



$$
1
$$

General introduction 


\subsection{Significance of dairy cattle farming in Eastern Africa}

The largest proportion of the world population is in developing countries. At 1.2 billion people, Africa is home to $16 \%$ of the world population, with a $67.3 \%$ projected growth by 2050 (UN, 2015). With 22.9\% malnourished people in Africa, there is an urgent need to intensify food production (FAO, 2012). The dairy cattle sector is one of the major sectors contributing to food and nutrition security, incomes, employment and insurance (Behnke and Muthami, 2011). However, dairy cattle productivity has roughly stagnated over the last 10 years in Africa (Figure 1).

Eastern Africa is the main dairy cattle producing region in Africa, accounting for $38 \%$ of the total milk produced between 2003 and 2013 (FAOSTAT, 2016). In this region dairy cattle are reared within large scale and smallholder production systems. Differences between these systems relate to the scale of investment and production. Large scale systems have from 20 to above 100 milking cows reared on an average of 160 acres whereas smallholder systems, even under intensification, are characterized by less than 5 milking cows reared on approximately 1 acre of land (Bebe et al., 2003a; Karanja, 2003). However, production is largely dominated by smallholder farmers who produce approximately $80 \%$ of total milk (Omore et al., 1999; FAO, 2011). Consequently, intensification of the smallholder system can have tremendous impact on the health, incomes at the household level and the economy of the society.

Challenges to intensification of smallholder systems fall into four broad categories i.e., economic, environmental, human resource and animal. Economic challenges include accessibility and stability of market outlets, availability of credit and the resilience of the systems to national and global economic turbulence (Muriuki and Thorpe, 2001). Environmental challenges include the harsh climatic conditions, high disease and parasite prevalence and insufficient and poor quality feeds. Human resource challenges include inadequate veterinary services and a low level of education of producers. Animal challenges are lack of well-defined breeding objectives and breeding programs resulting in low productivity and high mortality (Bebe et al., 2003; Wilson, 2009). Therefore, to be successful and sustainable, intensification interventions should have a holistic view of the smallholder system (Kosgey et al., 2006; van Arendonk, 2011). 
Figure 1.1 Mean annual milk yield in selected African countries between 2003 and 2013

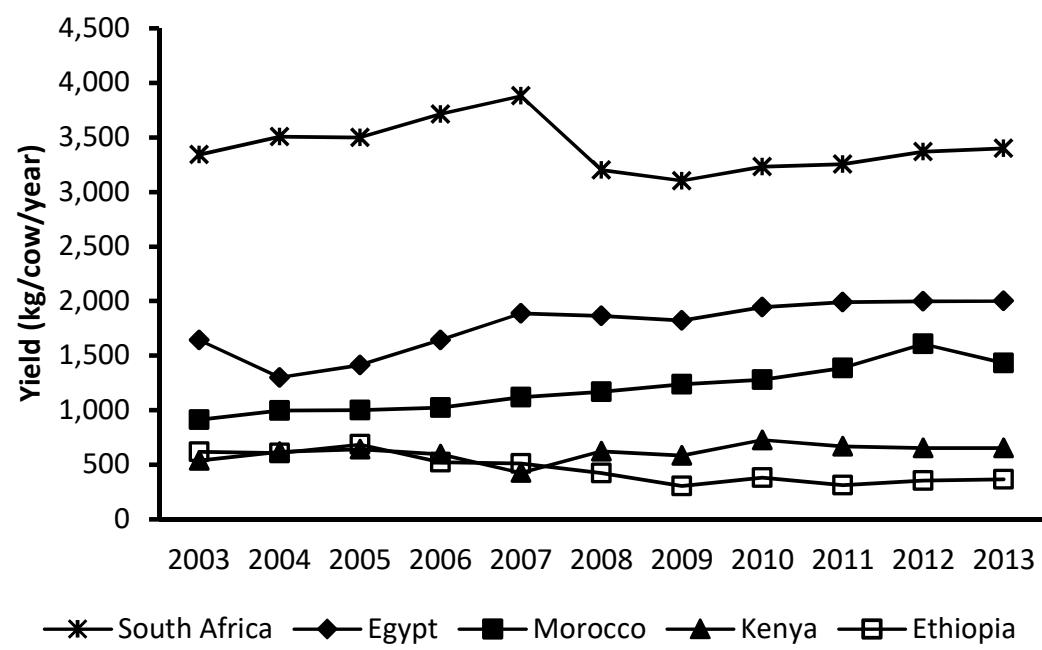

Source: (FAOSTAT, 2016)

\subsection{Current status of dairy cattle genetic improvement in} Kenya

Genetic improvement has played a key role in the intensification process for all livestock species in the world. In Kenya, dairy cattle farmers rely on semen importation from well-developed breeding programs in temperate regions to improve their herd performance (Ojango et al., 2012). Generally, there is paucity of successfully running local breeding programs in developing countries (Kosgey et al., 2006). The main reason for the absence of dairy cattle breeding programs are small herd sizes coupled with the absence of extensive pedigree and performance recording systems (Syrstad et al., 1998; Wasike et al., 2011). However, continuous importation of semen has resulted in a shift towards higher-yielding temperate genotypes. Increased percentage of genes from high-yield breeds in local crossbred cows has contributed to the evident increase in production within the large scale production system, as this system has the resource and knowledge capacity to rear such breeds. However, for the resource constrained smallholder system, high-yield breeds which require high inputs, are not an option. In these systems, cows perform below the their genetic potential, mortalities are high and there is an increased strain on resources in a system that is already resource deficient (Bebe et al., 2003; Menjo et al., 2009). Therefore, to achieve sustainable intensification in 
smallholder systems it is imperative to breed genotypes that fit into the local production and marketing systems.

There are two key reasons for the establishment of local breeding programs for sustainable intensification of dairy cattle productivity in Kenya. First, there is a difference in breeding objectives for developed and developing dairy cattle industries due to differences in production systems and markets (Marshall et al., 2011; Rege et al., 2011). Dairy farming in developed industries is practiced under highly intensive and mechanized large scale systems. The systems also are adequately supported by service sectors such as veterinary services, banks and transport systems. In addition, markets are well developed with a strong and well empowered consumer base. The opposite is generally the case for developing industries. This implies that the relative importance of the diverse breeding objective traits in terms of genetic and monetary performances differ between dairy systems in temperate and tropical systems (Madalena, 2008).

The second reason is the existence of unfavorable genotype by environment (GxE) interaction between temperate and tropical regions. When genetic correlation between two environments is less than 0.8 , there is need for environment specific breeding programs to optimize productivity in both environments (Smith and Banos, 1991; Mulder et al., 2006). Genetic correlations between tropical and temperate dairy cattle industries are generally expected to be low. As an example, the genetic correlation for milk yield between Holstein-Friesian populations in Kenya and the United Kingdom is 0.49 (Ojango and Pollott, 2002). More recently, (Okeno et al., 2010) showed that importation of germplasm from USA to Kenya can only be justified if the genetic correlation is higher than 0.70. Due to low correlations, continuous semen importation will result in economic losses for the smallholder producers (Okeno et al., 2010).

\subsection{Dairy cattle breeding in Kenya - Future approach}

Given these reasons, local genetic improvement interventions, with a holistic view on production and market realities of smallholder farmers is a more promising approach. However, the best strategy to sustainably create genetic superiorities remains a matter of debate (Marshall et al., 2011; Rege et al., 2011). Any strategy adopted must be sustainable to ensure stable long-term benefits (Madalena, 2008). Definition of a breeding objective, genetic evaluation, selection and mating of selected candidates are the major components of a breeding program. The breeding objective is a weighted linear function of traits to be improved (Hazel, 1943). For the smallholder dairy cattle sector, definition of breeding objectives for 
intensification must account for (a) adaptability of genotypes to the production environment and (b) diversity in the production and marketing systems. Given the tropical production environments and resource poor producers, the possibilities to modify the environment to suit the animals are limited. For this reason, adaptability and health of cows to the current production environment is crucial to their lifetime productivity and the long-term resilience of farms. Conventionally, derivation of trait weights is based on calculating marginal economic returns from trait improvement. The resulting economic values reflects the monetary value for unit change in the phenotype for each trait in the objective, holding change in other traits constant. Economic values tend to over-emphasize selection on production traits resulting in reduced adaptability and health problems (Groen et al., 1997; Rauw et al., 1998). This has contributed to poor performance of high performing breeds under the smallholder system.

Alternative approaches for deriving trait weights include restricted index, desired gains and non-market value approaches. The restricted index approach aims at constraining the genetic change for one or more traits in the objective at zero (Kempthorne and Nordskog, 1959; Cunningham et al., 1970; Lin, 2005). Desired gains approach on the other hand aims at achieving a pre-specified genetic response (Yamada et al., 1975; Brascamp, 1984). Lastly, the non-market value approach aims at placing heavier weights on non-marketable functional and health traits by specifying their non-market values (Olesen et al., 2000; Nielsen et al., 2005). These approaches offer criteria to incorporate sustainability in the breeding objectives for the resource constrained smallholder production system.

A second problem is the heterogeneity of dairy cattle production systems. The smallholder system, which is not able to produce sufficient heifers for replacement, relies on large scale system for supply (Bebe et al., 2003). This implies genes flow to smallholder systems from large scale system. Besides, heterogeneous genetic and environmental variances exist between farms with different production capacities (Muasya et al., 2007). Existence of significant differences in management and husbandry between large scale and smallholder systems may result in genotype by environment interactions that require attention when defining a breeding objective. Finally, milk is marketed through formal markets (milk processing factories) and informal channels (directly to consumers); each marketing fetching different prices per kg of milk sold (FAO, 2011). Therefore, definition of breeding objectives needs to account for diversity in production and marketing systems.

The next step in implementing a breeding program deals with estimation of breeding values, upon which selection and mating is based. Traditionally, breeding programs have relied on progeny testing (PT) to evaluate candidate sires with very 
high accuracies. To be successful, PT requires an extensive participation of commercial producers in pedigree and performance recording of test daughters (van Arendonk, 2011). However, there is limited scope for reliable pedigree and performance recording in the Kenya dairy industry. An alternative is genomic selection (GS) strategy, which has recently become the new standard in the dairy cattle sector. The comparative impact of these two selection strategies on genetic and monetary gains for situations with limited pedigree and performance recording is of interest for smallholder system.

GS relies on naturally occurring dense single nucleotide polymorphisms (SNP) as markers or haplotypes spanning the entire genome to estimate the variation for traits of interest explained by quantitative trait loci (QTL). QTL effects are estimated based on best linear unbiased prediction (GBLUP) procedures or Bayesian methods, using phenotypic and genotypic data from a section of the population (reference population) (Meuwissen et al., 2001). In later generations, selection candidates only need to be genotyped to determine the SNP or haplotypes they carry, and their genomic estimated breeding values (GEBV) are determined as the sum of the SNP or haplotype effects. Consequently, with GS GEBVs for juvenile animals can be computed, with accuracies as high as 0.8 , which allows selection at early age, greatly reducing generation intervals in dairy cattle (Goddard and Hayes, 2007; Calus et al., 2008). Because of this, GS generate huge economic benefits due to increase in genetic gains and reduction in operation costs (Schaeffer, 2006; König et al., 2009). This has been the main drive behind the fast adoption of GS selection by dairy cattle breeders (Hayes et al., 2009).

The amount of phenotypic information available (size of reference population) is one of the determinants of GEBV accuracies (Meuwissen et al., 2001; Goddard and Hayes, 2007). Consequently, for developing dairy cattle industries with limited recording, the benefits and practicability of GS remain contentious. GS has been described as a risky and expensive selection strategy for smallholder dairy systems (Marshall et al., 2011). To the contrary, it has been shown that GS schemes are cheaper than PT schemes for large scale developed dairy cattle industries, (Schaeffer, 2006; König et al., 2009). In addition, genotyping costs have been reducing in the recent past and are expected to become even cheaper as genotyping procedures are becoming more efficient (Guichoux et al., 2011; Shendure and Aiden, 2012). Therefore, evaluation of genetic and economic benefits of GS and PT schemes for developing dairy cattle system is needed if one would advise on the choice of a selection strategy. 


\subsection{Aims of this thesis}

The aim of this thesis was to optimize the design of a breeding program for smallholder dairy systems in developing countries where (a) the size of the population with pedigree and performance records is small and (b) adaptation and health traits play a crucial role to the productivity and resilience of farms. In the entire thesis, I use the Kenya dairy cattle system as a working example. The approach taken can be divided into three steps (1) the definition of a breeding objective, (2) the comparison of small-scale PT and GS schemes in terms of genetic gains and economic benefits and (3) the optimization of the breeding program. In the first step, the aim was to determine breeding objective traits, accounting for diversity in production and marketing systems (Chapter 2). To account for limited recording I define a breeding objective with 5 most important traits only. The relative importance of each trait across production and marketing systems is determined using the Analytical Hierarchical Process (AHP) \{Saaty, 1977 \#37\}. Different preferences among the production systems are aggregated into a single breeding objective using the Weighted Goal Programming (WGP) procedure \{Gonzalez-Pichon, 1999 \#73\}\{Sae-Lim, 2012 \#87\}.

In the second step I optimize the utility of the available limited phenotypic records (Chapter 3). In this Chapter, genetic superiorities achievable form PT and GS selection strategies for a small-sized nucleus breeding program are compared. The aim was to determine the selection strategy that maximizes genetic gains with limited number of phenotypic records. Beside genetic gains, adoption of a selection strategy is further determined by the economic outcome. Therefore, I further did an economic benefits analysis for PT and GS selection strategies for a breeding program under developing circumstances (Chapter 4). The aims of this Chapter were (a) to determine whether a dairy cattle breeding program in a developing country would break-even and (b) to determine which selection strategy would give highest gross margins.

In Chapter 5 I derive selection indexes for a 5-trait breeding objective. In this Chapter I determine the effect of economic and non-economic breeding objective weights on genetic gains for individual traits. The aim of the Chapter was to define weights for the traits in the breeding goal that best balance responses for production and adaptability traits. Non-market weights were based on desired gains and non-market values. The general discussion (Chapter 6) focusses on the technical challenges with respect to the implementation of a sustainable GS 
breeding program in Kenya. In particular, I discuss inbreeding, establishment of a reference population and sustainability of the breeding program.

\section{References}

Bebe, B.O., H.M.J. Udo, G.J. Rowlands, and W. Thorpe. 2003. Smallholder dairy systems in the Kenya highlands: cattle population dynamics under increasing intensification. Livest. Prod. Sci. 82:211-221.

Behnke, R., and D. Muthami. 2011. The contribution of livestock to the Kenyan economy. Nairobi, Kenya.

Brascamp, E.W. 1984. Selection indices with constraints. Anim. Breed. Abstr. 52:645-654.

Calus, M.P.L., T.H.E. Meuwissen, A.P.W. De Roos, R.F. Veerkamp, A.P.W. De Roos, and R.F. Veerkamp. 2008. Accuracy of Genomic Selection Using Different Methods to Define Haplotypes. Genetics. 178:553-561.

Cunningham, E.P., R.A. Moen, T. Gjedrem, and E.P. Cunningham1. 1970. Restriction of selection indexes. Biometrics. 26:67-74.

FAO. 2011. Dairy development in kenya. H.G. Muriuki, editor. Rome, Italy.

FAO. 2012. Economic growth, hunger and malnutrition. In The State of food insecurity. FAO, Rome, Italy. 15-27.

FAOSTAT. 2016. http://www.fao.org/faostat/en/\#data/QL.

Goddard, M.E., and B.J. Hayes. 2007. Genomic selection. J. Anim. Breed. Genet. 124:323-330.

Groen, A.F., T. Steine, J.-J. Colleau', J. Pedersen, J. Pribyl, N. Reinsch, J.-J. Colleau, J. Pedersen, J. Pribyl, N. Reinsch, J.-J. Colleau', J. Pedersen, J. Pribyl, and N. Reinsch. 1997. Economic values in dairy cattle breeding, with special reference to functional traits. Report of an EAAP-working group. Livest. Prod. Sci. 49:1-21.

Guichoux, E., C. Lepoittevin, E. Revardel, L. Lagache, S. Wagner, P. Chaumeil, P. Leger, O. Lepais, C. Lepoittevin, T. Malausa, E. Revardel, F. Salin, and R.J. Petit. 2011. Current trends in microsatellite genotyping. Mol. Ecol. Resour. 11:591-611.

Hayes, B.J., P.J. Bowman, A.J. Chamberlain, and M.E. Goddard. 2009. Genomic selection in dairy cattle: Progress and challenges. J. Dairy Sci. 92:433-443. doi:10.3168/jds.2008-1646.

Hazel, L.N. 1943. The genetic basis for constructing selection indexes. Genetics. 28:476-490.

Kempthorne, O., and A.W. Nordskog. 1959. Restricted selection indices. Biometrics. 
15:10-19.

König, S., H. Simianer, and A. Willam. 2009. Economic evaluation of genomic breeding programs. J. Dairy Sci. 92:382-391. doi:10.3168/jds.2008-1310.

Kosgey, I.S., R.L. Baker, H.M.J. Udo, J.A.M. Van Arendonk, and J.A.M. Van Arendonk. 2006. Successes and failures of small ruminant breeding programmes in the tropics: a review. Small Rumin. Res. 61:13-28.

Lin, C.Y. 2005. A simultaneous procedure for deriving selection indexes with multiple restrictions. J. Anim. Sci. 83:531-536.

Madalena, F.E. 2008. How sustainable are the breeding programs of the global main stream dairy breeds? - The Latin-American situation. Livest. Res. Rural Dev. 20(2).

Marshall, K., C. Quiros-campos, J.H.J. van der Werf, B. Kinghorn, J.H.J. Van Der Werf, and B. Kinghorn. 2011. Marker-based selection within smallholder production systems in developing countries 你. Livest. Sci. 136:45-54.

Menjo, D.K., B.O. Bebe, Okeyo A M, J.M.K. Ojango, A.M. Okeyo, and J.M.K. Ojango. 2009. Survival of Holstein-Friesian heifers on commercial dairy farms in Kenya. Appl. Anim. Husb. Rural Dev. 2:14-17.

Meuwissen, T.H.E., B.J. Hayes, and M.E. Goddard. 2001. Prediction of total genetic value using genome-wide dense marker maps. Genetics. 157:1819-1829.

Muasya, T.K., E.D. Ilatsia, T.M. Magothe, and A.K. Kahi. 2007. Heterogeneity of variance and its implications on dairy cattle breeding. S. Afr. J. Anim. Sci. 37:170-175.

Mulder, H.A., R.F. Veerkamp, B.J. Ducro, J.A.M. Van Arendonk, P. Bijma, J.A.M. Van Arendonk, and P. Bijma. 2006. Optimization of dairy cattle breeding programs for different environments with genotype by environment interaction. J. Dairy Sci. 89:1740-1752.

Muriuki, H., and W. Thorpe. 2001. Smallholder dairy production and marketing in eastern and sourthern Africa: Regional synthesis. In Proceedings of a SouthSouth workshop held at National Dairy Development Board (NDDB) Anand, India, 13-16 March 2001. D. Rangnekar and W. Thorpe, editors. Anand, India. 185-200.

Nielsen, H.M., L.G. Christensen, and A.F. Groen. 2005. Derivation of sustainable breeding goals for dairy cattle using selection index theory. J. Dairy Sci. 88:1882-1890.

Ojango, J.M.K., K. Kariuki, N.A. And Baltenweck, A. Njehu, and I. Baltenweck. 2012. Breeding management strategies adopted for dairy production under low input smallholder farming systems of East Africa. Research Report, ILRI pp. 
Ojango, J.M.K., and G.E. Pollott. 2002. The relationship between Holstein bull breeding values for milk yield derived in both the UK and Kenya. Livest. Prod. Sci. 74:1-12.

Okeno, T.O., I.S. Kosgey, and A.K. Kahi. 2010. Economic evaluation of breeding strategies for improvement of dairy cattle in Kenya. Trop. Anim. Health Prod. 42:1081-1086.

Olesen, I., A.F. Groen, and B. Gjerde. 2000. Definition of animal breeding goals for sustainable production systems. J. Anim. Sci. 78:570-582.

Omore, A., H. Muriuki, M. Kenyanjui, M. Owango, and S. Staal. 1999. The Kenya dairy sector - A rapid appraisal. Smallholder Dairy (Research \& Development) Project Report. Nairobi, Kenya.

Rauw, W.M., E. Kanis, E.N. Noordhuizen-Stassen, and F.J. Grommers. 1998. Undesirable side effects of selection for high production efficiency in farm animals: a review. Livest. Prod. Sci. 56:15-33.

Rege, J.E.O., K. Marshall, A. Notenbaert, J.M.K. Ojango, and A.M. Okeyo. 2011. Propoor animal improvement and breeding - What can science do. Livest. Sci. 136:15-28.

Schaeffer, L.R. 2006. Strategy for applying genome-wide selection in dairy cattle. J. Anim. Breed. Genet. 123:218-223. doi:10.1111/j.1439-0388.2006.00595.x.

Shendure, J., and E. Lieberman Aiden. 2012. The expanding scope of DNA sequencing. Nat. Biotechnol. 30:1084-1094.

Smith, C., and G. Banos. 1991. Selection within and across populations in livestock improvement. J. Anim. Sci. 69:2387-2394.

Syrstad, O., A.J. Ruane, J. Ruane, and A.J. Ruane. 1998. Prospects and strategies for genetic improvement of the dairy potential of tropical cattle by selection. Trop. Anim. Health Prod. 30:257-268.

UN. 2015. World Population Prospects, Key Findings and Advanced Tables. New York, USA. Working Paper No. ESA/P/WP. 241 pp.

van Arendonk, J.A.M. 2011. The role of reproductive technologies in breeding schemes for livestock populations in developing countries. Livest. Sci. 136:2937.

Wasike, C.B., T.M. Magothe, A.K. Kahi, and K.J. Peters. 2011. Factors that influence the efficiency of beef and dairy cattle recording system in Kenya: A SWOT AHP analysis. Trop. Anim. Health Prod. 43:141-152.

Wilson, R.T. 2009. Fit for purpose - the right animal in the right place. Trop. Anim. Health Prod. 41:1081-1090.

Yamada, Y., K. Yokouchi, and A. Nishida. 1975. Selection index when genetic gains of individual traits are of primary concern. Japan J. Genet. 50:33-41. 


\title{
2
}

\section{Multiple criteria decision making process to derive consensus desired gains for a dairy cattle breeding objective for diverse production systems}

\author{
C.M. Kariuki ${ }^{1,2}$, J.A.M. van Arendonk ${ }^{1,3}$, A.K. Kahi ${ }^{4}$, H. Komen ${ }^{1}$
}

${ }^{1}$ Animal Breeding and Genomics Centre, Wageningen University and Research, $6700 \mathrm{AH}$ Wageningen, The Netherlands; ${ }^{2}$ Department of Animal Sciences, Chuka

University, P.O. Box 109-60400, Chuka, Kenya; ${ }^{3}$ Hendrix Genetic Research, Technology and Services, 5830 AC, Boxmeer, The Netherlands; ${ }^{4}$ Animal Sciences and Genomics Group, Department of Animal Sciences, Egerton University, P.O. Box 536-20115, Egerton, Kenya

Journal of Dairy Science (In press) http://doi.org/10.3168/jds.2016-11454 


\begin{abstract}
The dairy cattle industry in Kenya contributes to food and nutrition security and is a source of income for numerous households. Selective breeding can enhance efficiency in this industry. The current approach that rely on semen importation and crossbreeding is sub-optimal and a local breeding program is needed. The dairy industry is characterized by diverse production and marketing systems. In order to define a breeding goal, a desired genetic gains approach is needed that can be used to optimize production in all systems. We used Analytic Hierarchy Process (AHP) to determine individual preference values for milk yield (MY), calving interval $(\mathrm{Cl})$, production life time (PLT), mature body weight (MBW), and fat yield (FY), respectively. Results show that classical classification of production systems into largescale and smallholder systems does not capture all differences in trait preferences. These differences became apparent when classification was based on productivity at the individual animal level, with high (HIP) and low intensity (LIP) producers and processors as the main important groups. High intensity producers had highest preferences for PLT and MY, while LIP had highest preference for $\mathrm{Cl}$ and PLT; processors preferred $\mathrm{MY}$ and FY the most. Highest disagreements between the groups were observed for FY, PLT, and MY. Individual and group preferences were aggregated into consensus preferences using Weighted Goal Programming. Desired gains were obtained as a product of consensus preferences and percentage genetic gains (G\%). These were 2.42, 0.22, 2.51, 0.15 and 0.87 for $\mathrm{MY}, \mathrm{Cl}, \mathrm{PLT}, \mathrm{MBW}$ and $\mathrm{FY}$, respectively. Consensus breeding goal can play a major role in the establishment and acceptability of a local breeding scheme for the highly diverse production and marketing circumstances in Kenya.
\end{abstract}

Key words: desired genetic gain, multi-criteria decision making process, breeding goal, multiple production systems. 


\subsection{Introduction}

The dairy cattle industry in Kenya relies heavily on importation of semen for genetic improvement. Significant genotype by environment interaction (GXE) have been reported between temperate countries, which are the main exporters, and the recipient tropical countries (Ojango and Pollot, 2002). Okeno et al. (2010) showed that with unfavorable GxE, continuous semen importation does not economically optimize the Kenya dairy sector. An alternative approach would be the establishment of local breeding schemes (Vargas and van-Arendonk, 2004).

The definition of a breeding objective forms the basis for the establishment of a breeding program. The breeding objective is a weighted linear function that specifies the desired rate and direction of change in traits identified for improvement. Conventionally, breeding objectives aim at economic optimization, which is achieved through the use of economic weights for breeding objective traits. Economic weights for breeding objective traits can be derived using profit functions or bio-economic modeling (Amer, 2006). In these approaches weights are derived as partial derivatives for a unit change of each trait in the breeding objective holding other traits constant (Ponzoni and Newton, 1989). This procedure requires clear specification of production (costs/inputs) and marketing (incomes/revenues) systems e.g., van Arendonk, (1991) and Kahi et al. (2004). Implicitly, with economic weights, homogeneity of costs and revenues is presumed among commercial producers i.e., economic weights relate to a specific production system.

Developing dairy cattle industries are characterized by multiple production systems, reflecting differences in costs and revenues (FAO, 2011). In Kenya, for instance, two distinct production systems have been identified corresponding with large scale and smallholder producers. Differences in costs between these systems emanate from scale of production and investment. Smallholder systems, even under intensification, are characterized by less than 5 milking cows reared on approximately 1 acre of land on average whereas large scale systems have an average of 33 milking cows reared on an average of 160 acres (Bebe et al., 2003a; Karanja, 2003). Large scale systems generally have a higher scale of mechanization and labor input, and have less tendency to be risk averse. However, due to low production levels, it is estimated that smallholder production systems have the highest relative production costs (Karanja, 2003).

On the other hand, differences in revenues emanate from the existence of multiple milk outlets. Markets determine not only the prices per $\mathrm{kg}$ of milk but also the level 
of production. Marketing systems in Kenya have been classified into informal and formal markets. Informal markets, that comprise of direct sales to individuals, hotels, and institutions such as schools and hospitals, account for $80 \%$ of the total milk sold (Omore et al., 1999). Formal markets include sales to cooperative and/or privately owner milk processing factories. Large scale producers rely mainly on the formal markets as the main outlets while the informal market is the major outlet for smallholder producers (Omore et al., 1999). Payment for milk by both formal and informal markets is currently based on volume. Differences in milk prices have been reported among these outlets (Thorpe et al., 2000; Karanja, 2003). Furthermore, fluctuations in milk prices are common in the Kenya dairy sector. Such fluctuations are due to instability in levels of production resulting from seasonality in feed quality and quantity. These factors complicate the derivation of economic values.

The implementation of separate breeding programs for each production system is unfeasible in the near future for two reasons. First, intricate dependence at the genetic level exist between the two production systems. Smallholder farmers are not self-reliant in production of replacement heifers but largely rely on large scale farms (Bebe et al., 2003a). Moreover, the large-scale system is a source of genetic material for smallholder farmers through provision of semen. Second, smallholder farmers hardly practice any pedigree and performance recording, making it impossible to rely on them when implementing a selective program. To account for these factors, Kahi et al. (2004) defined a breeding objective for the dairy sector in Kenya based entirely on the smallholder production system. However, an approach that compels large scale producers to adopt a smallholder breeding objective is not likely to optimize production for the former system. Therefore, use of profit functions to define genetic changes in the population may not optimize production in the Kenya dairy cattle industry.

A feasible alternative to define breeding objective for situations with diverse production systems benefitting from a single breeding scheme would be use of desired genetic gain approach (Amer, 2006). Of particular interest is an approach that allows for the estimation of consensus weights to account for differences between production systems. One such approach is the multiple decision making procedure Analytic Hierarchy Process (AHP) (Sae-Lim et al., 2012; Omasaki et al., 2016). The AHP computes individual weights for activities (traits) in a multiple decision making criteria (Saaty, 1977). These weights indicate the preferences given by an individual to each trait and are defined by scaling ratios using the principal eigenvector of a positive pair-wise comparison matrix. Individual preferences can 
then be aggregated into group and consensus preferences using Weighted Goal Programming (WGP) (Linares and Romero, 2002).

The Holstein-Friesian breed and its crosses form the predominant genotype accounting for more than $50 \%$ of the dairy cattle in Kenya (Bebe et al., 2003b; Ojango et al., 2012). The popularity of this breed is driven by semen importation by large scale producers and the flow of genes (through sale of heifers and artificial insemination) from large scale farmers to small scale farmers (Bebe et al., 2003b). Reliance of smallholder producers on large scale producers for semen and heifers can only increase the proportion of the breed and its crosses in the future. A breeding objective that would optimize the performance of the breed for the large scale and smallholder production systems would highly impact the Kenyan dairy value chain. Therefore, our objective was to define a consensus breeding objective for the Holstein-Friesian breed in Kenya that accommodates large and small scale producers, and processors.

\subsection{Materials and methods}

\section{Data collection}

The AHP was used to determine individual preferences based on importance (strengths) given to the different traits in dairy cattle production. Data was obtained using a field survey. The survey was conducted in Nakuru, Nyeri, Embu and Tharaka Nithi counties in Kenya. As a preliminary, we conducted an initial survey in which respondents were asked to rank 19 traits according to their perceived order of importance. Table 2.1 lists the 19 traits and their definitions. Out of sixty four respondents visited we obtained forty-seven responses from 18 large scale producers, 24 small scale producers and 5 processors. Ranking was on a scale of 1 to 19 , where the most important trait was given rank 1 and the least important rank 19. For situations where respondents had difficulties ranking all the 19 traits, they were asked to rank the first five most important traits. To ensure uniformity in trait descriptions, definitions were provided in the questionnaire. Efforts were also made during the survey to ensure proper understanding of each trait description. In addition, general information on the farm economy was also collected.

The second survey involved a total of 78 respondents who were classified into smallholder farmers (40), large scale farmers (24) and milk processors (14). This survey focused on the 5 highest valued traits for inclusion in the pair-wise comparison. Saaty's scale of intensity of importance (Saaty, 1977); Figure 2.1) was used to compare pairs of traits. In total 10 i.e., [ $5 \times(5-1) / 2]$ pairs of comparisons 
Table 2.1 Traits in the preliminary survey and their descriptions

\begin{tabular}{|c|c|}
\hline Trait & Description \\
\hline Milk yield & Amount of milk a cow produces per lactation \\
\hline Protein yield & Amount of milk protein a cow produces per lactation \\
\hline Fat yield & Amount of milk fat a cow produces per lactation \\
\hline Production persistence & $\begin{array}{l}\text { Ability to maintain the level of milk production through the } \\
\text { lactation }\end{array}$ \\
\hline Production life time & $\begin{array}{l}\text { The number of lactations a cow will have before voluntary or } \\
\text { involuntary culling }\end{array}$ \\
\hline Lactation length & The number of days a cow continues producing milk after calving \\
\hline Calving interval & The period between two consecutive calvings \\
\hline Calving ease & A measure of difficulty in dropping a calf \\
\hline Survival to 3 months & The ability of a calf to survive the first 3 months of life \\
\hline Mastitis & A measure of a cows inherent resistance to mastitis \\
\hline Backbone strength & $\begin{array}{l}\text { A measure of the strength of a cows backbone. Measured as a } \\
\text { "straight", "curved" or "arched" }\end{array}$ \\
\hline Legs strength & A measure of how strong the legs of a cow are \\
\hline Udder attachment & $\begin{array}{l}\text { A measure of how firmly the udder is attached. Affects walking } \\
\text { related problems, ease of milking and susceptibility to mastitis }\end{array}$ \\
\hline Teat length & A measure of the length of teats. Affects ease of milking \\
\hline Docility & $\begin{array}{l}\text { A measure of non-aggressiveness to other cows and handlers } \\
\text { (during milking and when not been milked) }\end{array}$ \\
\hline $\begin{array}{l}\text { Intake of low quality } \\
\text { roughages }\end{array}$ & Ability to ingest and convert low quality roughages \\
\hline Resistance to heat & Ability to perform well under high temperature conditions \\
\hline Resistance to ECF & A measure of inherent resistance to ECF \\
\hline Mature body weight & $\begin{array}{l}\text { A measure of feed requirements for maintenance. Large animals } \\
\text { have a high maintenance requirements }\end{array}$ \\
\hline
\end{tabular}

were done. The scale of intensity of importance was in a range of $1-9$. The value 1 indicated equal importance (i.e., meaning equal rate of genetic improvement for a pair of traits) while the value 9 indicated that the chosen trait is absolutely important over the other (i.e., only the important trait in a pair should be subjected to selection pressure). The intermediate values were as described in Figure 2.1.

To avoid unrealistic expectations and, by extension, unrealistic choices between traits we approximated possible genetic gains (as a percentage of the trait mean) after one generation of phenotypic selection for each trait. Response to selection was calculated using the formula

$G=i h^{2} C V \mu_{P}$ 
where $G$ = genetic gain, $i=$ intensity of selection, $h^{2}=$ heritability, $C V=$ coefficient of variation (calculated as $C V=\sigma_{P} / \mu_{P}$ ), $\sigma_{P}=$ phenotypic standard deviation and $\mu_{P}$ = phenotypic mean. $C V$ was used rather than $\sigma_{P}$ to account for scale differences of means and variances of traits reported in the literature (Falconer and Mackay, 1996). In addition, we put effort to use parameter estimates from studies conducted in the tropics. Percentage genetic gains were computed as

$G \%=i h^{2} C V \cdot 100 \%$

Estimates for the above parameters and the resulting possible genetic gains (as a \%) for the 5 traits are presented in Table 2.2.

Table 2.2 Heritability, phenotypic standard deviations, phenotypic means and expected genetic gains for 5 highest ranked traits

\begin{tabular}{lrrrrl}
\hline${ }^{1}$ Trait & \multicolumn{1}{c}{$\mathrm{h}^{2}$} & \multicolumn{1}{c}{$\sigma_{\mathrm{P}}$} & \multicolumn{1}{c}{$\mu_{\mathrm{P}}$} & $\mathrm{G} \%$ & Reference \\
\hline $\mathrm{MY}(\mathrm{kg})$ & 0.29 & $1,110.00$ & $4,557.0$ & $10.6 \%$ & (Ojango and Pollot, 2001) \\
$\mathrm{Cl}$ (days) & 0.047 & 75.34 & 406.0 & $1.3 \%$ & (Ojango and Pollot, 2002) \\
PLT (months) & 0.18 & 1781.25 & 47.5 & $10.1 \%$ & (Abou-Bakr, 2009) \\
MBW (kg) & 0.17 & 73.48 & 606.0 & $3.1 \%$ & (Abdallah and McDaniel, \\
& & & & & 2000) \\
FY (kg) & 0.24 & 49.35 & 276.9 & $6.4 \%$ & (Campos et al., 2015) \\
\hline
\end{tabular}

Intensity of selection (i) was fixed at 1.501 for all traits

${ }^{1} \mathrm{MY}=$ lactation milk yield, $\mathrm{Cl}=$ calving interval, $\mathrm{PLT}=$ production life time, $\mathrm{MBW}=$ mature body weight, and $F Y=$ lactation fat yield; $h^{2}=$ heritability, $\sigma_{P}=$ phenotypic standard deviation; $\mu_{P}=$ phenotypic mean; $G \%=$ genetic gain expressed as a percentage of the phenotypic mean

\section{Determination of traits for inclusion in pair-wise comparisons}

The five traits for inclusion in the pair-wise comparisons were determined using percentages. To determine the percentage for each trait we tabulated all traits ranked between 1 and 5 in the preliminary survey. We then calculated the percentage of times a trait was ranked within a given rank category. In addition, we calculated the percentage of times each trait was ranked among the 5 most important traits. Table 2.3 presents a summary of the percentages. Decision on the traits to include in the pair-wise comparisons was based on the two percentages. The traits with highest \%'s at individual trait and combined levels were chosen as the most preferred. As an example, fat yield did not have the highest \% in any of the 5 trait levels but was the $5^{\text {th }}$ highest at the combined level, and was included in the most preferred traits. The 5 highest ranked traits were milk yield (MY), production life time (PLT), calving interval (CI), fat yield (FY) and mature body weight (MBW). 
Table 2.3 Importance of traits expressed as a \% at individual rank level and for the 5 highest ranks combined

\begin{tabular}{|c|c|c|c|c|c|c|}
\hline \multirow[b]{3}{*}{${ }^{3}$ Trait } & \multicolumn{6}{|c|}{$\begin{array}{l}\text { Ranking (\% of respondents placing traits in respective } \\
\text { ranks) }\end{array}$} \\
\hline & \multicolumn{5}{|c|}{${ }^{1}$ Individual ranks } & \multirow[t]{2}{*}{${ }^{2}$ Combined } \\
\hline & 1 & 2 & 3 & 4 & 5 & \\
\hline Backbone strength & 2 & 3 & 2 & 2 & 11 & 4 \\
\hline Calving ease & 2 & 6 & 2 & 4 & 2 & 3 \\
\hline Calving interval & 6 & 9 & 19 & 9 & 14 & 11 \\
\hline Docility & 2 & 9 & 0 & 0 & 2 & 2 \\
\hline Fat yield & 0 & 6 & 14 & 4 & 9 & 7 \\
\hline $\begin{array}{l}\text { Intake of low quality } \\
\text { roughages }\end{array}$ & 0 & 0 & 0 & 0 & 0 & 1 \\
\hline Lactation length & 0 & 0 & 2 & 7 & 2 & 2 \\
\hline Leg strength & 0 & 0 & 2 & 9 & 0 & 2 \\
\hline Mastitis & 0 & 6 & 0 & 11 & 11 & 6 \\
\hline Mature body weight & 3 & 6 & 17 & 18 & 5 & 10 \\
\hline Milk yield & 66 & 0 & 7 & 4 & 7 & 19 \\
\hline Production lifetime & 3 & 38 & 14 & 18 & 7 & 15 \\
\hline Protein yield & 0 & 13 & 5 & 2 & 0 & 3 \\
\hline Resistance to ECF & 0 & 0 & 7 & 0 & 5 & 2 \\
\hline Survival to 3 months & 1 & 0 & 2 & 0 & 6 & 2 \\
\hline Teat length & 0 & 0 & 2 & 4 & 5 & 2 \\
\hline Udder attachment & 3 & 3 & 2 & 7 & 9 & 6 \\
\hline \multicolumn{7}{|c|}{$\begin{array}{l}{ }^{1} \text { Number of times (as a \%) each trait was ranked within each rank. Ranks are from } 1 \text { (highest } \\
\text { level of importance) to } 5 \text { (lowest level); }\end{array}$} \\
\hline \multicolumn{7}{|c|}{${ }^{2}$ Importance (as a \%) considering the 5 highest ranked traits together; } \\
\hline${ }^{3}$ Bolded traits had the & kking & & & & & \\
\hline
\end{tabular}

\section{Calculation of individual preferences}

The AHP is a ratio scaling method for weights in hierarchical structures using the principal eigenvector of a positive pairwise comparison matrix. For a comprehensive description of the method the reader is referred to (Saaty, 1977). Briefly, for each respondent, we wish to recover the vector $\boldsymbol{w}$ of weights for $n=5$ traits in the breeding objective from a matrix $\boldsymbol{A}$. The matrix $\boldsymbol{A}$ is constructed using intensities indicated in the pair-wise comparisons in the Saaty's scale. $\boldsymbol{A}$ was constructed such that it fulfilled the reciprocal property $a_{j i}=1 / a_{i j}$. The solution for vector $\boldsymbol{w}$ of weights was obtained by solving the system $(\boldsymbol{A}-n \boldsymbol{I}) \boldsymbol{w}=\mathbf{0}$ (Saaty, 1977). Individual preferences were attained by normalizing the eigenvector.

Large inconsistencies in responses from the respondents indicate randomness rather than logic; thus results cannot be expected to yield a reliable solution (Saaty, 1977). All responses were checked for consistency to ensure they had a consistency ratio $(C R)$ less than 0.1 . In a few cases where the $C R$ was greater the interview was 
re-done. All calculations were done using the Super Decisions software (Saaty, 2003).

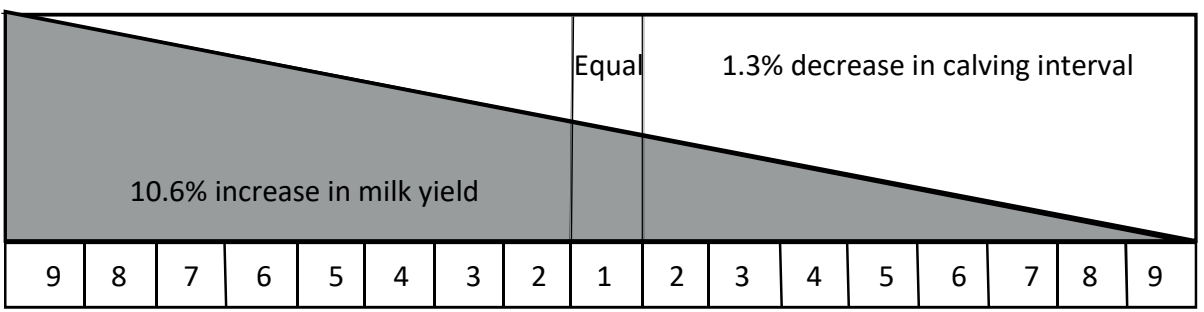

Figure 2.1 The Saaty scale for pair-wise comparison. Percentage possible genetic improvement is expressed within the upper row and intensity of importance is on the lower row. Scale of intensity is from 1 to $9.1=$ equal, $3=$ weak, $5=$ strong, $7=$ demonstrate and $9=$ absolute importance of one trait over the other. 2, 4, 6 and 8 are intermediate values between two adjacent judgements.

\section{Calculating consensus preferences and desired gains}

Group preferences. A two-step WGP procedure described by (Linares and Romero, 2002) was used to define the consensus weights. In the $1^{\text {st }}$ step, group preferences were obtained by minimizing the sum of disagreements between the individual preferences. This was achieved by solving the following WGP model Achievement function:

$\operatorname{Min} \sum_{i=1}^{q} \sum_{k=1}^{N_{j}}\left(n_{i k}+p_{i k}\right)^{\pi}$

subject to

\section{Goals:}

$W_{i}^{j}+n_{i k}-p_{i k}=a_{i}^{k j}$

where, $i=1,2, \ldots, q=$ number of traits in the breeding objective ( $q=5$ traits), $j=$ $1,2, \ldots, m$ social groups, $N_{j}=$ number of respondents in the $j^{t h}$ group, $a_{i}^{k j}=$ preference weight attached to the $i^{\text {th }}$ trait by the $k^{\text {th }}$ member of the $j^{\text {th }}$ group, $W_{i}^{j}$ $=$ preference weight attached to the $i^{\text {th }}$ trait by the $j^{\text {th }}$ social group, and, $n_{i k}$ and $p_{i k}$ are the negative and positive deviations of $a_{i}^{k j}$ from $W_{i}^{j}$, respectively. $\pi$ acts as a metric attached to the sum of deviation variables indicating the weight given the outlier group. Our objective was to minimize the sum of individual disagreements; 
we therefore set $\pi=1$ (Gonzalez-Pichon and Romero, 1999; Linares and Romero, 2002). How social groups were defined is explained in a later section.

Consensus preferences. The $2^{\text {nd }}$ step was to derive consensus preferences from group preferences obtained earlier by solving the following extended WGP model (Linares and Romero, 2002)

Achievement function:

$\operatorname{Min}(1-\lambda) D+\sum_{i=1}^{q} \sum_{j=1}^{m}\left(\bar{n}_{i j}+\bar{p}_{i j}\right)$

subject to

Goals :

$\sum_{i=1}^{q}\left(\bar{n}_{i 1}+\bar{p}_{i 1}\right)-D \leq 0$,

$\sum_{i=1}^{q}\left(\bar{n}_{i m}+\bar{p}_{i m}\right)-D \leq 0$,

$W_{i}^{S}+\bar{n}_{i j}-\bar{p}_{i j}=W_{i}^{j}$

where $q=$ number of traits, $m=$ number of social groups, $W_{i}^{j}=$ the $j^{\text {th }}$ group preference value for the $i^{\text {th }}$ trait, $W_{i}^{S}=$ consensus weight attached to the $i^{\text {th }}$ trait and $\bar{n}_{i 1}+\bar{p}_{i 1}=$ the sum of the negative and positive deviations of the $j^{\text {th }}$ social group preference value from the consensus preference value. $D$ represents the disagreement in each social group with respect to the consensus obtained and $\lambda$ represents the emphasis put on the minority group. We varied the values of $\lambda$ between 0 and 1 to obtain compromises between a model that defines the consensus by minimizing the disagreement of the most displaced social group and a model which defines the consensus by maximizing the average agreement; thus avoiding the ensuing associated biases (Linares and Romero, 2002).

Desired genetic gains. Desired genetic gains were obtained by multiplying the genetic gain with the consensus preferences for each trait. 


\section{Definition of social groupings}

In the present study, we investigated four criteria for definition of intensification. First, groups were defined based on the land size, number of cows and level of investment in machinery (Grouping A). Under this criteria farms with $\leq 10$ cows, $\leq 4$ hectares of land and did not own a tractor were classified as smallholder and the rest as large scale. Other social groupings were based on source of semen (imported vs local; Grouping B), average milk yield per cow per day (< $10 \mathrm{~kg}$ vs 10 $15 \mathrm{~kg} v>15 \mathrm{~kg}$; Grouping C), and amount of concentrate provided per cow per day ( $\leq 5 \mathrm{~kg}$ vs $>5 \mathrm{~kg}$; Grouping D). Processors were included in each grouping as a separate unique group.

\subsection{Results}

\section{Breeding goal traits}

Table 2.3 presents the traits included in the breeding goal. A wide range in choice of importance was observed with 17 of the 19 traits presented in the first questionnaire appearing among the 5 highest ranked. Traits with the highest proportions were $\mathrm{MY}, \mathrm{PLT}, \mathrm{Cl}, \mathrm{MBW}$ and $\mathrm{FY}$. These were chosen as the breeding objective traits.

\section{Individual preferences}

Figure 2.2 presents the median and interquartile ranges for individual preferences (ignoring social groupings) for the breeding objective traits. Medians were 0.219, $0.350,0.214,0.093$ and 0.048 for MY, PLT, Cl, MBW and FY, respectively. The large interquartile ranges observed indicate differences in preferences for these traits among respondents.

\section{Social preferences}

Second, we investigated the presence of social groupings by calculating social (group) preferences. The traditional classification of production systems into small scale and large scale producers (Grouping A) and grouping based on semen source (Grouping B) did not capture substantial differences in preference values (Figure 2.3). However, differences were observed for the other grouping criteria. Producers with lower milk production and lower use of concentrates (low intensity producers, LIP) had systematic lower preference values for MBW, MY and PLT compared to producers with high production and more concentrate use (high intensity producers, HIP). On the other hand, LIP had higher preference values for $\mathrm{Cl}$ and FY. Large differences were observed between producers in general and Processors. The largest disparities were observed for MY and FY which had highest preferences 
among Processors. For the other traits, the order of importance for processors was $\mathrm{PLT}, \mathrm{Cl}$ and $\mathrm{MBW}$, in a descending order.

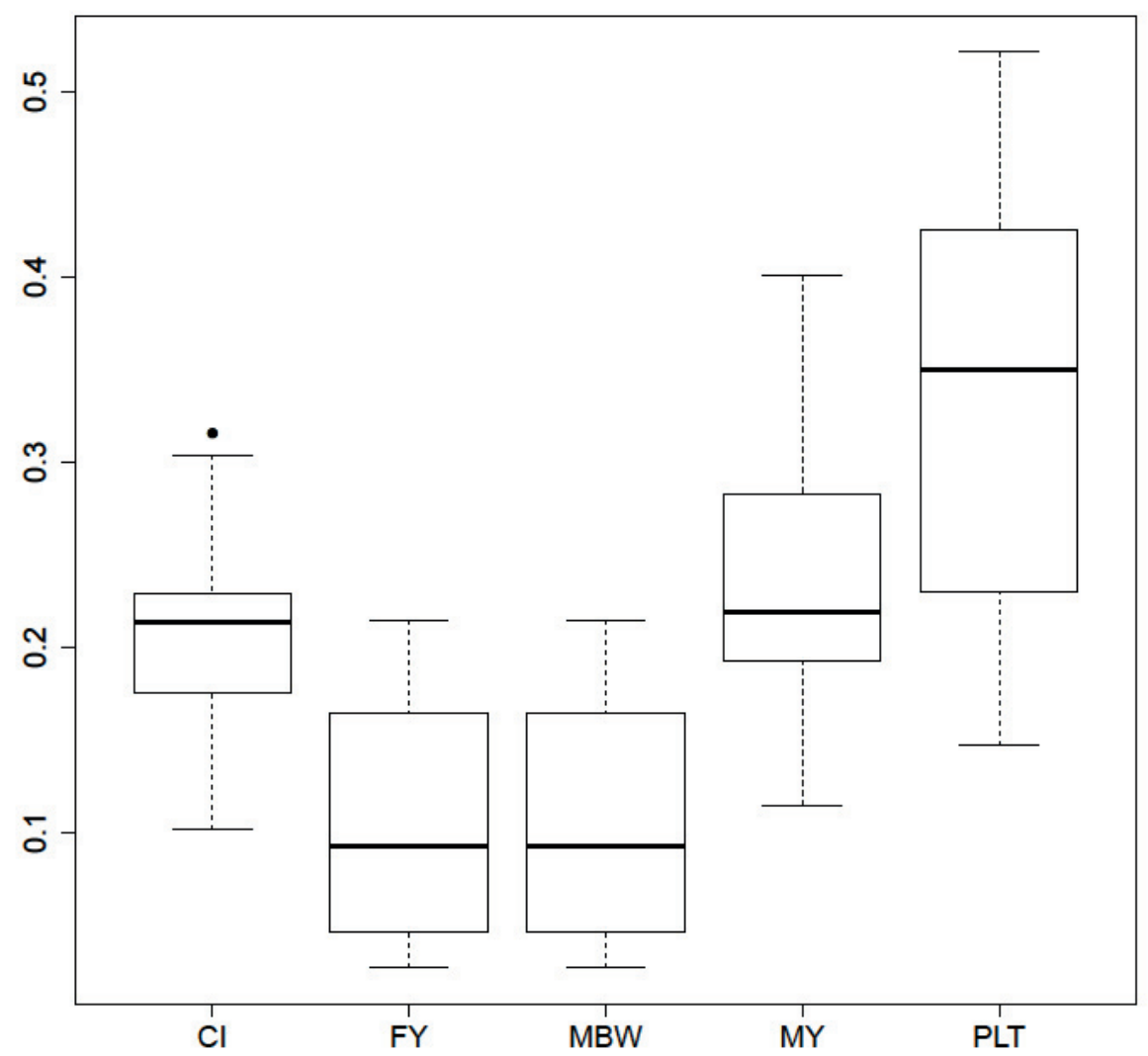

Figure 2.2 Box plots showing the median and quartiles for the five traits irrespective of respondents social group. $\mathrm{Cl}=$ calving interval; $\mathrm{FY}=$ fat yield; $\mathrm{MBW}=$ mature body weight; $\mathrm{MY}=$ milk yield PLT = production life time .

\section{Consensus preferences}

Third, we calculated consensus preferences for the social groupings with the largest disparities (Group C and D). Table 2.4 presents the consensus preferences. How to deal with outlier groups when determining consensus is defined by the metric $\lambda$. When $\lambda=0$, the consensus is defined by minimizing the disagreement of the most displaced social group while for $\lambda=1$ the consensus is defined by maximizing the average agreements among social groups. $\lambda$ values above 0.26 and 0.50 had the 

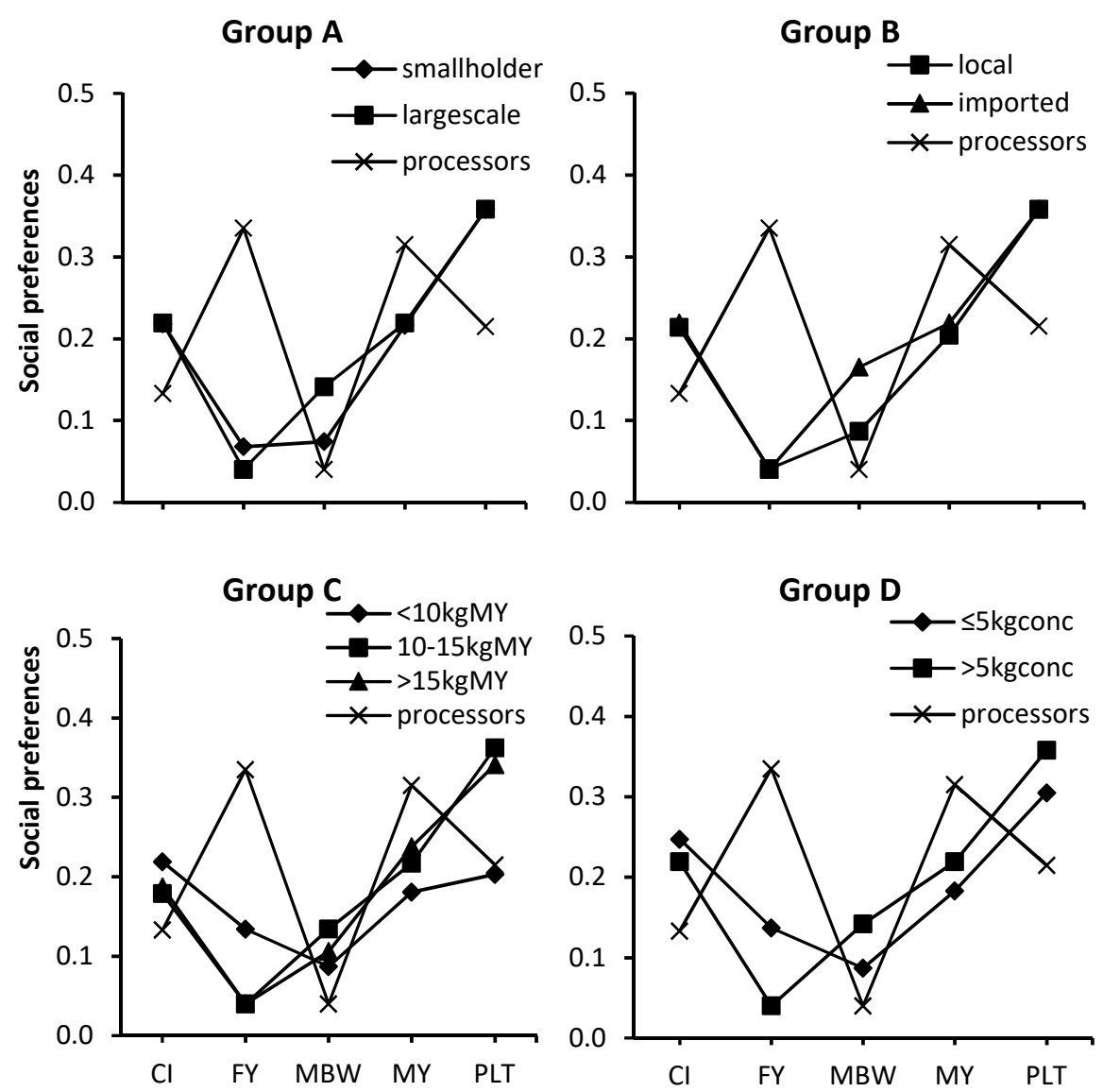

Figure 2.3 Social preference values. Social groups were defined based on the traditional criteria, milk yield per cow per day, amount of concentrate fed per cow per day, or, the source of semen (E)

Group A: based on traditional criteria; Group B: based on source of semen; imported = imported semen, local = locally produced semen; Group C: based on average milk yield per cow per day; $<10 \mathrm{kgMY}=$ less than $10 \mathrm{~kg}, 10-15 \mathrm{kgMY}=$ between 10 and $15 \mathrm{~kg},>15=$ above $15 \mathrm{~kg}$ milk yield per cow per day; Group D: based on amount of concentrate fed per cow per day; $\leq 5 \mathrm{~kg}=5 \mathrm{~kg}$ and below and $>5 \mathrm{~kg}=$ more than $5 \mathrm{~kg}$ of concentrates per cow per day. Processors were only 1 group. $\mathrm{MY}=$ milk yield, $\mathrm{Cl}=$ calving interval, $\mathrm{PLT}=$ production life time, $\mathrm{MBW}=$ mature body weight, $\mathrm{FY}=$ fat yield 
highest average agreement consensus for groups $C$ and D, respectively. However, these solutions were highly biased against the "processors" group which had a maximum disagreement equal to 0.465 and 0.570 units which are equivalent to 45 and $73 \%$ of the total disagreements, respectively. The most balanced solution was when the parameter $\lambda$ was $\leq 0.25$ and $>0$ for group $C$ and $\leq 0.50$ and $>0$ for Group $D$. The corresponding consensus values were $0.238,0.179,0.215,0.056$, and 0.134 for group C, and, 0.219, 0.153, 0.228, 0.040, and 0.173, for group D, for MY, Cl, PLT, $\mathrm{MBW}$ and $\mathrm{FY}$, respectively. Compared to average individual preferences (presented earlier) MY, MBW and FY had higher while $\mathrm{Cl}$ and PLT had lower consensus preference values.

\section{Desired gains}

Last, desired gains were computed as the product of $\mathrm{G} \%$ and the average of the best consensus values for groups $C$ and $D$ (Table 2.5). Derived desired gains were $2.42,-0.22,2.51,0.15$ and $0.87 \%$ for $\mathrm{MY}, \mathrm{Cl}, \mathrm{PLT}, \mathrm{MBW}$ and $\mathrm{FY}$, respectively.

Table 2.5 Most optimal consensus preferences and the corresponding desired genetic gains

\begin{tabular}{llllll}
\hline${ }^{1}$ Trait & $\mathrm{MY}$ & $\mathrm{Cl}$ & $\mathrm{PLT}$ & $\mathrm{MBW}$ & $\mathrm{FY}$ \\
\hline${ }^{2} \mathrm{Pref}$ & 0.229 & 0.166 & 0.249 & 0.048 & 0.136 \\
${ }^{3} \mathrm{G} \%$ & $10.6 \%$ & $-1.3 \%$ & $10.1 \%$ & $3.1 \%$ & $6.4 \%$ \\
${ }^{4} \mathrm{desiredG} \%$ & $2.42 \%$ & $-0.22 \%$ & $2.51 \%$ & $0.15 \%$ & $0.87 \%$ \\
\hline${ }^{1} \mathrm{MY}=$ milk yield, $\mathrm{Cl}=$ calving & interval, $\mathrm{PLT}$ & $=$ production & life time, $\mathrm{MBW}=$ mature body \\
weight, FY = fat yield; & & & \\
${ }^{2}$ Pref = consensus preferences; \\
${ }^{3} \mathrm{G} \%=$ genetic gains expressed as a percentage; \\
${ }^{4}$ desiredG\% = desired genetic gains
\end{tabular}

\subsection{Discussion}

Definition of a breeding objective is paramount when designing a breeding scheme. Breeding goal weights define the direction and level of genetic change required for specific traits. Inappropriate weights will result in genotype - production system mismatch and associated inefficiencies. The dairy industry in Kenya is characterized by diverse production and marketing systems, reflecting differences in costs and revenues. In this study we employed a multi-criteria decision making process to define consensus desired gains for breeding goal traits. 


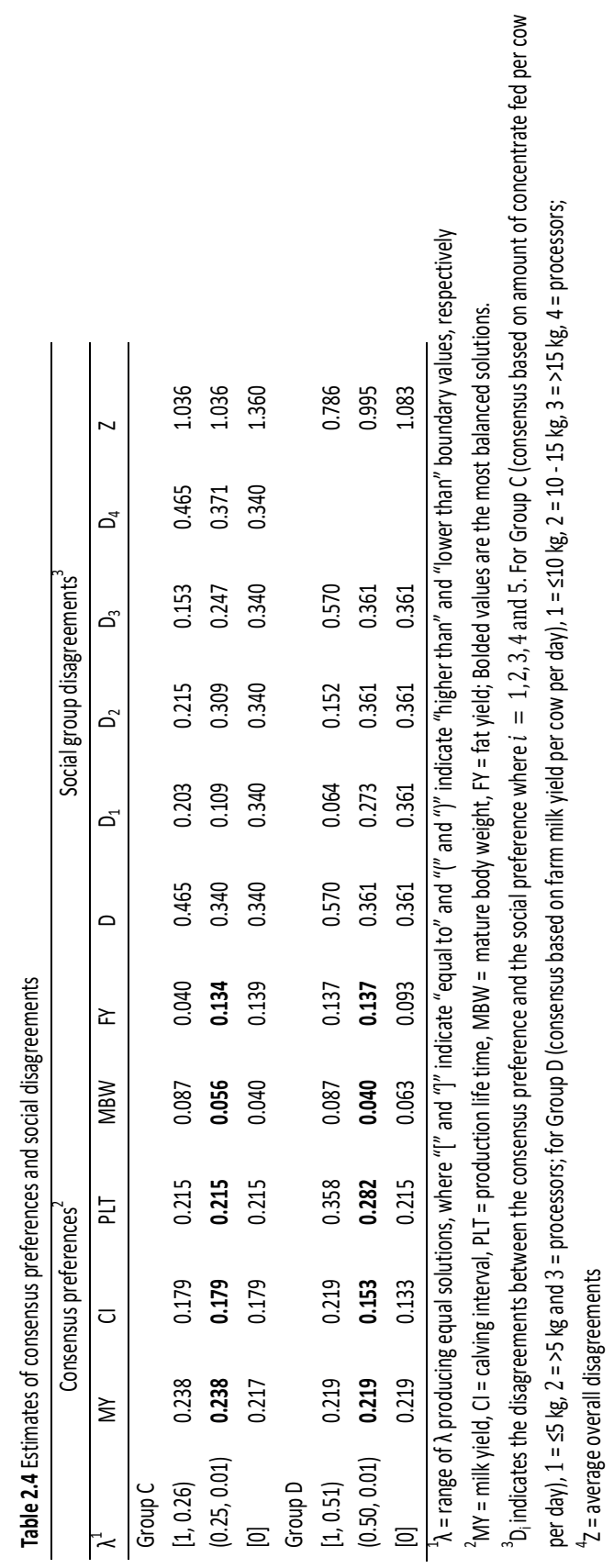




\section{Choice of criteria for determination of trait preferences}

Various participatory approaches have been proposed for derivation of trait preferences for breeding and conservation of livestock species. Such approaches are alternative to the formal economic weighting approach for situations with under-developed market channels and/or animals have non-monetary values, and for situations with multiple production and marketing systems. Some participatory approaches used in deriving trait preferences in livestock systems in the literature are conjoint analysis (Tano et al., 2003), choice experiments (Scarpa et al., 2003; Byrne et al., 2012), weighted indices (Bett et al., 2009; Mbuthia et al., 2015), Wilcoxon Signed Rank ranking (Gizaw et al., 2010) and AHP (Sae-Lim et al., 2012; Omasaki et al., 2016).

With index ranking, preferences are expressed as weighted averages of all the rankings for a particular trait (Bett et al., 2009) while with Wilcoxon Ranks, preferences are based on computed ranks (Gizaw et al., 2010). With conjoint analysis and choice experiments, preferences are defined as marginal changes in prices resulting from variation in the trait of interest (Scarpa et al., 2003). Conjoint analysis and choice experiments have been shown to identify differences in preferences among producers (social groups) when ranking traits (Tano et al., 2003; Byrne et al., 2012). However, the above approaches are not amenable to aggregation to consensus preferences.

Multiple criteria decision making (MCDM) procedures are preferred for aggregation of preferences as they allow participation of the decision makers, are flexible and transparent (Mirasgedis and Diakoulaki, 1997). One such MCDM procedure is WGP (Linares and Romero, 2002). The initial step in constructing consensus preferences is derivation of individual preference values for objective traits in the context of compromise programming i.e., pair-wise comparison of alternatives (Linares and Romero, 2002). AHP is a compromise programming approach, where individual preferences are expressed as normalized weights (Saaty, 1977). AHP therefore offers a suitable approach for a situation where the core objective is derivation of consensus preferences.

Use of AHP in derivation of consensus weights is limited by the number of traits that can be included in the objective. With more than seven traits, the AHP computations become unworkable. However, in our case, where the objective is to investigate the possibility of establishment of a breeding scheme for a developing industry, a breeding objective with few traits is probably more suitable as a starting point. 


\section{Breeding goal traits}

A main challenge to the implementation of a genetic improvement initiative in Kenya is the limited and erratic participation of producers in routine pedigree and performance recording (Wasike et al., 2011). A breeding goal with a few key traits can offer a realistic starting point. Therefore, we fixed the number of traits in the breeding goal to five. The key traits were determined to be $\mathrm{MY}, \mathrm{Cl}, \mathrm{PLT}, \mathrm{MBW}$ and FY. Previous studies have shown that sale of milk and culls are the main income sources for dairy producers in Kenya (Bebe et al., 2003b). Consequently, MY and MBW were highly ranked traits. Further, reproductive traits and fat content of the milk have been reported to be highly valued among smallholder producers (Bebe et al., 2003a). However, (Bebe et al., 2003a) did not include longevity in their study. In the present study PLT was highly ranked, which may indicate the desire to keep cows in production for longer and/or to reduce replacement costs. Disease resistance is an important trait in the tropical countries (Bebe et al., 2003b; Tano et al., 2003). However, in the present study most of the respondents in the survey viewed resistance to East Coast Fever (used as a measure of disease resistance) as not being very important as they could easily prevent the disease through regular dipping. In addition, selection for disease resistance would be hampered by lack of genetic parameters within a developing industry scenario.

\section{Definition of social groups and derivation of social preference values}

The first step in the definition of a breeding objective is specification of the production and marketing systems as this plays an important role in the identification of costs and revenues (Ponzoni and Newton, 1989). While desired gain breeding goals are not based on formal economic weighting, level of intensification (input and output levels) are to a large extent a major indicator of desired genetic change by dairy producers. Dairy cattle production systems in Kenya are generally classified into smallholder and large scale systems based on multiple criteria including land size, level of mechanization, labor input and output, level of feeding and household income (Okwenye, 1994; Bebe et al., 2003a; Kasirye, 2003). In developing countries scenario where the level of specialization is low, definition of intensification should be directly related to the product in consideration among the multiple products produced at the farm. As an example, the number of cows owned is likely to be highly confounded with the amount of land owned and may not indicate the desired level of productivity per cow. In this study we adopt a more targeted classification criteria based on the animal level (i.e., MY and feeding per cow per day). Such approach is more indicative of 
intensification at the product level rather than at farm level, and more likely to explain the producers desired gains. This is supported by the study of (Mubiru et al., 2007) who showed that MY is positively correlated to level of feeding and amount of expenses in terms of veterinary costs, and, negatively correlated to number of cows owned, labor input and land size.

Our results show that when intensification is described from an animal level substantial differences exist between high intensive producers ( $>10 \mathrm{~kg} \mathrm{MY}$ and $>5$ kg concentrate per cow per day) and low intensive producers ( $<10 \mathrm{~kg} \mathrm{MY}$ and $<5$ kg concentrate per cow per day). High intensity producers had higher preferences for MY, MBW and PLT (Group C and D). Increase in MY and MBW directly indicate an increase in feed requirement. Increased provision of high quality feeds can therefore be interpreted as direct consequence of the need for intensive production. Maximization of milk production to generate more cash through sale of milk and for family consumption are key driving factors for producers (Bebe et al., 2003a). In addition, MBW determine the market value of culls as they are mainly slaughtered for meat. On the other hand, increase in MY and MBW will require better feed of high quality. Larger cows will have a higher nutritional requirement for maintenance. High costs for concentrate feeds coupled with seasonal fluctuations in quality and quantity of fodder pose one the greatest challenge to dairy production in Kenya (Omore et al., 1999). The comparatively lower preference values for MY and MBW by low intensity produces may be indicative of a conscious knowledge between what they desire and what is practically profitable. However, the differences between LIP and HIP in their preference for MY were minimal.

Market outlets form an important group and need to be considered in the derivation of weights as they determine the demand for products and prices. Two market outlets exist in Kenya i.e., formal markets where milk is sold to Processors and informal markets where milk is sold directly to consumers. Processors had MY and FY as the highest preferred traits. Apparently, these are the traits that are likely to have the most direct impact on their profitability. Approximately $20 \%$ of the milk produced in Kenya is sold through the formal market (Omore et al., 1999). Future demand for pasteurized milk in Kenya will depend on household incomes (SDP, 2004; FAO et al., 2012). Recent increases in demand for animal products in developing countries have been attributed to increasing incomes and population sizes (FAO et al., 2012). High preference for MY by processors may indicate high market demand for milk while FY indicates a conscious need to maintain milk quality. In Kenya, milk is priced in terms of quantity. However, milk quality is important (SDP, 2004). 
In the present study, we did not directly consider the informal market. However, it is assumed that producers target the needs of the market and therefore, some aspects of the informal market needs are reflected in the LIP choices since this forms their main outlet (Omore et al., 1999). LIP had higher preferences for FY (Group C and D). This fully agrees with the fact that the informal market has a consumer preference for low priced, high butter-fat content raw milk (Omore et al., 1999; SDP, 2004). Therefore, the higher preference values for FY by LIP can be construed to indicate the need to maintain the quality of the milk consumed at the household level while at the same time satisfying the requirement of the informal market.

In conclusion, classification of farming systems need careful consideration as such classifications act as guide when making scientific or policy interventions. Our results indicate that measure of intensification should be based on the animal level rather than farm level. Based on this classification, it seems that the preference values computed from this study clearly tally with the reality of the production circumstances for the different groups. Each group evidently makes selection choices that will maximize the utility of their systems within the constraints they face.

\section{Consensus preferences and desired genetic gains}

While the differences in preference values for different groups observed in the present study may not be termed as extreme, it is evident that these preferences reflect the constraints faced by each group. Complexity in design and implementation of breeding programs, especially for dairy cattle that largely rely on producer participation, may explain the absence of such programs in developing countries. However, implementation of local breeding programs for dairy cattle provides a means to optimize developing dairy cattle industries (Vargas and van Arendonk, 2004; Okeno et al., 2010). A viable starting point may be the establishment of a single small-sized breeding program (Kariuki et al., 2014). The acceptance of such a breeding program by producers is likely to be determined by the breeding goal. Consensus in the definition of the breeding goal is therefore prudent.

Economic values based breeding objectives tend to over-emphasize selection for marketable production traits, mostly to the detriment of non-marketable functional and health traits (Groen et al., 1997; Rauw et al., 1998). For the Kenya dairy cattle industry challenges in the practical implementation of economic values based breeding objectives is apparent from the studies by Kahi and Nitter (2004) and Kahi et al. (2004). The first problem relates to the structure of marketing 
system where the value of milk is not broken down to constituent parts. Consequently, market value for milk components such as fat and protein is lacking. However, this does not imply that these components have no market value, but it could be argued that their value is inclusive in the volume price. This has led to economic values calculated based on this marketing system resulting in a negative value for FY (Kahi and Nitter, 2004). Other studies have shown consumers prefer milk with high fat content (Omore et al., 1999; SDP, 2004). This presents a special situation where consumer preferences are not reflected in commodity prices. The processors seems to have adjusted for this anomaly by setting a minimal fat percentage level when purchasing milk from producers, though these levels are not adequately communicated to producers (personal observation). A breeding objective with negative selection for FY is likely to be detrimental in the long term. Sale of culls is one of the main revenue sources for dairy producers (Bebe et al., 2003b). Kahi and Nitter (2004) estimated an economic value of Kenya shillings 7.95 for $\mathrm{MBW}$, indicating a strong positive selection for heavier animals. Heavier animals require more in terms of food quality and quantity for maintenance and production. The positive selection for heavier animals, particularly among smallholder producers, contradicts the expectations. A major challenge for dairy production is poor quality and insufficient quantities of feed and, high prices for concentrates (Rege et al., 2011). While body weight of culls is an important trait contributing directly to revenues, our results show a conscious judgement among producers between expectations and the realities of production. LIP had the lowest preference for MBW, which may be indicative of the challenges this group of producers face in cost of feeding. Overall, in our results MBW had the least preference of 0.048 .

Beside economic value estimation, definition of a national breeding objective for the dairy industry in Kenya is complicated by the diversity among the key players in the industry. To overcome this challenge, (Kahi et al., 2004) derived a breeding objective based on the smallholder system for the "current" (volume based) and "future" (volume and fat based) marketing systems. Since response to selection will always be expressed in the future, a breeding goal that considers a future marketing situation is desirable. However, failure to account for differences within the production systems is not likely to optimize production in these systems, and consequently, may be rejected. In addition, the assumption that the market will adjust the pricing criteria in the future to account for milk components and the probable values that consumers will be willing to pay for these components is difficult to predict. On the other hand, desired gains reflect the stakeholders expectations with respect to production and market circumstances. Desired gains, 
therefore, can be used to incorporate stakeholders views and wishes in the derivation of breeding objectives (Martin-Collado et al., 2015).

A single breeding objective for both high and low producers can provide a means for genetic improvement of dairy cattle in Kenya in the short term. By using consensus preferences pedigree and performance records from large scale producers can be optimally used to improve the entire value-chain. Initiation of a fully functional locally run breeding scheme can provide impetus for more participation of producers in recording of pedigrees and performances. We have used WGP to define consensus weights by minimizing disparities between different groups. The premise of our thinking is that the preference values for individual respondents are a measure of the utility they derive from the traits. Our results also suggest that such utility has a monetary basis as social preferences indicate conscious efforts within groups to maximize profitability within the constraints they face. In a descending order, desired genetic gains were 2.51, 2.42, -0.22, 0.87 and $0.15 \%$ for PLT, MY, Cl, FY and MBW, respectively. These desired gains can form a basis for the design of an optimal multi-trait breeding program that accounts for the diversity in the Kenya dairy cattle industry (Brascamp, 1978; Gizaw et al., 2010).

\subsection{Acknowledgements}

We are grateful to NUFFIC for providing funds to undertake this study. We also thank the farmers in Kenya who were involved in the survey. The first author also wishes to thank Thomas M. Magothe for providing logistics in data collection and Panya Sae-Lim for lessons on AHP.

\section{References}

Abdallah, J. M. and B. T. McDaniel. 2000. Genetic parameters and trends of milk, fat, days open, and body weight after calving in North Carolina Experimental Herds. J. Dairy Sci. 83:1364-1370.

Abou-Bakr, S. 2009. Genetic and phenotypic parameters of some lifetime and longevity traits in Holstein cows of commercial farm in Egypt. Egyptian J. Anim. Prod. 46:11-18.

Amer, P. R. 2006. Approaches to formulating breeding objectives. Pages 31-37 in Proc. 8th WCGALP, Belo Horizonte, MG, Brasil.

Bebe, B. O., H. M. J. Udo, G. J. Rowlands, and W. Thorpe. 2003a. Smallholder dairy systems in Kenya highlands: cattle population dynamics under increasing intensification. Livest. Prod. Sci. 82:211-221. 
Bebe, B. O., H. M. J. Udo, G. J. Rowlands, and W. Thorpe. 2003b. Smallholder dairy systems in the Kenya highlands: breed preferences and breeding practices. Livest. Prod. Sci. 82:117-127.

Bett, R. C., I. S. Kosgey, A. K. Kahi, and K. J. Peters. 2009. Analysis of production objectives and breeding practices of dairy goats in Kenya. Trop. Anim. Health Prod. 41:307-320.

Brascamp, E. W. 1978. Methods on economic optimization of animal breeding plans. Rapport B-134. Zeist, the Netherlands.

Byrne, T. J., P. R. Amer, P. F. Fennessy, P. Hansen, and B. W. Wickham. 2012. A preference-based appraoch to deriving breeding objectives: applied to sheep breeding. Anim. 6:778-788.

Campos, R. V., J. A. Cobuci, E. L. Kern, C. N. Costa, and C. M. McManus. 2015. Genetic parameters for linear type traits and milk, fat, and protein production in Holstein Cows in Brazil. Asian Australas. J. Anim. Sci. 28:476484.

Falconer, D. S. and T. F. C. Mackay. 1996. Introduction to quantitative genetics. 4th Edition ed. Pearson Education Ltd. , Edinburgh Gate, Harlow, Essex CM20 2JE, England.

FAO. 2011. Dairy development in Kenya. H. G. Muriuki, ed. Rome, Italy.

FAO, WFP, and IFAD. 2012. The state of food insecurity in the world 2012. Economic growth is necessary but not sufficient to accelerate reduction of hunger and mulnutrition. Rome, FAO.

Gizaw, S., H. Komen, and J. A. M. van Arendonk. 2010. Participatory definition of breeding objectives and selection indexes for sheep breeding in traditional systems. Livest. Sci. 128:67-74.

Gonzalez-Pichon, J. and C. Romero. 1999. Distance-based consensus methods: A goal programming approach. Omega 27:341-347.

Groen, A. F., T. Steine, J.-J. Colleau, J. Pedersen, J. Pribyl, and N. Reinsch. 1997. Economic values in dairy cattle breeding, with special reference to functional traits. Reoprt of an EAAP-working group. Livestock Production Science 49:1-21.

Kahi, A. K. and G. Nitter. 2004. Developing breeding schemes for pasture based dairy production systems in Kenya I. Derivation of economic values using profit functions. Livest. Prod. Sci. 88:161-177.

Kahi, A. K., G. Nitter, and C. F. Gall. 2004. Developing breeding schemes for pasture based dairy production systems in Kenya II. Evaluation of alternative objectives and schemes using a two-tier open nucleus and young bull system. Livest. Prod. Sci. 88:179-192. 
Karanja, A. M. 2003. The dairying industry in Kenya: The post-liberalization agenda. Tegemeo Institute, Egerton University, Kenya, 27th August, 2002.

Kariuki, C. M., H. Komen, A. K. Kahi, and J. A. M. van Arendonk. 2014. Optimizing the design of small-sized nucleus breeding programs for dairy cattle with minimal performance recording. J. Dairy Sci. 97:7963-7974.

Kasirye, N. F. M. 2003. Milk and dairy products, post-harvest losses and food safety in sub-Saharan Africa and the Near East in Prevention of Food Losses Program, FAO.

Linares, P. and C. Romero. 2002. Aggregation of preferences in an environmental economics context: a goal-programming approach. Omega 30:89-95.

Martin-Collado, D., T. J. Byrne, P. R. Amer, B. F. S. Santos, M. Axford, and J. E. Pryce. 2015. Analyzing the heterogeneity of farmers' preferences for improvements in dairy cow traits using farmer typologies. J Dairy Sci 98:4148-4161.

Mbuthia, J. M., T. O. Rewe, and A. K. Kahi. 2015. Analysis of pig breeding maganement and trait preferences in smallholder production systems in Kenya. Anim. Genet. Res. doi:10.1017/S207863361400054X.

Mirasgedis, S. and D. Diakoulaki. 1997. Multicriteria analysis vs. externalities assessment for the comparative evaluation of electricity generation systems. European J. Oper. Res. 102:364-379.

Mubiru, S. L., J. S. Tenywa, N. Halberg, D. Romney, W. Nanyeenya, I. Baltenweck, and S. Staal. 2007. Categorization of dairy production systems: A strategy for targeting meaningful development of the systems in Uganda. Livest. Res. Rural Dev. 19: Article \#100. http://www.Irrd.org/Irrd19/7/mubi19100.htm. Accessed May 25, 2016.

Ojango, J. M. and G. E. Pollot. 2001. Genetics of milk yield and fertility traits in Holstein-Friesian cattle on large-scale Kenyan farms. J. Anim. Sci. 79:17421750.

Ojango, J. M. K., K. Kariuki, A. Njehu, and I. Baltenweck. 2012. Breeding management strategies adopted for dairy production under low-input smallholder farming-Research Report. ILRI, Nairobi, Kenya.

Ojango, J. M. K. and G. E. Pollot. 2002. The relationship between Holstein bull breeding values for milk yield derived in both the UK and Kenya. Livest. Prod. Sci. 74:1-12.

Okeno, T. O., I. S. Kosgey, and A. K. Kahi. 2010. Economic evaluation of breeding strategies for improvement of dairy cattle in Kenya. Trop. Anim. Health Prod. 42:1081-1086. 
Okwenye, A. A. 1994. Rehabilitation of the dairy industry in Uganda. World Anim. Rev. 79 (2).

Omasaki, S. K., J. A. M. van Arendonk, A. K. Kahi, and H. Komen. 2016. Defining a breeding objective for Nile tilapia that takes into account the diversity of smallholder production systems. J. Anim. Breed. Genet. 133:404-413.

Omore, A., H. Muriuki, M. Kenyanjui, M. Owango, and S. Stall. 1999. The Kenya Dairy Sub-sector: A rapid appraisal. Smallholder Dairy (Research \& Development) Project Report. MOA/KARI/ILRI.

Ponzoni, R. W. and S. Newton. 1989. Developing breeding objectives for Australian beef cattle production. Anim. Prod. 49:35-47.

Rauw, W. M., E. Kanis, E. N. Noordhuizen-Stassen, and F. J. Grommers. 1998. Undesirable side effects of selection for high production efficiency in farm animals: a review. Livestock Production Science 56:15-33.

Saaty, R. W. 2003. Decision Making in Complex Environments: The Analytic Hierarchy Process (AHP) for Decision Making and the Analytic Network Process (ANP) for Decision Making with Dependence and Feedback. Super Decisions. Creative Decisions Foundation, Pittsburgh, PA.

Saaty, T. L. 1977. A scaling method for priorities in hierarchical structures. J. Math. Psy. 15:234-281.

Sae-Lim, P., H. Komen, A. Kause, J. A. M. van Arendonk, A. J. Barfoot, K. E. Martin, and J. E. Parsons. 2012. Defining desired genetic gains for rainbow trout breeding objective using analytic hierarchy process. J. Anim. Sci. 90:17661776.

Scarpa, R., E. S. K. Ruto, P.Kristjanson, M. Radeny, A. G. Drucker, and J. E. O. Rege. 2003. Valuing indigenous cattle breeds in Kenya: an empirical comparison of stated and revealed preference value estimates. Ecol. Econ. 45:409-426.

Smallholder Dairy Project (SDP). 2004. The demand for dairy products in Kenya. SDP Policy Brief 1. Smallholder Dairy (R\&D) Project, Nairobi, Kenya.

Tano, K., M. Kamuanga, M. D. Faminow, and B. Swallow. 2003. Using conjoint analysis to estimate farmer's preferences for cattle traits in West Africa. Ecol. Econ. 45:393-407.

Thorpe, W., H. G. Muriuki, A. Omore, M. O. Owango, and S. Staal. 2000. Dairy development in Kenya: the past, the present and the future. Available at https://cgspace.cgiar.org/handle/10568/1723. Accessed May 5, 2016.

van Arendonk, J. A. M. 1991. Use of profit equations to determine relative economic value of diary cattle herd life and production from field data. J. Anim. Sci. 74:1101-1107. 
Vargas, B. and J. A. M. van Arendonk. 2004. Genetic comparison of breeding schemes based on semen importation and local breeding schemes: Framework and application to Costa Rica. J. Dairy Sci. 87:1496-1505.

Wasike, C. B., T. M. Magothe, A. K. Kahi, and K. J. Peters. 2011. Factors that influence the efficiency of beef and dairy cattle recording system in Kenya: $A$ SWOT-AHP analysis. Trop. Anim. Health Prod. 43:141-152. 


\section{3 \\ Optimizing the design of small sized nucleus breeding programs for dairy cattle with minimal performance recording}

C.M. Kariuki ${ }^{1,2}$, H. Komen², A.K. Kahi' ${ }^{4}$, J.A.M. van Arendonk ${ }^{2,3}$

${ }^{1}$ Department of Animal Sciences, Chuka University, P.O. Box 109-60400, Chuka, Kenya; ${ }^{2}$ Animal Breeding and Genomics Centre, Wageningen University and Research, $6700 \mathrm{AH}$ Wageningen, The Netherlands; ${ }^{3}$ Hendrix Genetics, 5830 AC, Boxmeer, The Netherlands; ${ }^{4}$ Animal Sciences and Genomics Group, Department of Animal Sciences, Egerton University, P.O. Box 536-20115, Egerton, Kenya 


\begin{abstract}
Dairy cattle breeding programs in developing countries are constrained by minimal and erratic pedigree and performance recording on cows on commercial farms. Small-sized nucleus breeding programs offer a viable alternative. Deterministic simulations using selection index theory were performed to determine the optimum design for small-sized nucleus schemes for dairy cattle. The nucleus was made up of 197 bulls and 243 cows distributed in 8 non-overlapping age-classes. Each year 10 sires and 100 dams were selected to produce the next generation of male and female selection candidates. Conception rates and sex ratio were fixed at 0.90 and 0.50 , respectively, translating to 45 male and 45 female candidates joining the nucleus per year. Commercial recorded dams provided information for genetic evaluation of selection candidates (bulls) in the nucleus. Five strategies were defined i.e., only nucleus records (DP), progeny records in addition to nucleus records (PT), only genomic information (GS), dam performance records in addition to genomic information (GS+DP), and progeny records in addition to genomic information (GS+PT). Alternative PT, GS, GS+DP and GS+PT schemes differed in the number of progeny per sire and size of reference population. The maximum number of progeny records per sire was 30, and the maximum size of the reference population was 5000. Results show that GS schemes had higher responses and lower accuracies compared to other strategies; the higher response being due to shorter generation intervals. Compared to similar sized progeny testing schemes, genomic selection schemes would have lower accuracies but these are offset by higher responses per year, which might provide additional incentive for farmers to participate in recording.
\end{abstract}

Key words: Minimal recording, breeding program, genomic selection, genetic gain 


\subsection{Introduction}

Genetic improvement of livestock populations relies on the ability to create a selection differential and to disseminate superior germplasm to the commercial population. Breeding programs require a well-defined recording, selection and dissemination structure. There has been an impasse in the implementation of wellorganized and effective breeding programs in Kenya and other developing countries due to technical and infrastructural constraints (Kosgey et al., 2006; Marshall et al., 2011; Rege et al., 2011). As a consequence, dairy farmers in Kenya need to rely on importation of semen to achieve improvement on their farms. The imported semen is produced by sires resulting from breeding programs in temperate countries. However, the response in Kenya might be disappointing due to genotype by environment interaction (GXE). For example, Ojango and Pollot (2002) reported a genetic correlation of 0.49 between sires performing in both the United Kingdom and Kenya, indicating a substantial GxE. Importation of semen from temperate regions, therefore, might not be the economically optimal strategy for improving dairy cattle production in Kenya (Okeno et al., 2010). An alternative strategy is the establishment of a local breeding program (Vargas and van Arendonk, 2004; Mulder et al., 2006). However, this requires an investment in infrastructure and performance recording.

The effectiveness of a local breeding program can be measured by its ability to generate genetic progress through identification of superior individuals to be used as parents of the next generation. Artificial insemination has greatly increased the reproductive capacities of sires. In dairy cattle breeding, the largest proportion of response to selection is generated through the selection of sires because they have a high reproductive capacity. The high reproductive capacity of sires offers opportunities for high selection intensities and high accuracies of selection. On the other hand, the accuracy of selection is dependent on the amount of performance and pedigree information available for genetic evaluation of selection candidates. Very high accuracies in the sire pathway have been achieved with progeny testing (PT) based breeding programs. Attainment of these high accuracies requires each candidate sire to have 100 - 250 daughters of which performances are recorded; which translates to 10,000 - 25,000 daughters annually for a program involving 100 candidates (van Arendonk, 2011). However, participation of commercial producers in recording in Kenya is minimal and/or erratic (Wasike et al., 2011). Consequently, efforts to establish a local national dairy cattle improvement scheme based on progeny testing has been unsuccessful. A number of studies looked into the 
opportunities of nucleus breeding schemes which are less dependent on large scale recording of pedigree and performance than progeny testing schemes. Genomic selection (Meuwissen et al., 2001) has currently caused a major change in livestock improvement programs in developed countries. Genomic selection (GS) can greatly increase the response to selection particularly in species with long generation intervals (Schaeffer, 2006). From a genetic point of view, GS also enables the establishment of more effective nucleus breeding programs in developing livestock industries (van Arendonk, 2011). However, the suitability of GS in a genetic improvement strategy for livestock sectors in developing countries is disputed and requires further research.

Adoption of innovations in technology require careful consideration, comparing all possibilities to minimise risks while preventing loss of opportunity for improvement. Marshall et al. (2011) describe GS as a high-risk approach compared to PT for developing livestock sectors. Research on the technical and institutional factors influencing the successful establishment of GS breeding program for developing livestock sectors is therefore crucial. The first step in the implementation of a sound breeding program is to optimise the genetic evaluation process given the current limitations in performance and pedigree recording. The objective of the current study was therefore to compare GS and PT evaluation strategies on response to selection and accuracy when reliable pedigree and performance recording is minimal.

\subsection{Materials and methods}

\section{The population structure}

The nucleus. The general structure of the population consisted of 1) a nucleus with selection candidates, elite dams and elite sires which are used as parents for the next generation of selection candidates, 2) a group of commercial recorded cows (CRC) to provide information for genetic evaluation and 3) commercial nonrecorded cows, which benefitted from the selection efforts in the nucleus. The nucleus had cow and bull populations of 243 and 197 individuals, respectively, distributed into 8 non-overlapping age classes. The annual culling rate in the nucleus was fixed at $15 \%$. Each year 100 cows and 10 bulls within the nucleus were selected as elite dams and active sires, respectively. The sex ratio at birth, and conception rate within the nucleus were fixed at 0.50 , and 0.90 . Therefore, there were 45 male and 45 female new candidates born each year.

Selection was done annually. All new born males and females in the nucleus automatically become selection candidates. For all strategies considered 
candidates were eligible for selection only when all information required for the specified selection strategy became available. Therefore, the number of candidates attaining selection age was affected by annual culling. For instance, when all information for selection of sires was available before 1 year of age the number of new males candidates was 43 (after accounting for culling) but when this information became available when bulls were 6 years old the number of new candidates was 22 . All simulated schemes considered the same nucleus population. Within the nucleus both males and females were simulated to have a maximal lifespan of eight years, and selection candidates attained sexual maturity when one year old. The period between mating and calving was approximately one year. Therefore, cows were modelled to drop their first calf towards the end of their second year or early the third year, and had their first phenotypic record before they were 4 years old.

\section{Interaction between the nucleus and the commercial cow} population. Figure 3.1 presents the interaction between the nucleus and the commercial cow population. All selection was done in the nucleus. Selected sires were used on both nucleus and commercial dams. Selected dams were used only for production of new selection candidates in the nucleus. Commercial recorded dams provided information for the evaluation of young bulls; either as cows to produce test daughters under PT schemes or as the reference population in GS schemes. We wanted to look at situation where the number of records on performance and pedigree recorded cows is limited. The current number of unique dam performance records submitted to the national data archive in Kenya, "The Livestock Recording Centre", ranges between 200 and 1,000 per annum (personal communication with the officer-in-charge). We therefore investigated a range of $500-5,000$ commercial recorded dams per year.

\section{Alternative breeding schemes}

Most economically important traits in dairy cattle are related to productivity of cows and in most cases initial records are available after the first lactation. Therefore, in this study simulations considered a single trait recorded in dams only and records were available after the first lactation. Three levels of heritability of this single trait were used $(0.15,0.30$ and 0.50$)$ to determine the effect of heritability on response to selection and the optimum scheme.

Selection strategies were defined by the type of information used for genetic evaluation of male and female selection candidates. In all cases, we simulated an animal model genetic evaluation of the animals in the nucleus population considering all genetic relationships. Table 3.1 details the sources of evaluation 
information for alternative selection strategies. Five strategies were defined. In the first strategy (DP) evaluation was based on phenotypes recorded within the nucleus only i.e., phenotype records for dams within the nucleus. The second strategy (PT) was similar to DP, but with additional information for evaluation of bull candidates coming from daughter phenotypes in the commercial population. In the third strategy (GS) evaluation was exclusively on genomic information i.e., phenotypic information was used solely for estimation of allelic effects. Strategy four (GS+DP) was similar to GS, but nucleus cows/females had phenotypic records as additional information. The fifth strategy (GS+PT) was similar to GS+DP, but bulls had daughter phenotypes in the commercial population as additional information. The logic here is that the commercial dams that provide the progeny information can also be genotyped and then used as reference population. In this case the commercial dam information is used twice.

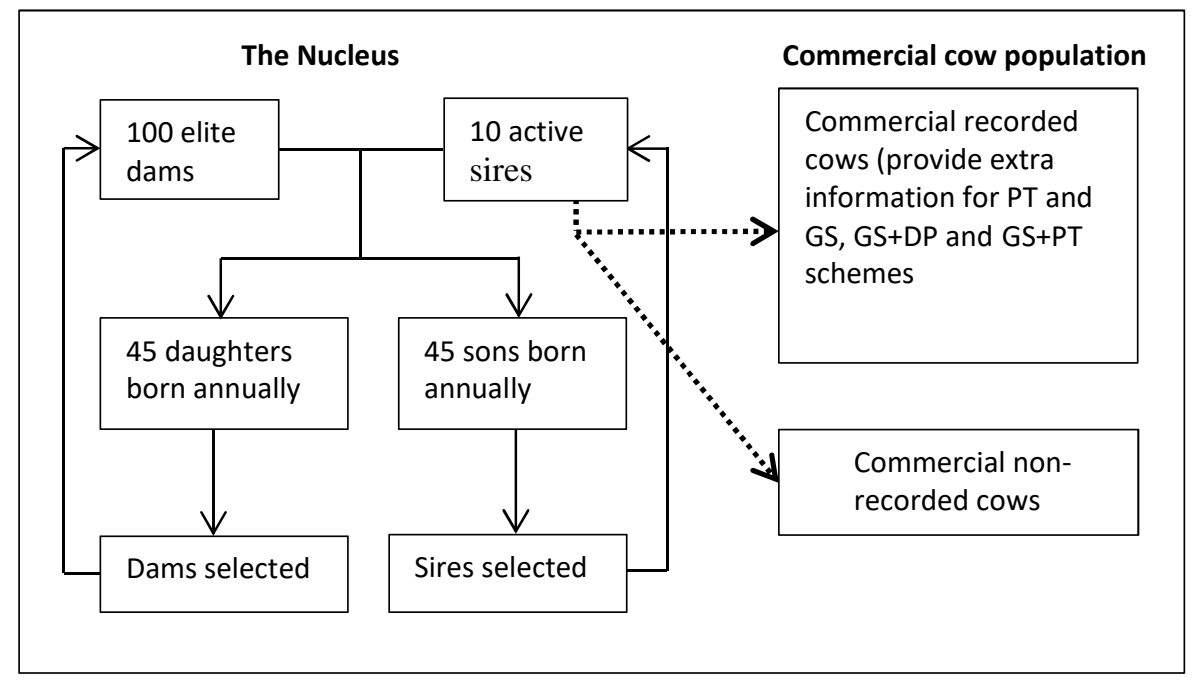

Figure 3.1 The interaction between the nucleus and the commercial cow population. All selection was in the nucleus and selected sires were used in the nucleus and the commercial cow population (thick dotted lines). The nucleus was closed (continuous lines). Information from the commercial recorded cows provided extra information for evaluation of selection candidates in progeny testing (PT), genomic selection (GS), genomic selection and dam performance in the nucleus (GS+DP) and genomic selection and progeny testing (GS+PT) schemes. 


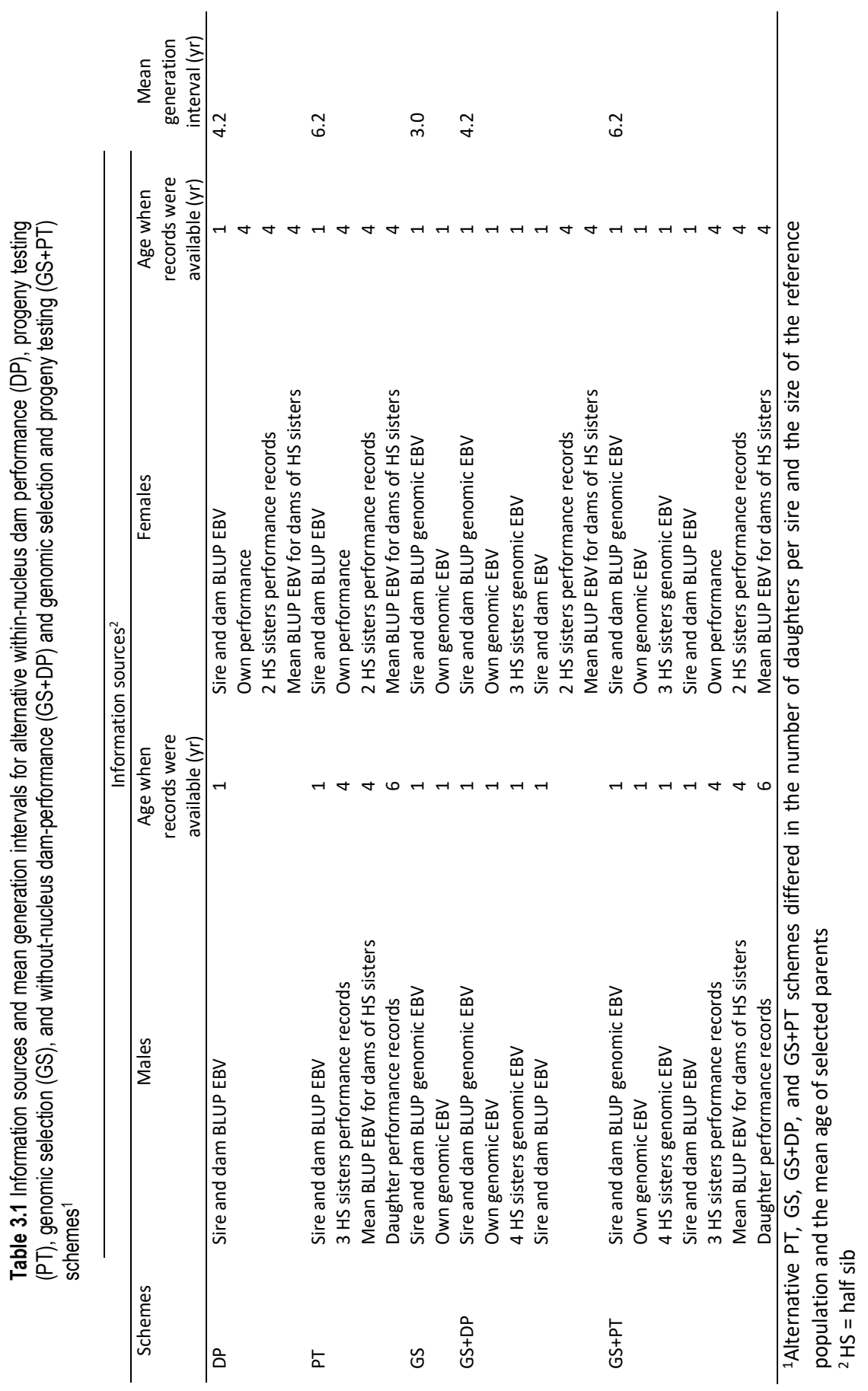


Within nucleus (DP) schemes. The base schemes (DP) considered a situation where there was no performance recording within the commercial cow population. Each year 100 elite dams were mated to 10 active sires to produce 45 male and 45 female selection candidates. Therefore, each candidate bull had five half-sib sisters and each candidate dam had four half-sib sisters at birth. Under DP schemes, sires were selected only on pedigree information and performance records of half-sib sisters were ignored. This allowed selection of bulls when 1 year old. Dams were selected after own performance records were available.

Progeny testing (PT) schemes. Under PT schemes, phenotypic records were collected on progeny in the commercial population as an extra source of information for male candidates. PT schemes therefore considered a situation where semen was collected from 45 one year old bulls and used to inseminate cows in commercial recorded group to produce test daughters. The number of cows in the commercial recorded group determined the number of test daughters that a candidate bull could produce. Two PT scenarios were simulated. In the first scenario (PT-15), schemes with 2,500 cows available annually in the commercial recorded group were simulated. Under the PT-15 schemes young bulls were evaluated on performance records of 15 daughters in addition to the performance of relatives within the nucleus. The second scenario (PT-30) simulated schemes with 5,000 cows available annually in the commercial recorded group. This resulted to each candidate bull within PT-30 schemes having 30 daughters with first lactation records. The number of daughters per test bull was computed by fixing the conception rate and survival rates at $80 \%$ for the commercial recorded dam population. Bulls could be selected as parent for next generation of nucleus animals from an age of 6 years onwards.

Genomic selection (GS) schemes. For GS, GS+DP and GS+PT schemes four sizes of reference populations (i.e., 500, 1,000, 2,500 and 5,000) were simulated. For comparison purposes, the number of selected sires and dams within the nucleus for genomic schemes were equal to those in DP and PT schemes. For GS+PT-500, GS+PT-1000, GS+PT-2500, and GS+PT-5000 schemes the number of progeny records per candidate bull were $3,6,15$, and 30 , respectively. In GS schemes bulls and dams were selected when one year of age, while in GS+DP schemes bulls were selected when 1 year old and dams when four years old. In GS+PT bulls were selected when six years old and dams when four years old.

Following the procedure of Dekkers (2007) genomic information was mimicked in the selection index calculations by including a correlated trait with heritability equal to unity. The reliability of genomic information was included as genetic correlation between this additional trait and primary trait. In all schemes where genomic information was a source of information, reference populations were 
constructed by genotyping and phenotyping the available commercial dams. Using a reference population consisting of animals which are genotyped and phenotyped will yield higher accuracies than a population with genotypes of sires with phenotyped daughters (van Grevenhof et al., 2012).

The phenotypic and genetic correlations were calculated as $h r_{g \hat{g}}$ and $r_{g \hat{g}}$, respectively, where $h$ is the square root of the heritability of the trait and $r_{g} \hat{g}$ is the accuracy of the genomic EBV. $r_{g} \hat{g}$ is determined by the size of the reference population $\left(n_{P}\right)$, the effective number of loci in the base population $\left(n_{G}\right)$, and the correlation of the true breeding value of the genotyped individuals and their phenotypes $(r)$, and was computed as (Dekkers, 2007; Daetwyler et al., 2008),

$r_{g \hat{g}}=\sqrt{\frac{\lambda r^{2}}{\lambda r^{2}+1}}$

where $\lambda=n_{P} / n_{G} . n_{G}$ depends on the historic effective size of the base population $\left(N_{E}\right)$ and the size of the genome, $L$, in Morgan and was computed as $n_{G}=2 N_{E} L$. $N_{E}$ was taken to be 156 (Muasya et al., 2013) and $L$ was equal to 30. Reference populations were constructed by genotyping and phenotyping the same animals. Therefore, $r^{2}=h^{2}$.

Generation intervals. In dairy cattle breeding, selected sires and dams remain in the breeding population as active sires and dams for several years before culling. Thus, selected parents are in different age-class classes. For such situations, it is important to account for differences in the mean performance between the ageclass cohorts due to selection (Ducrocq and Quaas, 1988). This study therefore simulated selection by truncation with overlapping generations. The classical formula for determining the response to selection is modified to account for overlapping generations as (Ducrocq and Quaas, 1988),

$\Delta G=\frac{\sum_{j=1}^{\# \text { ageclasses }} i_{j} r_{I H, j} \sigma_{A, j} \frac{n_{j}}{n_{\text {total }}}}{L}$

where $i_{j}$ is the selection intensity in age class $j, r_{I H, j}$ is the accuracy of selection for age class $j, \sigma_{A, j}$ is the additive genetic standard deviation for age class $j, n_{j}$ is the number of selected parents from age class $\mathrm{j}, n_{\text {total }}$ is the total number of selected parents and $L$ the generation interval. The above equation is implemented in SelAction (Rutten et al., 2002), the software which we used for our calculations. Age classes were defined by the year of birth so that animals of the same age belonged to the same class. 


\section{Investigations on the effect of the size of the nucleus on response to selection}

The effect of the size of the nucleus on the response to selection was investigated by simulating the response for a trait with heritability equal to 0.30 . Nucleus sizes considered in the alternative schemes were 100, 200, 400, 600, 800 and 1,000 elite dams selected annually. For all schemes 10 sires were selected each year. For simplicity, only the maximal size of the CRC group was considered. Therefore, the number of progeny records per sire for alternative PT and GS+PT schemes was fixed at 30 while the size of the reference population for GS, GS+DP and GS+PT schemes was fixed at 5,000 dams. However, the number of selection candidates were proportionately adjusted taking into account the size of the nucleus, conception and culling rates, and sex ratio in the nucleus as explained earlier.

\subsection{Results}

\section{Response to selection}

Response to selection was influenced by the selection strategy, amount of information available and heritability. Figure 3.2 compares the responses for alternative strategies for a situation with 2,500 CRC and heritability equal to 0.15 , 0.30 and 0.50 , expressed in genetic standard deviation $\left(\sigma_{g}\right)$. With the heritability $=$ 0.15 , responses were approximately equal for all strategies ranging between 0.020 and $0.025 \sigma_{g}$. Higher responses were observed for larger heritabilities. Increasing the heritability to 0.30 while maintaining the size of CRC at 2,500 increased the response in GS and GS+DP schemes by 7- and 9.5\% compared to a PT scheme, respectively. GS schemes had the highest sensitivity to increase in heritability. For instance, GS schemes had an $100 \%$ increase in response when heritability was doubled from 0.15 to 0.30 compared to $92-$, $75-$ and $72 \%$ increases for GS+DP, PT and GS+PT schemes, respectively, for a situation with 2,500 CRC. Increasing the heritability to 0.50 from 0.30 and the number of CRC 2,500 to 5,000 resulted in $59 \%$ increase in response for the GS scheme compared to 55-, 42-, and $43 \%$ increases for a similar for GS+DP, GS+PT and PT schemes.

Figure 3.3 compares the effect of increasing the size of the CRC population from 2,500 to 5,000 for heritability equal to 0.30 and 0.50 . Generally, increasing the size of CRC from 2,500 to 5,000 increased the response observed for all strategies. The highest increases were observed in the GS-only strategy. The GS+DP and GS+PT schemes had higher responses than comparable (in size) DP and PT schemes. The highest response was obtained with genomic selection with a CRC population of 
5,000 . However, GS schemes with a reference population of 500 and 1,000 cows had much lower responses that the base scheme (Table 3.2).

To standardize the comparison, the selection strategies under investigation were benchmarked against the basic scheme i.e. DP. This was to determine the extra response per year in genetic standard deviation expressed as a percentage, that could be achieved by adopting any of the alternative strategies and increasing the level of investment in recording, either of phenotypes or genotypes, from 2,500 to 5,000 CRC. A GS selection strategy had 15.0-, 24.3- and 29.3\% increase in response compared to 20.0-, 13.4- and 5.2\% increase for PT selection strategy for a situation with 2,500 CRC and heritability equal to $0.15,0.30$ and 0.50 , respectively (Table 3.2). When the CRC group had a population 5,000 cows, increases in response for GS schemes were $60.0-, 70.3-$ and $72.4 \%$ for heritability equal to $0.15,0.30$ and 0.50 , respectively. When CRC was 500 or $1,000, \mathrm{GS}+\mathrm{DP}$ schemes had highest responses followed by GS+PT schemes and GS schemes, for all heritabilities.

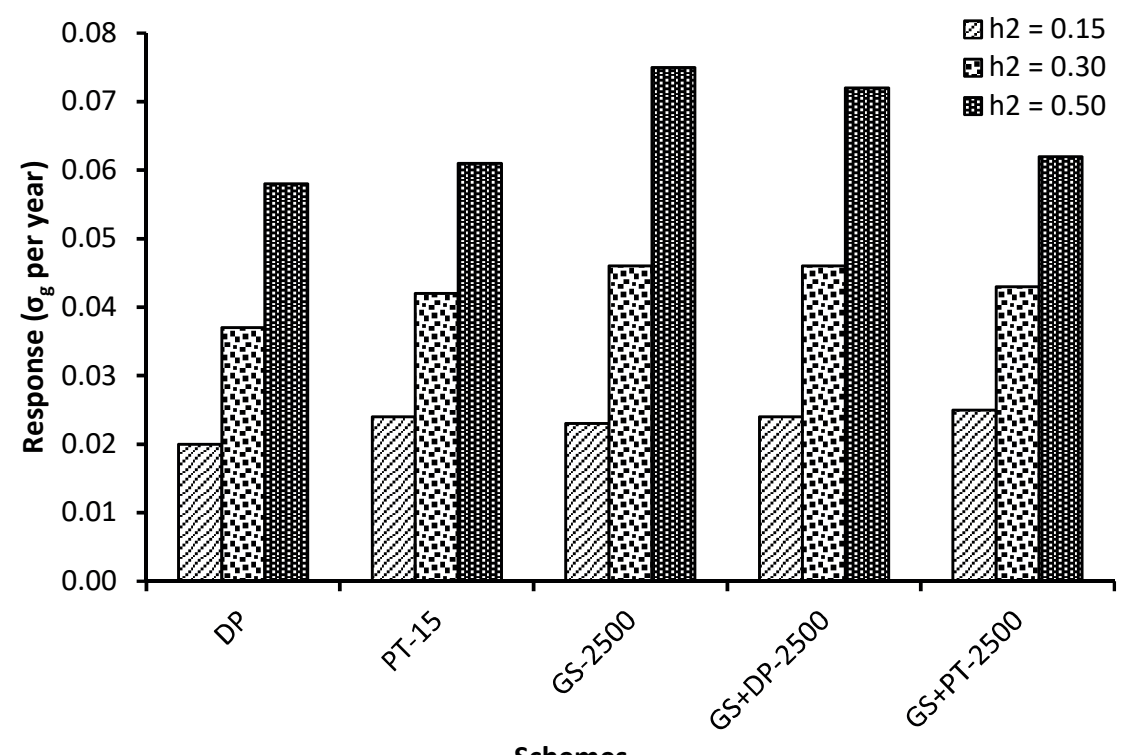

Figure 3.2 Effects of heritability on response to selection, in genetic standard deviation $\left(\sigma_{\mathrm{g}}\right)$, for within nucleus dam performance (DP), progeny testing (PT), genomic selection (GS), genomic selection and dam performance within the nucleus (GS+DP) and genomic selection and progeny testing (GS+PT) schemes for a situation with 2,500 commercial recorded dams and heritabilities (h2) equal to $0.15,0.30$ and 0.50 . 


\section{Accuracy of index}

Index accuracies for sires in DP, GS, GS+DP and GS+PT schemes are presented in Table 3.2. PT yielded the highest accuracies. Accuracies for PT and combined GS+PT selection were comparable, implying that the contribution of additional genomic information to a progeny testing scheme on accuracy was negligible. GS+DP selection had slightly higher accuracies than GS. Accuracy was sensitive to the amount of information available for evaluation for all strategies considered. This sensitivity was highest for GS and lowest for PT strategies, implying that GS could outperform PT testing when the reference population was sufficiently large.

Table 3.2 Accuracies and extra response $(\Delta R)$ in genetic standard deviations, expressed as a percentage when comparing alternative schemes to the basic DP scheme, for equal CRC and $h^{2}$

\begin{tabular}{|c|c|c|c|c|c|c|}
\hline \multirow{3}{*}{ Schemes $^{1}$} & \multicolumn{6}{|c|}{ Parameters ${ }^{2}$} \\
\hline & \multicolumn{2}{|c|}{$\mathrm{h}^{2}=0.15$} & \multicolumn{2}{|c|}{$\mathrm{h}^{2}=0.30$} & \multicolumn{2}{|c|}{$\mathrm{h}^{2}=0.50$} \\
\hline & $\Delta R(\%)$ & $r_{1}$ & $\Delta \mathrm{R}(\%)$ & $r_{1}$ & $\Delta \mathrm{R}(\%)$ & $r_{1}$ \\
\hline PT-15 & 20.0 & 0.497 & 13.5 & 0.623 & 5.2 & 0.719 \\
\hline PT-30 & 40.0 & 0.604 & 27.0 & 0.727 & 15.5 & 0.811 \\
\hline GS-500 & -45.0 & 0.069 & -43.2 & 0.098 & -39.7 & 0.126 \\
\hline GS-1000 & -25.0 & 0.098 & -18.9 & 0.137 & -15.5 & 0.176 \\
\hline GS-2500 & 15.0 & 0.137 & 24.3 & 0.214 & 29.3 & 0.272 \\
\hline GS-5000 & 60.0 & 0.214 & 70.3 & 0.297 & 72.4 & 0.372 \\
\hline GS+DP-500 & 5.0 & 0.195 & 5.4 & 0.265 & 5.2 & 0.331 \\
\hline GS+DP-1000 & 10.0 & 0.207 & 10.8 & 0.282 & 12.1 & 0.353 \\
\hline GS+DP-2500 & 20.0 & 0.239 & 24.3 & 0.327 & 24.1 & 0.409 \\
\hline GS+DP-5000 & 40.0 & 0.283 & 43.2 & 0.386 & 41.4 & 0.479 \\
\hline GS+PT-500 & -15.0 & 0.329 & -13.5 & 0.435 & -15.5 & 0.526 \\
\hline GS+PT-1000 & 0.0 & 0.392 & -2.7 & 0.510 & -6.9 & 0.608 \\
\hline GS+PT-2500 & 25.0 & 0.511 & 16.2 & 0.640 & 6.9 & 0.735 \\
\hline GS+PT-5000 & 45.0 & 0.622 & 29.7 & 0.744 & 17.2 & 0.825 \\
\hline
\end{tabular}

1Selection strategies: DP = within nucleus dam performance; $\mathrm{PT}=$ progeny testing; $\mathrm{GS}=$ genomic selection; GS+PT = genomic selection and within nucleus dam performance; GS+PT = genomic selection and progeny testing.

${ }^{2}$ Parameters: $h^{2}=$ heritability; $\Delta R=$ extra response; $r_{l}=$ accuracy

\section{Effect of selection strategy on age distribution of selected sires}

For the different schemes, selection of parents for production of nucleus selection candidate was possible only after information from all sources was available. Inclusion of progeny phenotypes as sources of information (PT and GS+PT) resulted in a minimum age of selected sires of 6 years. The age distribution of active sires is 
given in Figure 3.4. For GS schemes, more than $60 \%$ of the active bulls were 2 years old and only $14 \%$ of the active bulls were more than 3 years old. Generally, DP, GS and GS+DP schemes had more intensive use of young bulls. The differences in mean generation interval are reflected in the differences in response between schemes (Figure 3.2 and 3.3).

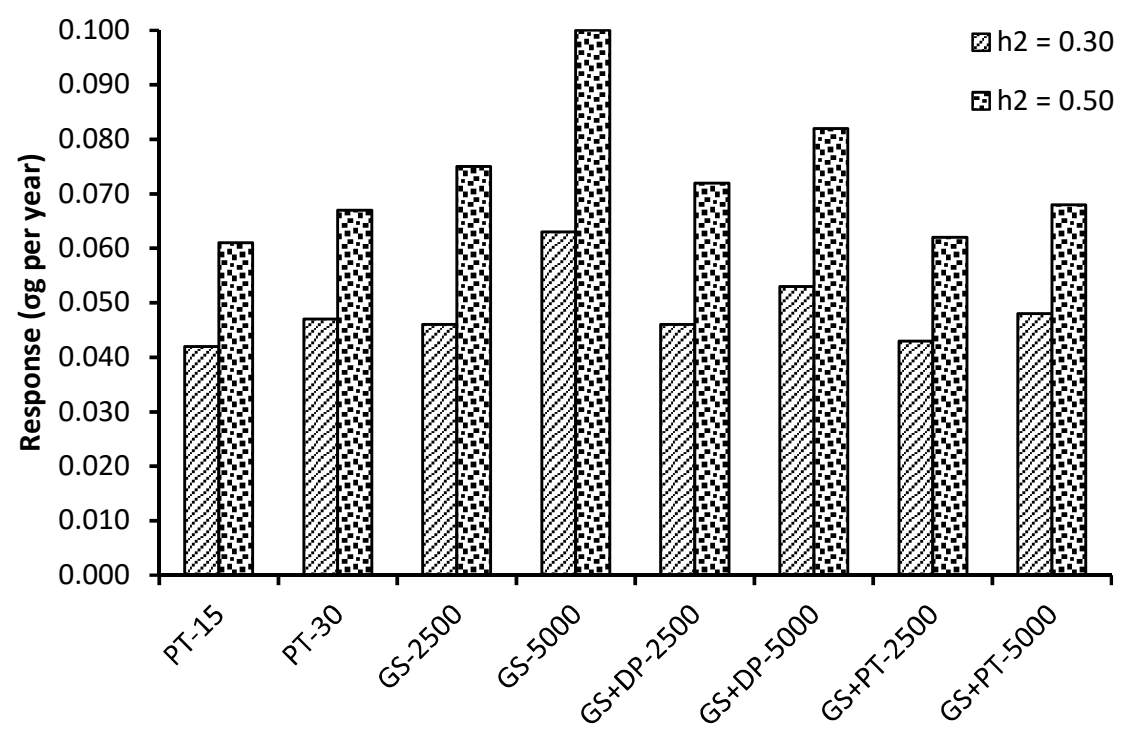

Schemes

Figure 3.3 Effects of increasing the number of commercial recorded cows on response to selection, in genetic standard deviation $\left(\sigma_{\mathrm{g}}\right)$, for alternative progeny testing (PT), genomic selection (GS), genomic selection and dam performance within the nucleus (GS+DP) and genomic selection and progeny testing (GS+PT) schemes for situations where the number of commercial recorded dams were 2500 and 5000 and heritabilities (h2) equal to 0.30 and 0.50 .

\section{Effect of the nucleus size on response}

Figure 3.5 presents the effects on response due to increasing the nucleus size from 100 to 1,000 elite dams while maintaining the number of active sires at 10 , for a trait with heritability equal to 0.30 . Response in all schemes increased with larger nucleus sizes. However, results show a diminishing increase as the nucleus size gets much larger. However, increasing the nucleus is likely to have a big effect on the rate of inbreeding as it increases the selection intensity in the sires. Inbreeding was 
not considered in the current study as SelAction cannot calculate rates of inbreeding in overlapping generations.

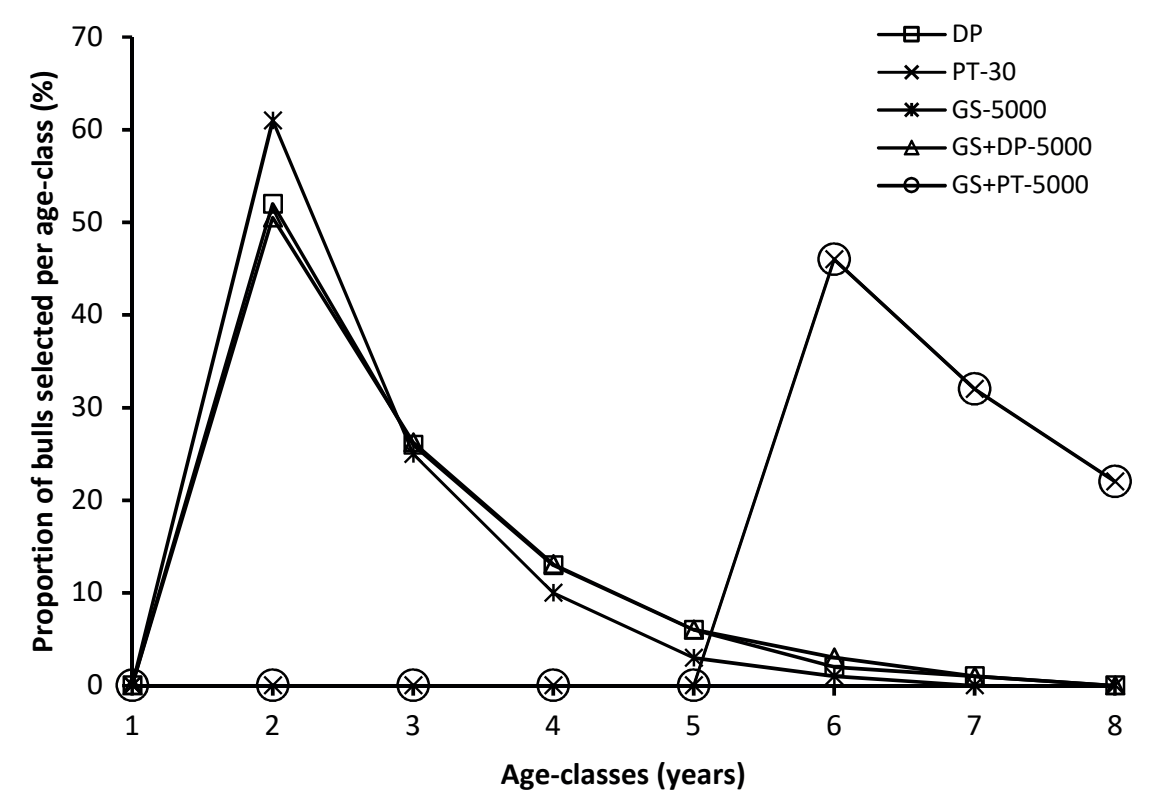

Figure 3.4 Effect of the selection criteria on proportions of active sires in different ageclasses for within nucleus dam performance (DP), progeny testing (PT), genomic selection (GS), genomic selection and dam performance within the nucleus (GS+DP) and genomic selection and progeny testing (GS+PT) schemes for a trait with heritability equal to 0.50 and 5,000 commercial recorded dams.

\subsection{Discussion}

\section{Response to selection}

The aim of the current study was to optimise the design of small-sized nucleus genetic improvement dairy cattle schemes for situations where phenotype records are limited. Such schemes are important when producers' participation in pedigree and performance recording is minimal or for unique small-sized populations kept for specific products. Before adoption it is important to predict the possible benefits of alternative selection strategies so as to determine the best alternative. We compared alternative selection strategies by benchmarking possible responses to schemes were recording was only within the nucleus and evaluation was on phenotypic information only (DP schemes). Our results show that GS schemes had 
higher annual responses for traits with moderate to high heritability and a moderately small population size i.e., 2,500 to 5,000 CRC. In actual breeding schemes selection is not for a single trait but an aggregate of a group of traits i.e., a total merit index. Heritability as expressed in this study can therefore be considered as the index heritability. A lower index heritability could reflect a more unfavorable genetic correlation between traits in the index.

Higher responses in GS were particularly due to the ability to greatly reduce the generation intervals for schemes utilizing this selection strategy (Pryce et al., 2010). Shortening of generation intervals will result in more rounds of selection per unit time, hence increasing the achievable gains per period time. GS based selection schemes are therefore highly attractive for situations where it is possible to reduce generation intervals (van Grevenhof et al., 2012). All schemes would benefit from larger nucleuses (Figure 3.5). A larger nucleus size would increase the number of selected parents and hence reduce accumulation of inbreeding.

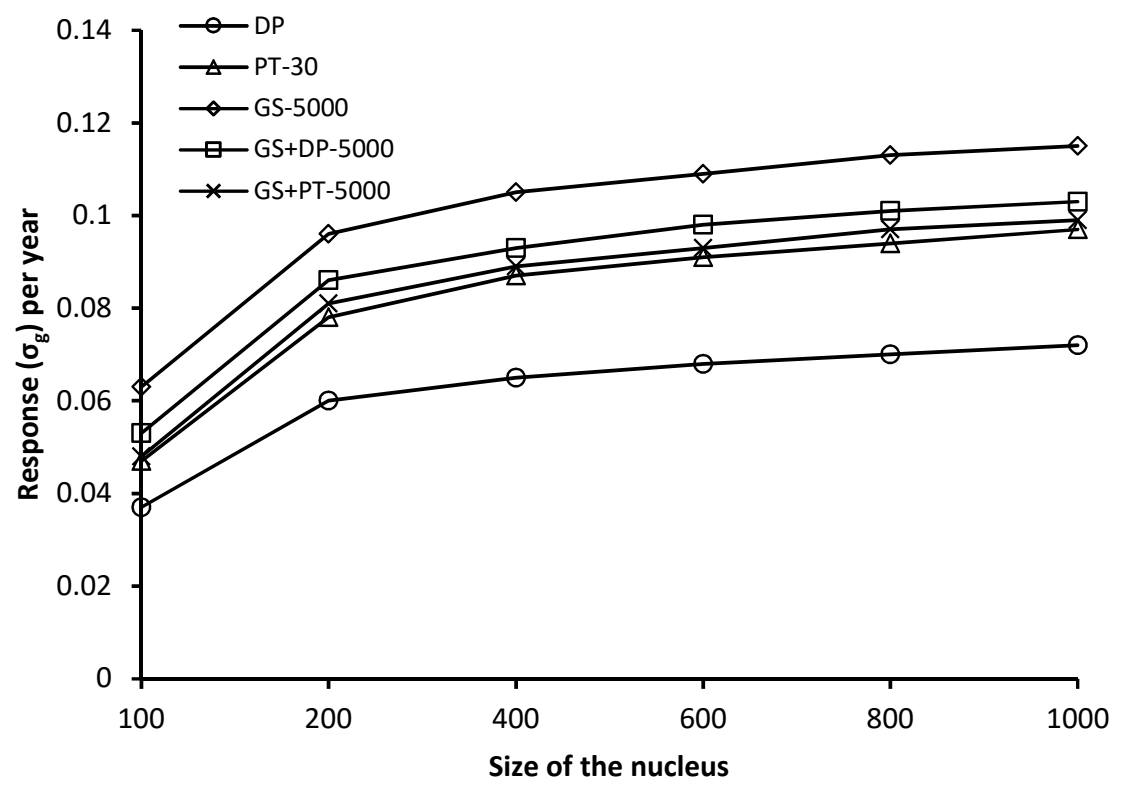

Figure 3.5 Effect of the nucleus size on response to selection for within nucleus dam performance (DP), progeny testing (PT), genomic selection (GS), genomic selection and dam performance within the nucleus (GS+DP) and genomic selection and progeny testing (GS+PT) schemes for a trait with a heritability of 0.30 and 5,000 commercial recorded dam available. Nucleus sizes considered were 100, 200, 400, 600, 800 and 1,000 dams. 


\section{Risks associated with adoption of alternative strategies}

Risk is an important factor when deciding the selection strategy for adoption. GS has been described as a high risk approach for creating genetic improvement in developing countries (Marshall et al., 2011). Components of risk for a breeding program are variance of the response and inbreeding.

Population size in our study referred to the number of animals on which phenotypic records were collected. The mortality rates of calves in developing countries can be high due to infectious diseases or the harsh environment. The number of calves that need to be produced to reach the simulated population sizes is consequently a lot higher. The higher mortality will also increase the risk associated with the small-sized nucleus scheme.

Variance of response. Deviation of the realized response from the predicted response is an attribute of the prediction error. The prediction error variance is determined by the accuracy of EBVs and inbreeding (Meuwissen, 1991). Low accuracy implies larger variability of the estimated genetic value from the true value. Consequently, realized responses from breeding programs with lower selection accuracy are likely to deviate highly from the expectation. In addition, producers may be unwilling to buy semen from bulls with low reliabilities. Therefore, small-sized artificial insemination schemes will find it difficult to survive competition with larger schemes in a global dairy breeding market. However, for schemes aimed at breeding for "unique" products or qualities e.g. breeding for disease and heat tolerance in the tropics, such competition is not likely to have significant effects to the ability of these schemes to succeed as they target different market niches.

Therefore, the most important risk for low accuracy breeding programs is high variances in realized responses. In the present study, GS attained very low accuracies compared to PT. The use of genome wide dense single nucleotide polymorphs i.e., genomic selection, has increased the number of markers available for estimation of associations between markers and QTLs (Meuwissen et al., 2001). However, sampling errors are determined by the sample size and heritability of the trait under consideration. Smaller sample sizes result in larger sampling errors with the situation aggravated when concerned traits have low heritability (Lande and Thompson, 1990; Meuwissen et al., 2001). Consequently, a large proportion of the additive genetic variance may not be explained by markers when the reference population is small. Hence, the realized response is likely to be lower than predicted (Moghaddar and van der Werf, 2009). Variance in realized response due 
to low accuracies poses a major challenge for the GS strategy as it is characterized by low accuracies ( Pryce et al., 2010; Lillehammer et al., 2011; van Grevenhof et al., 2012). Such accuracies are generally much lower for smaller reference populations (Figure 3.4). Previous study show that a population of approximately 100000 dams with genotypes and phenotypes are required to attain an accuracy above 0.90 (van Grevenhof et al., 2012).

Previous studies that have considered the potential of GS have assumed that such schemes will attain high accuracies (Schaeffer, 2006; Konig et al., 2009). Such accuracies are not achievable for small-sized schemes. Alternatives that involve combination of information sources have been studied. Such alternatives have been pre-selection of sires and combined use of phenotypic and genotypic information for selection (Schrooten et al., 2005; Pryce et al., 2010). For small-sized nucleus schemes pre-selection of sires will not be viable as the available number of candidates is generally small hence all new-borns need to be included as candidates. Results from this study show that the combined use of progeny phenotypes with genomic information (GS+PT schemes) will have negligible impact on response compared to use of progeny phenotypes only (PT schemes) (Figure 3.2 and 3.3). This is because all the benefits of reduced generation intervals are lost with such schemes. A compromise would be to combine female phenotypic information from nucleus dam (i.e. excluding progeny phenotypes) with genomic information. In this study, GS+DP-5000 schemes, had relatively higher responses compared to PT and higher accuracies compared to GS only when heritability of the trait was 0.3 or higher.

Another option to maximize achievable accuracy within the constraint of a smallsized reference population is to adopt an improved genome-wide prediction method. Genome-wide prediction methods can be categorized based on how they model the variance of markers across the genome. Linear methods assume homogeneity of variance for all markers and include variants of genomic best linear unbiased prediction. Non-linear Bayesian methods allow for heterogeneity of variance between markers. For small reference populations, previous simulation studies have shown that Bayesian predictions will yield higher accuracies compared to linear predictions (Meuwissen et al., 2001; Daetwyler et al., 2010).

Comparing schemes only on accuracies while ignoring responses may not give a balanced conclusion. In the present study adoption of a GS scheme would result in $70.3 \%$ increase in response compared to the basic scheme. Adoption of the GS+DP scheme would result in $43.2 \%$ extra response. (Table 3.2). Therefore, despite the expected larger fluctuations in response for GS schemes, they will have higher 
mean performance at the population level, which compensates for the fluctuations.

Inbreeding. Inbreeding leads to increased homozygosity within the population resulting in reduced genetic variance, inbreeding depression and increase in problems associated with lethal genes. Future inbreeding is determined by the coancestry of parents. With small-sized nucleus schemes, where the number of parents is small, the rate of inbreeding is expected to be higher. This will have the effect of reduced response to selection in the long term. Accumulation of inbreeding in future generations can be minimised by minimising co-ancestry in the parents (Wray and Goddard, 1994; Brisbane and Gibson, 1995; Meuwissen, 1997). Methodologies have been developed to minimize inbreeding for small populations with overlapping generations (Meuwissen and Sonesson, 1998; Sonesson and Meuwissen, 2001).

The procedures of Meuwissen and Sonesson (1998) and Sonesson and Meuwissen (2001) where derived with best linear unbiased prediction (BLUP) EBV selection in mind. The BLUP EBVs of relatives are highly correlated which can lead to more coselection of relatives. The expected level of inbreeding accumulation in GS schemes should be equal to that in PT schemes as inbreeding is determined mainly by the co-ancestry of selected parents. However, with GS it is possible to make a distinction between EBVs of full-sibs as this strategy can explain some of the variance due Mendelian sampling and hence reduce co-selection of siblings (Daetwyler et al., 2007).

\section{General discussion}

Unfavourable GxE between sires performing in temperate and tropical countries necessitates the establishment of breeding programs within tropical production systems so as to economically optimise tropical dairy cattle industries. However, in developing countries (such as the case in Kenya) commercial herd pedigree and performance recording is minimal and inconsistent. Failure of the recording system to meet farmer expectations and to offer tangible returns are the main weaknesses in the pedigree and performance recording system in the Kenya dairy cattle (Wasike et al., 2011). This limits the opportunities to implement a genetic improvement program that relies on progeny testing. An alternative approach for creating genetic improvement of diary sector is therefore imperative. In addition, attractive and viable genetic improvement strategies are required for cases with small "unique" populations with well-developed recording systems.

Alternative selection strategies i.e., DP, PT, GS, GS+DP and GS+PT, within the limitation of minimal recording were studied and the risks involved discussed. 
Adoption of a selection strategy that maximizes response to selection per period time would be the most beneficial. Our results show that this is achieved through use of GS. Risks associated with alternative strategies is an important factor to consider (Marshall et al., 2011). While GS schemes are expected to have higher risks compared to PT schemes due to the lower accuracies, such schemes will generally have a higher mean performance. Therefore, we expect higher overall population mean performance if GS is adopted. In addition, GS are expected to have lower inbreeding accumulation over time compared to PT schemes due to minimized co-selection of siblings as discussed earlier.

Other indirect effects of the selection strategy on the industry are worth consideration. Lack of tangible returns to producers for their recording efforts is a major deterrent from future participation (Wasike et al., 2011). Adoption of a strategy that would maximize the achievable response in the shortest possible time would be helpful in such a situation. Furthermore, with a system where recording structures are not well established the accuracy of information coming from participating producers is likely to be low. As a consequence, reliabilities of estimates of population parameters and expected response will be low. Accuracy of such information can be verified by use of genomic information, in particular the accuracy of the pedigree information. Therefore, the overall risk associated with GS schemes may indeed be lower than that expected from PT strategy.

Reduction in the amount of recording required will have a monetary advantage. In the current study, we constructed the reference population by use of genotypes and phenotypes from the same animal. Genotyping need not be done annually but periodically. With well stipulated genotyping intervals, phenotypic performances can be reduced to only the year previous to the genotyping period. This minimizes the amount of recording compared to PT strategy that require continuous recording. Another factor to consider is that small-sized PT dairy cattle selection schemes are constrained in flexibility in the number of selection candidates. The limited number of cows to produce test daughters implies that it is practically impossible to increase the information available per candidate sire or to increase the number of male candidates without lowering the number of evaluation records. On the other hand, potential exists of evaluating more candidates (also from outside the nucleus) with GS as the number of candidates evaluated is independent of the number of CRC.

The implementation of a breeding scheme is complicated and requires more details and considerations than could be addressed in the present study. However, the aim of this study was to investigate the potential for small-sized nucleus dairy genetic 
improvement program. Our results show that the greatest potential for such programs lie in genomic selection.

\subsection{Conclusion}

Feasibility exists for creating genetic gain through use of genomic selection in small-sized nucleus dairy cattle breeding programs. An optimal breeding scheme would rely on annual genotyping of 5,000 commercially recorded cows in the genetic evaluation. Compared to similar sized progeny testing schemes, genomic selection schemes would have lower accuracies but these are offset by higher responses per year, which might provide additional incentive for farmers to participate in recording.

\subsection{Acknowledgements}

The authors are grateful to The Netherlands Organization for International Cooperation in Higher Education (NUFFIC) for financing this study. The first author would like to thank Elizabeth M. van Grevenhof for her assistance with getting started with SelAction.

\section{References}

Brisbane, J. R. and J. P. Gibson. 1995. Balancing selection response and rate of inbreeding by including relationships in selection decisions. Theor. Appl. Genet. 91:421-431.

Daetwyler, H. D., B. Villanueva, P. Bijma, and J. A. Woolliams. 2007. Inbreeding in genome-wide selection. J. Anim. Breed. Genet. 124:369-376.

Daetwyler, H. D., B. Villanueva, and J. A. Woolliams. 2008. Accuracy of predicting the genetic risk of disease using a genome-wide approach. PLoS One 3:e3395.

Daetwyler, H. D., R. Pong-Wong, B. Villanueva, and J. A. Woolliams. 2010. The impact of genetic architecture on genome-wide evaluation methods. Genetics 185:1021-1031.

Dekkers, J. C. M. 2007. Prediction of response to marker-assisted and genomic selection using selection index theory. J. Anim. Breed. Genet. 124:331-341.

Ducrocq, V. and R. L. Quaas. 1988. Prediction of genetic response to truncation selection across generations. J. Dairy Sci. 71:2543-2553.

Konig, S., H. Simianer, and A. Willam. 2009. Economic evaluation of genomic breeding programs. J. Dairy Sci. 92:382-391. 
Kosgey, I. S., R. L. Baker, H. M. J. Udo, and J. A. M. van Arendonk. 2006. Successes and failures of small rimunant breeding programmes in the tropics: a review. Small Rumin. Res. 61:13-28.

Lande, R. and R. Thompson. 1990. Efficiency of marker-assisted selection in the improvement of quantitative traits. Genetics 124:743-756.

Lillehammer, M., T. H. E. Meuwissen, and A. K. Sonesson. 2011. A comparison of dairy cattle breeding designs that use genomic selection. J. Dairy Sci. 94:493500.

Marshall, K., C. Quiros-Campos, J. H. J. van der Werf, and B. Kinghorn. 2011a. Marker-based selection within smallholder production systems in developing countries. Livest. Sci. 136:45-54.

Meuwissen, T. H. E. 1991. Expecatation and variance of genetic gain in open and closed nucleus and prgeny testing schemes. Anim. Prod. 53:133-141.

Meuwissen, T. H. E. 1997. Maximizing the response of selection with a predefined rate of inbreeding. J. Animal Sci. 75:934-940.

Meuwissen, T. H. E., B. J. Hayes, and M. E. Goddard. 2001. Prediction of total genetic value using genome-wide dense marker maps. Genetics 157:18191829.

Meuwissen, T. H. E. and A. K. Sonesson. 1998. Mazimizing the response of selection with a predefined rate of inbreeding: overlapping generations. J. Animal Sci. 76:2575-2583.

Moghaddar, N. and J. H. J. van der Werf. 2009. Effect of the accuracy of an estimated QTL effect on response to marker-assisted selection. in Proc. Assoc. Advanc. Anim. Breed. Genet., Barossa Valley, South Australia.

Muasya, T. K., K. J. Peters, and A. K. Kahi. 2013. Breeding structure and genetic variability of the Holstein Friesian dairy cattle population in Kenya. Genet. Res. 52:127-137.

Mulder, H. A., R. F. Veerkamp, B. J. Ducro, J. A. M. van Arendonk, and P. Bijma. 2006. Optimization of dairy cattle breeding programs for different environments with genotype by environment interaction. J. Dairy Sci. 89:1740-1752.

Ojango, J. M. K. and G. E. Pollot. 2002. The relationship between holstein bull breeding values for milk yiels derived in both the UK and Kenya. Livest. Prod. Sci. 74:1-12.

Okeno, T. O., I. S. Kosgey, and A. K. Kahi. 2010. Genetic evaluation of breeding strategies for improvement of dairy cattle in Kenya. Trop. Anim. Health and Prod. 42:1073-1079. 
Pryce, J. E., M. E. Goddard, H. W. Raadsma, and B. J. Hayes. 2010. Deterministic models of breeding scheme designs that incorporate genomic selection. J. Dairy Sci. 93:5455-5466.

Rege, J. E. O., K. Marshall, A. Notenbaert, J. M. K. Ojango, and A. M. Okeyo. 2011. Pro-poor animal improvement and breeding - what can science do? Livest. Sci. 136:15-28.

Rutten, M. J. M., P. Bijma, J. A. Woolliams, and J. A. M. van Arendonk. 2002. SelAction: Software to predict selection response and rate of inbreeding in livestock breeding programs. Heredity 93:456-458.

Schaeffer, L. R. 2006. Strategy for applying genome-wide selection in dairy cattle. J. Anim. Breed. Genet. 123:218-223.

Schrooten, C., H. Bovenhuis, J. A. M. van Arendonk, and P. Bijma. 2005. Genetic progress in multistage dairy cattle breeding schemes using genetic markers. J. Dairy Sci. 88:1569-1581.

Sonesson, A. K. and T. H. E. Meuwissen. 2001. Minimization of rate of inbreeding for small populations with overlapping generations. Genet. Res. 77:285-292.

van Arendonk, J. A. M. 2011. The role of reproductive technologies in breeding schemes for livestock populations in developing countries. Livest. Sci. 136:29-37.

van Grevenhof, E. M., J. A. M. van Arendonk, and P. Bijma. 2012. Response to genomic selection: The Bulmer effect and the potential of genomic selection when the number of phenotypic records is limiting. Genet. Sel. Evol. 44:26.

Vargas, B. and J. A. M. van Arendonk. 2004. Genetic comparison of breeding schemes based on semen importation and local breeding schemes: Framework and application to Costa Rica. J. Dairy Sci. 87:1496-1505.

Wasike, C. B., T. M. Magothe, A. K. Kahi, and K. J. Peters. 2011. Factors that influence the efficiency of beef and dairy cattle recording system in Kenya: $A$ SWOT-AHP analysis. Trop. Anim. Health and Prod. 43:141-152.

Wray, N. R. and M. E. Goddard. 1994. Increasing long-term response to selection. Genet. Sel. Evol. 26:431-451. 


\section{4}

\section{Economic evaluation of progeny testing and genomic selection for small-sized nucleus dairy cattle breeding programs in developing countries}

C.M. Kariuki ${ }^{1,2}$, E.W. Brascamp ${ }^{2}$, H. Komen², A.K. Kahi ${ }^{4}$, J.A.M. van Arendonk ${ }^{2,3}$

${ }^{1}$ Department of Animal Sciences, Chuka University, P.O. Box 109-60400, Chuka, Kenya; ${ }^{2}$ Animal Breeding and Genomics Centre, Wageningen University and Research, $6700 \mathrm{AH}$ Wageningen, The Netherlands; ${ }^{3}$ Hendrix Genetics, 5830 AC, Boxmeer, The Netherlands; ${ }^{4}$ Animal Sciences and Genomics Group, Department of Animal Sciences, Egerton University, P.O. Box 536-20115, Egerton, Kenya Journal of Dairy Science (2017) 100:2258-2268 


\begin{abstract}
In developing countries, minimal and erratic performance and pedigree recording impede implementation of large-sized breeding programs. Small-sized nucleus programs offer an alternative but rely on their economic performance for their viability. We investigated the economic performance of two alternative small-sized dairy nucleus programs i.e., progeny testing (PT) and genomic selection (GS), over a 20 years investment period. The nucleus was made up of 453 male and 360 female animals distributed in 8 non-overlapping age classes. Each year 10 active sires and 100 elite dams were selected. A population of commercial recorded cows (CRC), of sizes 12,592 and 25,184, was used to produce test daughters in PT or to create a reference population in GS. Economic performance was defined as gross margins, calculated as discounted revenues minus discounted costs following a single generation of selection. Revenues were calculated as cumulative discounted expressions (CDE, kg) x 0.32 (Euro per $\mathrm{kg}$ of milk) $\times 100,000$ (size commercial population). Genetic superiorities, deterministically simulated using pseudo-BLUP index and CDE determined using gene flow. Costs were for one generation of selection. Results show that GS schemes had higher cumulated genetic gain in the commercial cow population and higher gross margins compared to PT schemes. Gross margins were between 3.2 and 5.2-fold higher for GS, depending on size of the CRC. The increase in gross margin was mostly due to a decreased generation interval and lower running costs in GS schemes. In PT schemes many bulls are culled before selection. We therefore also compared two schemes where semen was stored instead of keeping live bulls. As expected, semen storage resulted in an increase in gross margins in PT schemes but gross margins remained lower than those of GS schemes. We conclude that implementation of small-sized genomic selection breeding schemes can be economically viable for developing countries.
\end{abstract}

Key words: Economic evaluation, small-sized breeding programs, progeny testing, genomic selection 


\subsection{Introduction}

Dairy production makes an important contribution to poverty reduction and food security in developing countries. Different dairy production systems are present in developing countries reflecting the wide range in production and marketing conditions (Mburu et al., 2007; Mubiru et al., 2007). Genetic improvement offers an opportunity to improve the efficiency of dairy value chains. Genetic improvement can be realized by importation of exotic germplasm or by local breeding programs. Local breeding programs for developing dairy cattle industries provide a means to address unfavorable genotype by environment (GxE) interaction resulting from importation of exotic germplasm (Ojango and Pollot, 2002; Vargas and Arendonk, 2004; Okeno et al., 2010a). However, minimal routine pedigree and performance recording impede the implementation of large-sized breeding programs in many developing countries (Wasike et al., 2011). Small-sized programs may provide the means for improving local genetic resources in countries where infrastructure for large-size pedigree registration and milk recording are lacking (Kariuki et al., 2014). From literature, it is well known that small-sized breeding programs can create significant genetic gains (Okeno et al., 2010b; Gizaw et al., 2014; Kariuki et al., 2014). However, successful implementation of such programs will ultimately be determined by their economic results.

Recent studies have shown genomic selection (GS) in large-size dairy cattle breeding programs to have genetic and monetary advantages over traditional progeny testing (PT) (Schaeffer, 2006; Konig et al., 2009). Genetic advantages mainly relate to the reduction of generation intervals with GS (Goddard and Hayes, 2007). Decrease in generation intervals and elimination of the need for test daughters can result in significant reduction in operational costs for dairy cattle breeding programs (Schaeffer, 2006). Besides reduced costs, GS schemes will benefit monetarily from higher annual genetic gains and earlier expression of genetic superiorities. Early expression of genetic superiorities reduces the effect of discounting on revenues (Brascamp, 1978). However, these studies considered large, well developed breeding programs. Results can, therefore, not be directly translated to developing countries.

Successful implementation of small-sized nucleus dairy cattle schemes for developing countries is faced by two challenges. First, expected annual genetic gains will be lower due to the smaller size of the breeding population and the smaller number of animals participating in pedigree and performance recording. The second challenge relates to net revenues. Developing dairy cattle sectors are 
largely dominated by low input - low output smallholder systems. It is, therefore, challenging for systems to generate the revenues required for an economic sound breeding program. This is particularly important for GS that require extra investment in genotyping of selection candidates and the phenotyping and genotyping of the reference population. The first condition for a breeding program is that it generates sufficient revenues to cover operation costs. Economic appraisal of breeding programs is therefore imperative, particularly for high-risk situations in developing countries (Marshall et al., 2011).

A dairy cattle genetic improvement program will result in (a) improved performance at the production level due to use of superior bulls and, (b) increased demand of superior semen. Revenues from genetic improvement are hence realized at two separate levels i.e. breeding firms selling semen and at the commercial producers where genetic superiority is expressed. Two criteria exist for economic appraisal of breeding programs (Brascamp, 1978). The first criterion focuses on breeding firms and aims at maximization of profits by increasing the semen market share. For such situations, economic appraisal determines the economic impact of changes in market share due to adoption of alternative schemes e.g. (Dekkers and Shook, 1990; Brascamp et al., 1993). The second criterion focuses on producers and aims to increase productivity and/or reduce production costs at the commercial producers' level. Such an approach considers a national breeding program where revenue is generated from sale of end products such as milk or meat (Brascamp et al., 1993; Konig et al., 2009). For small-sized nucleus schemes in developing countries economic appraisal from a national perspective seems more suitable as the aim of such schemes is to address challenges posed by importation of germplasm (Ojango and Pollot, 2002; Vargas and Arendonk, 2004; Okeno et al., 2010a). We, Kariuki et al. (2014), recently illustrated the feasibility of small-sized GS or PT programs. However, the adoption of such schemes is dependent on their economic performance. The aim of the current study was therefore to economically appraise GS and PT selection strategies for small-sized dairy cattle breeding programs in developing countries from a national perspective.

\subsection{Materials and methods}

\section{Breeding program}

Economic evaluation was for a single breeding program under two selection strategies i.e., progeny testing (PT) and genomic selection (GS). With PT, commercial recorded cows (CRC) were used to provide test daughters while with 
GS they were used to create a reference population. In the PT schemes, male candidates were evaluated on the performance of their $1^{\text {st }}$ crop of daughters and parental breeding values and, female candidates were evaluated on their $1^{\text {st }}$ lactation record and parental breeding values. As a result, under PT, female and male candidates were available for selection from the $4^{\text {th }}$ and $6^{\text {th }}$ year of age onwards, respectively. Selection in the GS strategy in both sexes was solely on genomic breeding values and candidates were available for selection from the $1^{\text {st }}$ year of age onwards. The effect of the selection strategy on the distribution of selection candidates in the nucleus is shown in Table 4.1. The breeding objective was to improve milk yield. We used two heritabilities i.e., 0.15 and 0.30 . Phenotypic standard deviation for milk yield for the Holstein-Friesian population in Kenya was set equal to 1,110 kg (Ojango and Pollot, 2002; Kahi and Nitter, 2004).

In the face of limited by participation of producers in pedigree and performance recording we evaluated a small-sized nucleus; ignoring inbreeding. The basic structure of the breeding program is illustrated in Figure 3.1 and comprised of (a) a closed nucleus where all genetic improvement was generated and (b) a commercial population of 100,000 cows benefiting from genetic improvement in the nucleus. The nucleus was made up of 360 female and 485 male selection candidates (including calves) distributed in 8 one year long age-classes (Table 4.1). 100 male and 100 female selection candidates been born annually. Males and females were modeled to attain sexual maturity at the age of 1 year, and were mated immediately after. Consequently, cows dropped their first calf when 2 years old and had their first performance record by the end of their $3^{\text {rd }}$ year. Each year 100 elite dams and 10 active sires were selected. Survival rate was fixed at 0.85 and 0.75 for males and females, respectively.

Size of commercial recorded population. Two sizes of CRC population were considered, where CRC-cows are recorded cows in herds which for most part are not recorded. In determining the required number of CRC we worked from the hypothesis that PT was the most feasible selection strategy for developing countries(Marshall et al., 2011). Due to the low participation of producers in recording, we considered relatively small numbers of test daughters per candidate bull. We modeled two situations (a) where each candidate bull had 15 complete daughter records (DR) and (b) each candidate had 30 DR. Therefore, the size of the CRC for each situation was determined by the conception rate in CRC cows, sex ratio at birth and survival of test daughters, fixed at $0.80,0.50$ and 0.75 , respectively. Candidate bulls were mated to CRC at the start of their $2^{\text {nd }}$ year (accounting for culling only of 85 candidate bulls were evaluated; Table 4.1). In addition, daughter records were available at the start of their $4^{\text {th }}$ year of life i.e., 


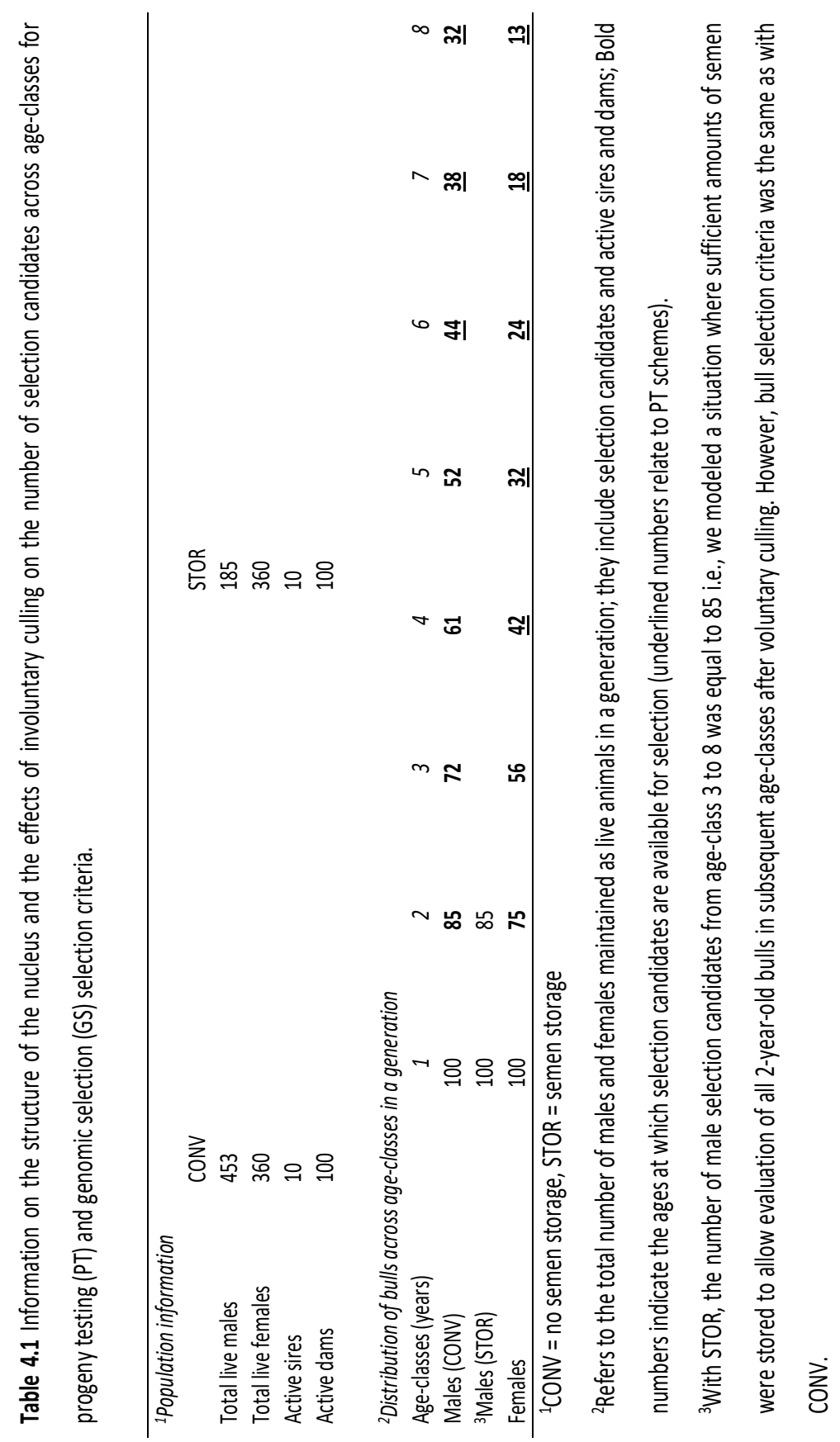


records were only available form daughters surviving to 3 years of age. Therefore, to obtain 15 and 30 DR per candidate bull we required a total of 12,593 and 25,184 $\mathrm{CRC}$, respectively. We denoted the PT scheme with $15 \mathrm{DR}$ per candidate bull as PT15 and that with 30 DR as PT30. Under GS schemes, the same sizes of CRC were considered, but they were used to create a reference population. Equivalent GS schemes were denoted as GS15 and GS30.

Use of bulls. Bull maintenance costs can be reduced by early culling combined with semen storage. In addition, early storage of semen overcomes the decline in the number of selection candidates over time resulting from involuntary culling when using fresh semen (Skjervold and Langholz, 1964). We therefore compared the economic significance of a situation where semen was frozen and stored and bulls culled (STOR) against the conventional system where only fresh semen is used and bulls are maintained as live animals in the bull-station (CONV) for both GS and PT strategies. For STOR, we assumed that the entire amount of semen required for production of test daughters and insemination of commercial cows was collected and stored from 2-year-old bulls, after which they were culled, irrespective of the selection strategy. The amount of semen collected was determined by number of cows to be inseminated and number of straws required per conception (fixed at 1.7). For CONV semen for production of test-daughters was collected from 2-yearold bulls while semen for use on the commercial herd was collected from selected sires in both PT and GS schemes.

Deterministic simulations of genetic superiorities. Genetic superiorities were determined through deterministic simulation based on pseudo-BLUP selection index theory with 8 non-overlapping age-classes as (Hazel, 1943; Ducrocq and Quaas, 1988; Villanueva et al., 1993).

$$
\Delta G=\frac{\sum_{j=1}^{\text {no.ofage-classes }} i_{j} r_{I H, j} \sigma_{A, j} \frac{n_{j}}{n_{\text {total }}}}{L}
$$

where $i_{j}, r_{I H, j}, \sigma_{A, j}$ and $\frac{n_{j}}{n_{\text {total }}}$ were intensity of selection, accuracy, additive genetic standard deviation and the proportion of parents in the $\mathrm{j}^{\text {th }}$ age-class and, $L$ the generation interval. All simulations were implemented in SelAction (Rutten et al., 2002). The program accounts for reduction in variance due to selection (Bulmer, 1971). In addition, it also corrects selection intensities for finite population sizes (Meuwissen, 1991). 
Genetic superiorities for GS breeding programs were simulated by including an "extra" correlated trait with heritability equal to unity in the model as suggested by (Dekkers, 2007). Genetic and phenotypic correlations between the true and "extra" trait were calculated as $r_{g} \hat{g}$ and $h r_{g}$, respectively, where $h$ is the square root of the heritability and $r_{g} \hat{g}$ the accuracy of genomic EBV which was calculated based on (Dekkers, 2007):

$$
r_{g \hat{g}}=\sqrt{\frac{\lambda h^{2}}{\lambda h^{2}+1}}
$$

where $\lambda=n_{P} / n_{G} ; n_{G}$ depends on the size of historic effective base population size $\left(N_{E}\right)$ and the size of the genome $(L)$ in Morgan and was computed as $n_{G}=$ $2 N_{E} L . N_{E}$ was equal to 156 (Muasya et al., 2013) and $L$ was equal to $30 . n_{P}$ was the size of the reference population i.e., 12,593 and 25,184 and, $h^{2}$ was equal to the heritability.

\section{Economic evaluation}

Comparison of the economic performance of the selection strategies was based on gross margins, which we defined as the difference between discounted revenues and discounted costs. Revenues were defined as expressed genetic gains in the commercial cow population following one generation of selection. Revenues were computed as cumulative discounted expressions (CDE) (Brascamp, 1978), expressed in $\mathrm{kg}$ and for a time horizon of 20 years. Revenues and costs were discounted to the year of birth of selection candidates.

Gene flow method was used to model the passage of genetic superiorities from selected parents to offspring in subsequent age by sex classes through reproduction and ageing. An age-class was 1 year period. Gene frequencies per sex in an age-class at a particular year $t$ was expressed by a vector $\boldsymbol{m}_{t} \cdot \boldsymbol{m}_{t}$ was calculated as (Brascamp, 1978)

$$
\mathbf{m}_{t}=\mathbf{R} \mathbf{n}_{t-1}+\mathbf{P m}_{t-1}
$$

where $\boldsymbol{R}$ is a matrix defining gene transmission through reproduction, $\boldsymbol{P}$ is a matrix defining gene transmission through reproduction and ageing, and

$$
\mathbf{n}_{t}=\mathbf{Q} \mathbf{n}_{t-1}
$$

where $\boldsymbol{n}$ is a vector with gene frequencies in the first age class and $\boldsymbol{Q}$ is a matrix defining ageing. CDE were calculated as (Brascamp, 1978),

$$
\mathrm{CDE}=\sum_{t=1}^{20} \mathbf{m}^{\prime}(t) \mathbf{h}\left(\frac{1}{1-r}\right)^{t}
$$


where, $\boldsymbol{m}$ is a vector with gene frequencies in defined age-classes in all tiers by sex subclasses originating from the selected parents, $\boldsymbol{h}$ is an incidence vector describing the relative frequency of expression of the trait, $r$ is the discount rate; which was fixed at 4 and $7 \%$. Vector $\boldsymbol{h}$ was determined based on expected proportions of lactating cows in different age-classes and effects of age on milk production. All calculations were done using the program GFLOW (Brascamp, 1978). Revenues were calculated as:

Revenue $=\mathrm{CDE} \times 0.32 \times 100000$

where 0.32 is the value in euros of $1 \mathrm{~kg}$ of raw milk in Kenya and 100,000 represents the size of the commercial population.

Gene flow pathways. Proportions of selected sires and dams from different age-classes were determined through truncation on estimated breeding values (Ducrocq and Quaas, 1988). Gene flow pathways were categorized as (a) flow of genes within the nucleus and (b) flow of genes from the nucleus to the commercial population. Within the nucleus, we accounted for flow of genes from sires and dams to male and female offspring. Flow of genetic superiority from the nucleus to commercial cows was through use of selected ("elite") nucleus sires to breed commercial cows. For simplicity, the effect of use of young sires on the CRC was ignored. There was no selection in the commercial herd.

$\boldsymbol{R}$ and $\boldsymbol{P}$ matrices for the alternative strategies were determined by the age at which selection was done. With PT schemes sires were evaluated and selected based on daughter performances. Dams in the nucleus were evaluated and available as selection candidate after they completed their $1^{\text {st }}$ lactation. As a result, for PT strategy sires were available for selection from 6 years of age and dams from 4 years. For GS strategy, sires and dams were selected based on genomic information early in life and were available for selection from the $1^{\text {st }}$ year of age.

\section{Calculation of costs}

Data on costs were collected through a group discussion with stakeholders in Kenya. The stakeholders included dairy farmers and representatives from government agencies involved in livestock genetic improvement, such as the Livestock Recording Centre (involved with performance recording and genetic evaluations), Kenya Animal Genetic Resources Centre (maintains the bull station), Kenya Agricultural Research Institute and the Ministry of Agriculture.

We assumed that the nucleus comprised of individually owned commercial farms with consistent recording history where female candidates and elite dams were housed, and a government owned bull station where male candidates and active sires were maintained. Only costs for running the bull station for a single 
generation i.e., 8 years were considered. Total costs were discounted to the $1^{\text {st }}$ year. Maintenance costs for female candidates and selected dams was borne by the producers and were assumed equal in both schemes (except for genotyping costs).

Labor costs. Labor costs were defined as costs for hire of personnel involved in the daily management of bulls in the station. The average labor requirement under the Kenya situation was estimated to be 1 person for every 10 bulls. Distinction was not made for the age of bulls. The average monthly labor cost per individual laborer was €136.

Health costs. Health costs were due to routine parasite and disease control. Costs were for purchase of dip compounds and oral anthelmintics. De-worming and dipping was done four times per year. Dipping costs and deworming costs were fixed at $€ 9.5$ and $€ 3.5$ per animal, respectively.

Feed costs. The main feed sources were hay, concentrates and mineral licks. The cost of a $15 \mathrm{~kg}$ hay bale, $70 \mathrm{~kg}$ sack of concentrates and $2 \mathrm{~kg}$ sack of mineral salts were $€ 2.3, € 22.7$ and $€ 3.6$, respectively. Feeding costs per bull per year was fixed at $€ 509$.

Housing costs. In the present study, we included a fixed value of $€ 3$ per month per animal as the housing costs.

Bull-dam contracting and insemination costs. This included costs for contracting elite dams and insemination. Insemination of CRC with young bulls was accounted as a bull station cost. Cost were $€ 455$ for contracting a bull-dam and $€ 45$ per insemination.

Genotyping costs. Genotyping costs comprised of costs for sample collection, DNA extraction and genotyping. Total genotyping cost per animal was set at $€ 50$. Genotyped animals were bulls and cows in the nucleus and cows in the reference population. Genotyping of bulls and cows was done annually for each new batch of calves born in the nucleus. For the reference population, we assumed the CRC to reflect the initiation of genomic selection. The CRC were therefore modelled to have been genotyped at the same time. However, future generations will benefit from genomic information obtained from this initial group. To account for future gains attributable to genomic information from the initial group we modelled a situation where funds for genotyping were borrowed from a commercial entity and repaid within 10 years. The principal amount borrowed was equal to the actual genotyping costs. An interest rate of $11 \%$, based on the average interest rate for Kenya Central Bank (CBK, 2016) for the period between January and June, 2016, was charged. Total amount repayable after 10 years was calculated as $T=P(1+r t)$ 
where, $T$ is the total repayable amount, $P$ is the borrowed amount $r$ is the interest rate charged and $t$ is equal to 10 years. For simplicity, we assumed a fixed rate interest paid annually. Amount repaid annually was calculated as $T / 10$. CRC genotyping cost was fixed as the repayment amount for the initial year.

Semen collection costs. Cost of semen collection was fixed at $€ 2.5$ per straw. Costs for storage of semen and purchase of storage containers and liquid nitrogen were ignored.

\subsection{Results}

\section{Genetic superiorities for alternative CONV PT and GS schemes}

Table 4.2 presents genetic superiorities per generation, accuracy of selection for sires at the latest age of selection $\left(\mathbf{r}_{\mathbf{H}}\right)$ and average generation intervals $(\overline{\mathbf{L}})$ for alternative PT and GS schemes. Overall, $\mathrm{r}_{\mathrm{IH}}$ was higher for equivalent PT schemes. As expected, $r_{H}$ were higher with higher $h^{2}$ and larger size of CRC population (number of offspring). In addition, PT schemes also had higher genetic superiorities than equivalent GS schemes. For instance, genetic superiorities in the sire pathway were less by 24 and $18 \%$ for GS15 scheme compared to PT15 scheme for $h^{2}$ equal to 0.15 and 0.30 , respectively. Further, the sire pathway in the GS30 scheme had 19 and $12 \%$ lower genetic superiorities than the same pathway in the PT30 scheme for $\mathrm{h}^{2}$ equal to 0.15 and 0.30 , respectively. On the other hand, for PT schemes $\overline{\mathrm{L}}$ were on average 2.36 times longer than for GS schemes. Annual genetic gain $(\boldsymbol{\Delta} \mathbf{G})$ was 35 and $61 \mathrm{~kg}$ for PT15 scheme and 73 and $135 \mathrm{~kg}$ for GS15 scheme for $\mathrm{h}^{2}$ equal to 0.15 and 0.30 , respectively. $\Delta \mathrm{G}$ was 41 and $77 \mathrm{~kg}$ for PT30 scheme and 95 and $168 \mathrm{~kg}$ for GS30 scheme for $h^{2}$ equal to 0.15 and 0.30 , respectively.

\section{Impact of semen storage (STOR) on genetic superiorities}

Semen storage (STOR) had higher impact on genetic superiorities in PT schemes compared to GS schemes (Table 4.2). For PT15 schemes STOR increased genetic superiorities by $15 \%$ irrespective of the heritability while for GS15 schemes the increase was $2 \%$. Higher genetic superiorities in STOR resulted from an increase in number of selection candidates across age-classes (Table 4.1). For CONV the number of selection candidates in later age-classes was lower due to culling. However, the number of selection candidates with STOR was constant across ageclasses and was determined by the number of bulls in age-class 2. Consequently, STOR schemes had higher intensities across male-age classes than CONV. 
Table 4.2 Genetic superiorities per generation for milk yield $(\mathrm{kg})$, accuracy of selection for sires only $\left(r_{H H}\right)$ and average generation intervals $(\overline{\mathrm{L}})$.

\begin{tabular}{|c|c|c|c|c|c|c|c|c|c|}
\hline \multirow[b]{2}{*}{$\Delta \mathrm{G}$} & \multirow[b]{2}{*}{$h^{2}$} & \multicolumn{2}{|l|}{ PT15 } & \multicolumn{2}{|l|}{ РT30 } & \multirow{2}{*}{$\begin{array}{l}\text { GS15 } \\
\text { Sires }\end{array}$} & \multicolumn{3}{|c|}{ GS30 } \\
\hline & & Sires & Dams & Sires & Dams & & Dams & Sires & Dams \\
\hline \multicolumn{10}{|c|}{ CONV } \\
\hline & 0.15 & 174.7 & 31.9 & 211.8 & 30.1 & 132.7 & 49.5 & 173.4 & 64.7 \\
\hline & 0.30 & 301.7 & 57.3 & 348.7 & 56.7 & 245.3 & 91.5 & 305.7 & 114.0 \\
\hline \multicolumn{10}{|c|}{ STOR } \\
\hline & 0.15 & 206.6 & 31.9 & 250.5 & 29.3 & 136.1 & 49.3 & 177.9 & 64.5 \\
\hline & 0.30 & 356.7 & 56.4 & 412.1 & 53.1 & 251.7 & 91.2 & 313.6 & 113.6 \\
\hline \\
\hline \multicolumn{10}{|c|}{ CONV } \\
\hline & 0.15 & 0.42 & & 0.60 & & 0.32 & & 0.43 & \\
\hline & 0.30 & 0.56 & & 0.72 & & 0.43 & & 0.56 & \\
\hline \multicolumn{10}{|c|}{ STOR } \\
\hline & 0.15 & 0.48 & & 0.63 & & 0.32 & & 0.43 & \\
\hline & 0.30 & 0.61 & & 0.76 & & 0.43 & & 0.56 & \\
\hline \multicolumn{2}{|l|}{$\overline{\mathrm{L}}$} & 5.9 & & & & 2.5 & & & \\
\hline \multicolumn{10}{|c|}{$\begin{array}{l}\text { CONV }=\text { no semen storage, STOR }=\text { semen storage, } h^{2}=\text { heritability, PT15 and PT30 are } \\
\text { progeny testing schemes with } 12,592 \text { and } 25,184 \text { cows in the commercial population, } \\
\text { respectively. GS15 and GS30 are equivalent genomic selection schemes with commercial } \\
\text { cows used as the reference population. }\end{array}$} \\
\hline
\end{tabular}

\section{Cumulative genetic gains for alternative PT and GS schemes}

Table 4.3 presents the cumulative genetic gain in the commercial cow population for alternative PT and GS schemes in the $20^{\text {th }}$ year. The cumulative genetic gain was derived as the CDE over the investment period at $0 \%$ discounting. It reflects the genetic level that results from running the same program over time. Overall, GS had higher cumulative genetic gains compared to PT for both CONV and STOR schemes. For CONV schemes with $\mathrm{h}^{2}$ equal to 0.15 , GS15 and GS30 schemes had 115 and 134\% higher cumulated genetic gains than PT15 and PT30 schemes, respectively. Similarly, for $\mathrm{h}^{2}$ equal to 0.30 , cumulated genetic gains were 129 and 150\% higher for GS15 and GS30 contrasted to equivalent PT15 and PT30 schemes, respectively. In addition, differences in cumulated genetic gains were influenced by selection pathways; selection in sires had a larger impact than selection in dams.

Moreover, STOR resulted in increased cumulated genetic gains for both PT and GS schemes. However, the increase was larger for PT schemes than for GS schemes. With $\mathrm{h}^{2}$ equal to 0.15 , increase in cumulated genetic gains for PT15 and PT30 schemes was 33.1 and $40.1 \mathrm{~kg}$ while for GS15 and GS30 was 8.5 and $11.1 \mathrm{~kg}$, respectively. 
Table 4.3 Cumulative genetic superiority (CDE with $0 \%$ discounting) for milk yield $(\mathrm{kg})$ in the commercial cow population after 20 years.

\begin{tabular}{|c|c|c|c|c|c|}
\hline \multirow[b]{2}{*}{ Scheme } & \multirow[b]{2}{*}{$h^{2}$} & \multicolumn{2}{|l|}{ CONV } & \multicolumn{2}{|l|}{ STOR } \\
\hline & & 0.15 & 0.30 & 0.15 & 0.30 \\
\hline PT15 & & 193.0 & 333.9 & 226.1 & 391.1 \\
\hline РТ30 & & 231.2 & 381.8 & 271.3 & 447.9 \\
\hline GS15 & & 414.3 & 765.9 & 422.8 & 781.6 \\
\hline GS30 & & 541.6 & 954.6 & 552.7 & 974.2 \\
\hline
\end{tabular}

CONV $=$ no semen storage, STOR $=$ semen storage, $\mathrm{h}^{2}=$ heritability, PT15 and PT30 are progeny testing schemes with 12,592 and 25,184 cows in the commercial populations, respectvely. GS15 and GS30 are equivalent genomic selection schemes with cows used as the reference populations.

\section{Costs for alternative CONV and STOR PT and GS schemes}

Table 4.4 presents a breakdown of costs for CONV and STOR schemes at $4 \%$ discounting and $\mathrm{h}^{2}$ equal to 0.30 . Costs related to production of test daughters i.e., semen collection and insemination of CRC, were higher than cost for genotyping. Consequently, CONV PT schemes had higher overall costs than equivalent CONV GS schemes. On the other hand, STOR resulted in lower bull maintenance costs but higher semen collection costs. However, the decrease in bull maintenance costs was larger than the increase in semen collection costs resulting in a decrease in the overall costs for STOR compared CONV schemes. As expected, schemes with larger CRC population size had higher costs. Similar observations were made for $h^{2}=0.15$ and for a $7 \%$ discount rate (results not shown).

\section{Gross margins for alternative CONV GS and PT schemes}

Figure 4.2 presents gross margins for alternative CONV PT and GS schemes at 4 and $7 \%$ discounting and $h^{2}$ equal to 0.15 . Generally, gross margins were positive for all schemes and GS schemes had higher gross margins than equivalent PT schemes. With $\mathrm{h}^{2}$ equal to 0.15 and $4 \%$ discount rate, using GS instead of PT for a situation with 12,592 CRC (GS15), increased gross margins 4.2-fold while for a situation with 25,184 CRC (GS30) the increase was 5.2-fold. For $h^{2}$ equal to 0.30 , these ratios were 3.2 (GS15) and 3.7 (GS30). Increase in $\mathrm{h}^{2}$ resulted in an increase in gross margins for all schemes. With $\mathrm{h}^{2}$ equal to 0.30 and $4 \%$ discount rate, gross margins were (in '000 euros) 4,070, 12,984, 4,406 and 16,505 for PT15, GS15, PT30, and GS30, respectively.

\section{Economic impact of semen storage (STOR)}

Figure 4.3 presents the increase in gross margins resulting from semen storage for PT and GS schemes. PT schemes benefitted the most from STOR with between 26 
and $54 \%$ increases in gross margins compared to between 0.3 and $3.4 \%$ increases in GS schemes. However, despite these increases GS schemes had higher overall gross margins.

Table 4.4 Discounted costs ('000 Euros at $4 \%$ discount rate and $h^{2}=0.30$ ) for CONV and STOR PT and GS schemes.

\begin{tabular}{|c|c|c|c|c|c|c|}
\hline \multirow[b]{2}{*}{ Bull use } & \multirow[b]{2}{*}{ Scheme } & \multicolumn{5}{|l|}{ Item } \\
\hline & & $\begin{array}{l}{ }^{1} \text { Bull } \\
\text { maintenance }\end{array}$ & $\begin{array}{l}{ }^{2} \text { Contracting } \\
\text { and } \\
\text { insemination }\end{array}$ & $\begin{array}{l}\text { Semen } \\
\text { collection }\end{array}$ & Genotyping & Total \\
\hline \multirow[t]{4}{*}{ CONV } & PT15 & 376 & 551 & 1,060 & 0 & 1,986 \\
\hline & РТ30 & 376 & 1,042 & 1,111 & 0 & 2,521 \\
\hline & GS15 & 376 & 61 & 1,008 & 152 & 1,528 \\
\hline & GS30 & 376 & 61 & 1,008 & 222 & 1,666 \\
\hline \multirow[t]{4}{*}{ STOR } & PT15 & 110 & 551 & 1,277 & 0 & 1,939 \\
\hline & РT30 & 110 & 1,042 & 1,329 & 0 & 2,481 \\
\hline & GS15 & 110 & 61 & 1,226 & 152 & 1,549 \\
\hline & GS30 & 110 & 61 & 1,226 & 222 & 1,619 \\
\hline
\end{tabular}

PT15 and PT30 are progeny testing schemes with 12,592 and 25,184 cows in the commercial populations. GS15 and GS30 are equivalent genomic schemes with commercial cows populations being used as the reference populations.

${ }^{1}$ Bull maintenance costs includes costs for feeding, housing, health and labor.

${ }^{2}$ Contracting and insemination costs includes costs for contracting bull dams and insemination of bull dams and commercial recorded cows.

\subsection{Discussion}

\section{Genetic Performance}

Small-sized nucleus dairy cattle breeding scheme in developing countries can increase efficiency of production for smallholder producers (Hinks, 1974; Rege et al., 2011). Strategies to maximize the utility of such programs would be advantageous for the entire value chain (Nicholas and Smith, 1983). In the present study, we investigated the economic feasibility of such programs and opportunities to maximize their utility in terms of genetic gains and profitability. Genetic and economic performance for PT and GS under a developing dairy industry situation were investigated. Genetic performance of the alternative strategies was based on CDE (Brascamp, 1978). Our results show that small-sized nucleus breeding programs can create significant genetic gains in the commercial cow population. In addition, GS resulted in higher genetic gains in the commercial population than PT. For instance, the genetic gain in the commercial population was $150 \%$ higher for the GS30 scheme compared to the PT30 scheme. 
Differences in the genetic performance between GS and PT relate to their effects on accuracy and generation intervals (Goddard and Hayes, 2002; Kariuki et al., 2014). PT schemes had much higher accuracies compared to GS schemes. This is in agreement with the literature which indicates that GS schemes require very large number of cows in the reference population to achieve high accuracies (Meuwissen et al., 2001; Goddard and Hayes, 2007). However, for small-sized programs it is difficult to increase the reference population (at least in the short-term) due to minimal recording among producers. On the other hand, GS reduced the generation intervals with more than $50 \%$, which resulted in the genetic gain of the commercial cow population being more than $87 \%$ higher. This study confirms earlier findings that despite lower accuracy, even small-sized GS schemes can outperform PT schemes in annual genetic gains (Schaeffer, 2006; Konig et al., 2009).

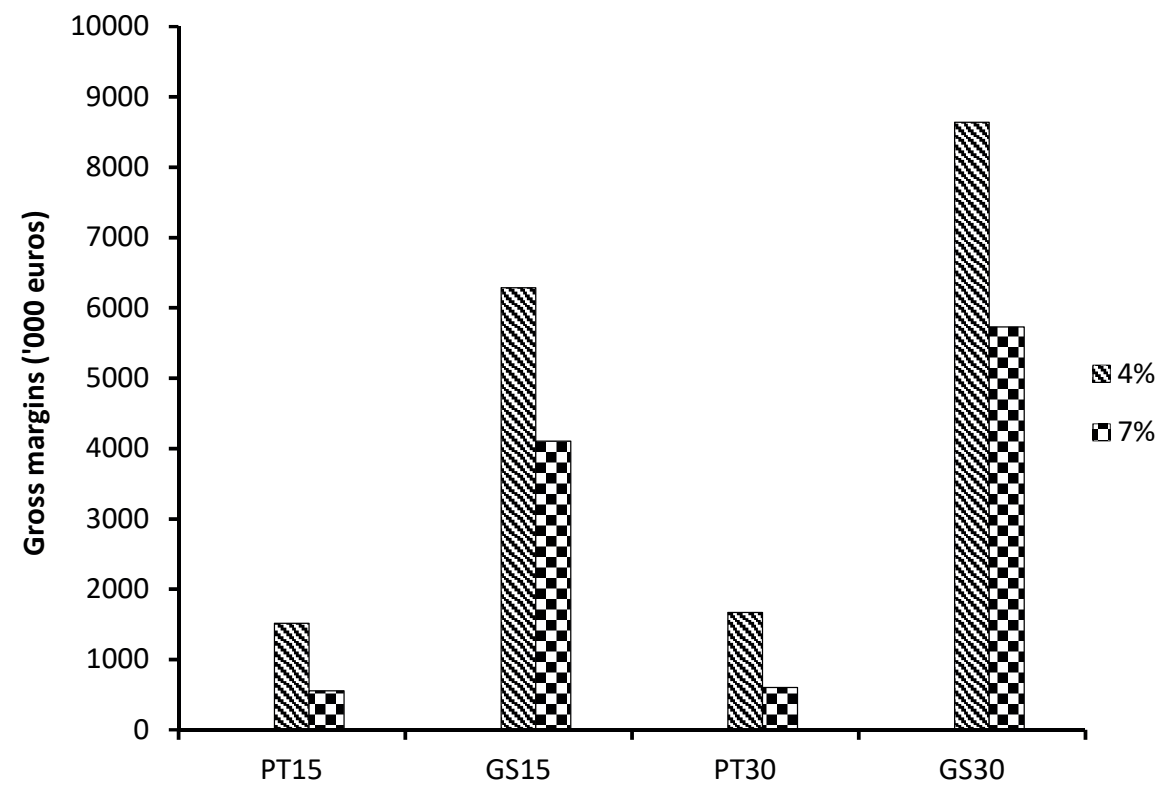

Figure 4.2 Gross margins for alternative CONV PT and GS schemes with $h^{2}=0.15$ and discount rates equal to $4 \%$ and $7 \%$ for $\mathrm{T}=20$ years following one generation of selection. PT15 and PT30 are progeny testing schemes with 12,592 and 25,184 commercial recorded cows. GS15 and GS30 are equivalent GS schemes with commercial recorded cows used as the reference population. 


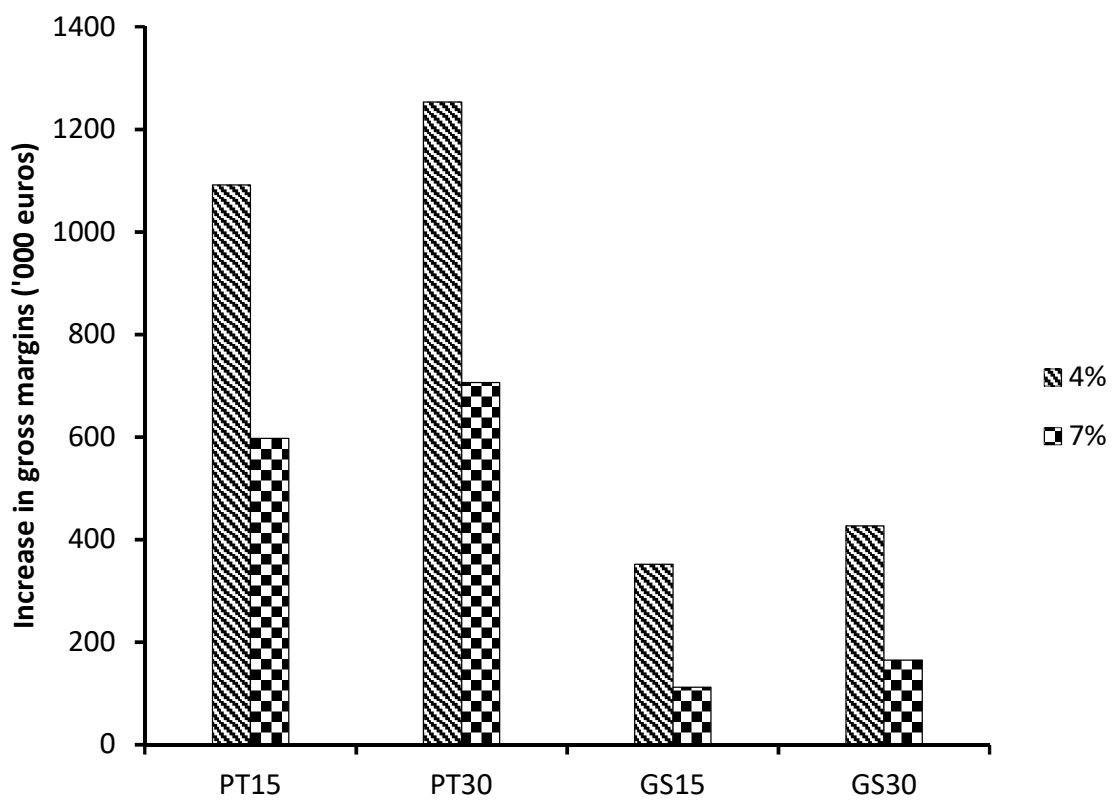

Figure 4.3 Increase in gross margins due to adoption of STOR for PT and GS schemes with $\mathrm{h}^{2}$ $=0.30$ and discount rates $=4$ and $7 \%$. PT15(30) $=$ progeny testing schemes with $12,592(25,184)$ commercial recorded cows, GS15(30) = equivalent genomic selection schemes with commercial recorded cows used as the reference populations. With $h^{2}=0.30$ and $4 \%$ discount rate, gross margins were (in '000 euros) 4,070, 12,984, 4,406 and 16,505 for PT15, GS15, PT30, and GS30, respectively.

\section{Costs}

Costs are an important factor in deciding on any business investment. The common notion is that GS schemes are costlier to run as they require genotyping of many individuals (Marshall et al., 2011). To the contrary, our results show that PT breeding programs are more expensive to run. Costs involved in production of test daughters for evaluation of young bulls were higher than genotyping costs. This is in agreement with the literature (Schaeffer, 2006; Konig et al., 2009). In our study, we fixed the genotyping cost to $€ 50$ per individual, which reflects the current costs for DNA collected and genotyping with a 64k SNP (personal communication, Erwin Koenen, CRV, The Netherlands). In addition, advances in genotyping technologies will lead to further decline in genotyping costs (Guichoux et al., 2011; Shendure and Aiden, 2012). We charged the full costs of milk recording to the breeding program where some of these costs might be charged to the farmer as it also provides information for herd management. The reductions in costs of phenotyping 
are expected to be smaller. GS rather than PT is therefore more likely to get cheaper in the future.

\section{Semen storage}

Semen freezing coupled with voluntary culling of bulls early in life can be an effective cost cutting measure for both GS and PT schemes (Skjervold and Langholz, 1964). This measure reduced bull maintenance costs by $71 \%$ for both strategies. In addition, STOR schemes had slightly higher CDE due to an increase in the numbers of selection candidates and thereby higher selection intensities, due to the elimination of effect of culling. As expected, the increase in CDE was more for PT schemes where selection occurs late in life. Small-sized breeding programs can therefore utilize semen freezing to improve their economic performance, especially for PT schemes.

\section{Economic Performance}

The primary purpose for the present study was to determine whether small-sized nucleus dairy breeding programs in developing countries can generate sufficient gross margins to be self-sustaining. Our results show both breeding programs had substantial positive gross margins irrespective of the selection criteria. However, to maximize the profitability of the program, we further compared the economic impact of PT and GS selection criteria. Our results indicate that GS schemes will out-perform equivalent PT schemes in gross margins. This follows from the advantages accrued from GS selection criterion discussed earlier i.e., shorter generation intervals and lower operational costs. The overall effect of these advantages was higher genetic gain in the commercial population that translated to higher gross margins for GS schemes (Schaeffer, 2006; Konig et al., 2009).

Besides the effect on genetic gains, generation intervals also influence the extent of discounting. Prolonged L in PT schemes does not only delay expressions but also lead to a higher reduction of the monetary value of the expressed superiorities due to the effect of time on the value of money (Brascamp, 1978). Therefore, in addition to higher cumulative genetic gain in the commercial population, breeding programs selecting parents on genomic estimated breeding values stands to benefit from less impact of discounting on the monetary value of revenues.

We fixed the discount rate at two levels i.e., 4 and 7\%. Animal breeding investment appraisals should be considered as public ventures and as such should take a social discount rate (Smith, 1978). Social discount rates range between 2 - 5\% (Bird and Mitchell, 1980). However, it may be argued that breeding programs for developing dairy industries targeted for smallholder production systems face a higher risk of 
not obtaining any returns compared to those for developed industries (Marshall et al., 2011). To account for such risk, we used an upper discount rate of $7 \%$ (Brascamp, 1978). Discount rates used in studies focused on tropical dairy systems in the literature ranged between 3 and 10\% (Mpofu et al., 1993; Kahi et al., 2004; Okeno et al., 2010a). Our result showed that even with higher discount rates, small-sized nucleus dairy cattle schemes in developing countries are profitable.

\section{Practical considerations}

To optimize efficiency of the developing dairy cattle industries in tropical environments it is imperative to match genotypes to the production circumstances (Kosgey et al., 2006; Rege et al., 2011). This can be achieved by implementation of locally run breeding programs selecting for breeding objectives that reflect the production realities of tropical production systems.

For breeding programs in developing countries, it is important to have a holistic view of all factors that may influence their success (Kosgey et al., 2006). For such programs to be successful there is need for careful planning (Marshall et al., 2011). Conventionally, dairy cattle breeding has been based on progeny testing programs. However, the biggest hindrances to the implementation of conventional dairy cattle breeding programs in the tropics are poor infrastructure for PT with unreliable commitment of participating farmers, and inconsistent pedigree and performance recording by producers (Wasike et al., 2011). For developing industries, the few farms participating in recording are usually the best performing farms with best cows. To implement a PT based breeding program would therefore require such farms to be willing to use young untested bulls. Such willingness may be lacking. Moreover, high rates in drop-out and entrance of new producers increases volatility in the breeding program. For PT schemes, this poses a challenge since there is need for specific family relationship to be maintained between the CRC and bull selection candidates.

On the other hand, a GS scheme can be established by using the available recorded cows to form a reference population. Cows with phenotypes can be genotyped and this information can be used to estimate SNP effects, which in turn can be used for evaluation. This presents two major advantages for the success of a GS for developing dairy industries. First, direct relationship between the selection candidate and the recorded cows is eliminated. Accuracies of genomic breeding values are higher when the reference population is closely related to the selection candidates (Bastiaansen et al., 2012), which is the case with our present study. In addition, for the high drop-out rates DNA can be used to reconstruct the pedigree. This minimizes the adverse effects of high volatility of producer participation in 
recording on success of evaluation of bulls, which in turn increases the chances for success of GS schemes. Second, with GS, evaluation of bull selection candidates is not dependent on test daughter performances. Therefore, pedigree and performance information from top farms can be used to evaluate young bulls without requiring these farms to use untested bulls on their cows.

In this study our goal was to investigate the economic performance of PT and GS for small-sized breeding program. Therefore, we intentionally considered a small nucleus size as a bench-mark, the reasoning being that profitability is bound to be higher with larger breeding programs (Schaeffer, 2006; Konig et al., 2009). Our results show that GS is superior to PT for developing dairy cattle industries. However, besides economic performance, the minimal size of a breeding program will further depend on the rate of inbreeding. While for simplicity inbreeding was not considered, it is important to pay attention to the effect of the alternative selection strategies on the rate of inbreeding. Irrespective of the size of a breeding program, GS will have less build-up of inbreeding over time as the strategy can explain some of the variation due to Mendelian sampling hence minimize coselection of siblings (Daetwyler et al., 2007). In addition, accumulation of inbreeding can be minimized by increasing the nucleus size and minimizing coancestry in the parents (Meuwissen, 1997; Sonesson and Meuwissen, 2001). It is relatively easier to increase the nucleus size with GS compared to PT as increase in nucleus size for PT must be accompanied by an increase in size of CRC.

\subsection{Conclusion}

Small-sized nucleus dairy breeding programs in developing countries can generate sufficient revenues to secure their sustainability. In addition, GS schemes will outperform PT schemes on genetic gains and economic performance. Higher performance of GS is explained by the short generation intervals, lower operation costs and less discounting of revenues. Besides, breeding programs could benefit from cost cutting measures such as semen storage and early culling of bulls. Ultimately, implementation of a breeding program and choice of selection strategy will be determined by the ability to generate profit. GS schemes will not only yield higher gross margins compared to PT schemes but are also less demanding in terms of infrastructure and performance recording. We therefore conclude that small sized GS nucleus dairy cattle schemes are economically feasible for developing dairy cattle industries. 


\subsection{Acknowledgements}

The authors are grateful to The Netherlands Organization for International Cooperation in Higher Education (NUFFIC) for financing this study. We also gratefully acknowledge the input from the stakeholders in the workshop.

\section{References}

Bastiaansen, J. W. M., A. Coster, M. P. L. Calus, J. A. M. van Arendonk, and H. Bovenhuis. 2012. Long-term response to genoimc selection: effects of estimation method and reference population structure for different genetic architectures. Genetic. Sel. Evol. 44:3.

Bulmer, M. G. 1971. The effect of selection on genetic variability. The American Naturalist 105:201-211.

Bird, P. J. W. N. and G. Mitchell. 1980. The choice of discount rates in animal breeding investment appraisal. Anim. Breed. Abst. 48:499-505.

Brascamp, E. W. 1978. Methods on economic optimization of animal breeding plans. Report B-134. Zeist, the Netherlands.

Brascamp, E. W., J. A. M. van Arendonk, and A. F. Groen. 1993. Economic appraisal of the utilization of genetic markers in dairy cattle breeding. J. Dairy Sci. 76:1204-1213.

CBK. 2016. Central Bank Rates. Accessed Jul. 26, 2016. https://www.centralbank.go.ke/ondex.php/balance-of-paymentstatistics/interest-rates-2.

Daetwyler, H. D., B. Villanueva, P. Bijma, and J. A. Woolliams. 2007. Inbreeding in genome-wide selection. Journal of Animal Breeding and Genetics 124:369376.

Dekkers, J. C. M. 2007. Prediction of response to marker-assisted and genomic selsction using selection index theory. J. Anim. Breed. Genet. 124:331-341.

Dekkers, J. C. M. and G. E. Shook. 1990. Genetic and economic evaluation of nucleus breeding schemes for commercial artificial insemination firms. J. Dairy Sci. 73:1920-1937.

Ducrocq, V. and R. L. Quaas. 1988. Prediction of genetic response to trunction selection across generations. J. Dairy Sci. 71:2543-2553.

Gizaw, S., T. Getachew, S. Goshme, A. Valle-Zarate, J. A. M. van Arendonk, S. Kemp, A. O. Mwai, and T. Dessie. 2014. Efficiency of selection for body weight in a ooperative village breeding program of Menz sheep under smallholder famring system. Animal 8:1249-1254. 
Goddard, M. E. and B. J. Hayes. 2002. Optimisation of response using molecular data. Page 3 in Proc. 7th World Congr. Appl. Livest. Prod. 19-23 August, 2002, Montepellier, France, 3-10.

Goddard, M. E. and B. J. Hayes. 2007. Genomic selection. J. Anim. Breed. Genet. 124:323-330.

Guichoux, E., L. Lagache, S. Wagner, P. Chaumeil, P. Leger, O. Lepais, C. Lepoittevin, T. Malausa, E. Revardel, F. Salin, and R. J. Petit. 2011. Current trends in microsatellite genotyping. Mol. Ecol. Res. 11:591-611.

Hazel, L. N. 1943. The genetic basis for constructing selection indexes. Genetics 28:476-490.

Hinks, C. J. M. 1974. The planning and organization of progeny testing with particular reference to numerically small populations and breeds of dairy cattle. Z. Tierzücht. ZüchtBiol. 91:169-175.

Kahi, A. K. and G. Nitter. 2004. Developing breeding schemes for pasture based dairy production systems in Kenya I. Derivation of economic values using profit functions. Livest. Prod. Sci. 88:161-177.

Kahi, A. K., G. Nitter, and C. F. Gall. 2004. Developing breeding schemes for pasture based dairy production systems in Kenya II. Evaluation of alternative objectives and schemes using a two-tier open nucleus and young bull system. Livest. Prod. Sci. 88:179-192.

Kariuki, C. M., H. Komen, A. K. Kahi, and J. A. M. van Arendonk. 2014. Optimizing the design of small-sized nucleus breeding programs for dairy cattle with minimal performance recording. J. Dairy Sci. 97:7963-7974.

Konig, S., H. Simianer, and A. Willam. 2009. Economic evaluation of genomic breeding programs. J. Dairy Sci. 92:382-391.

Kosgey, I. S., R. L. Baker, H. M. J. Udo, and J. A. M. van Arendonk. 2006. Successes and failures of small ruminant breeding programmes in the tropics: a review. Small Rumin. Res. 61:13-28.

Marshall, K., C. Quiros-Campos, J. H. J. van der Werf, and B. Kinghorn. 2011. Marker-based selection within smallholder production systems in developing countries. Livest. Sci. 136:45-54.

Mburu, L. M., J. W. Wakhungu, and W. G. Kang'ethe. 2007. Characterization of smallholder dairy production systems for livestock improvement in Kenya highlands. Livest. Res. Rural Dev. 19:Article \#110.

Meuwissen, T. H. E. 1991. Reduction of selection differentials in finite populations with a nested full-half sib family structure. Biometrics 47:195-203.

Meuwissen, T. H. E. 1997. Maximizing the response of selection with a predefined rate of inbreeding. Journal of Animal Science 75:934-940. 
Meuwissen, T. H. E., B. J. Hayes, and M. E. Goddard. 2001. Prediction of total genetic value using genome-wide dense marker maps. Genetics 157:18191829.

Mpofu, N., C. Smith, W. van Vuuren, and E. B. Burnside. 1993. Breeding strategies for genetic improvement of dairy cattle in Zimbabwe 2. Economic evaluation. J. Dairy Sci. 76:1173-1181.

Muasya, T. K., K. J. Peters, and A. K. Kahi. 2013. Breeding structure and genetic variability of the Holstein Friesian dairy cattle population in Kenya. Anim. Genet. Res. 52:127-137.

Mubiru, S. L., J. S. Tenywa, N. Halberg, D. Romney, W. Baltenweck, and S. Staal. 2007. Categorization of dairy production systems: A strategy for targeting meaningful development of the systems in Uganda. Livest. Res. Rural Dev. 19:Article \#10.

Nicholas, F. W. and C. Smith. 1983. Increased rates of genetic change in dairy cattle by embryo transfer and splitting. Anim. Prod. 36:341-353.

Ojango, J. M. K. and G. E. Pollot. 2002. The relationship between Holstein bull breeding values for milk yield derived in both the UK and Kenya. Livest. Prod. Sci. 74:1-12.

Okeno, T. O., I. S. Kosgey, and A. K. Kahi. 2010a. Economic evaluation of breeding strategies for improvement of dairy cattle in Kenya. Trop. Anim. Health Prod. 42:1081-1086.

Okeno, T. O., I. S. Kosgey, and A. K. Kahi. 2010b. Genetic evaluation of breeding strategies for improvement of dairy cattle in Kenya. Trop. Anim. Health and Production 42:1073-1079.

Rege, J. E. O., K. Marshall, A. Notenbaert, J. M. K. Ojango, and A. M. Okeyo. 2011. Pro-poor animal improvement and breeding - what can science do? Livest. Sci. 136:15-28.

Rutten, M. J. M., P. Bijma, J. A. Woolliams, and J. A. M. van Arendonk. 2002. SelAction: Software to predict selection response and rate of inbreeding in livestock breeding programs. Heredity 93:456-458.

Schaeffer, L. R. 2006. Strategy for applying genome-wide selection in dairy cattle. J. Anim. Breed. Genet. 123:218-223.

Shendure, J. and E. L. Aiden. 2012. The expanding scope of DNA sequencing. Nature Biotech. 30:1084-1094.

Skjervold, H. and H. J. Langholz. 1964. Factors affecting the optimum structure of A.I. breeding in dairy cattle. Z. Tierzücht. ZüchtBiol. 80:25-40.

Smith, C. 1978. The effect of inflation and form of investment on the estimated value of genetic improvement in famr livestock. Animal Prod. 26:101-110. 
Sonesson, A. K. and T. H. E. Meuwissen. 2001. Minimization of rate of inbreeding for small populations with overlapping generations. Genetics Research 77:285-292.

Vargas, B. and J. A. M. van Arendonk. 2004. Genetic comparison of breeding schemes based on semen importation and local breeding schemes: Framework and application to Costa Rica. J. Dairy Sci. 87:1496-1505.

Villanueva, B., N. R. Wray, and R. Thompson. 1993. Prediction of asymptotic rates of response from selection on multiple traits using univariate and multivariate best linear unbiased predictors. Anim. Prod. 57:1-13.

Wasike, C. B., T. M. Magothe, A. K. Kahi, and K. J. Peters. 2011. Factors that influence the efficiency of beef and dairy cattle recording system in Kenya: $A$ SWOT-AHP analysis. Trop. Anim. Health Prod. 43:141-152. 


\title{
Incorporating sustainability in breeding objectives for developing small-holder dairy cattle production systems
}

\author{
C.M. Kariuki ${ }^{1,2}$, J.A.M. van Arendonk ${ }^{3}$, A.K. Kahi ${ }^{4}$, H. Komen ${ }^{1}$
}

\begin{abstract}
${ }^{1}$ Animal Breeding and Genomics Centre, Wageningen University and Research, $6700 \mathrm{AH}$ Wageningen, The Netherlands; ${ }^{2}$ Department of Animal Sciences, Chuka University, P.O. Box 109-60400, Chuka, Kenya; ${ }^{3}$ Hendrix Genetic Research, Technology and Services, 5830 AC, Boxmeer, The Netherlands; ${ }^{4}$ Animal Sciences and Genomics Group, Department of Animal Sciences, Egerton University, P.O. Box 536-20115, Egerton, Kenya
\end{abstract}

To be submitted to Livestock Science 


\begin{abstract}
Dairy cattle farming in developing countries is mainly by resource poor smallholder farmers. Intensification of production in developing smallholder production systems is being driven by increasing demand for animal products. Intensification can benefit from genetic improvement. An important step in genetic improvement is definition of a breeding objective. Definition of breeding objectives for resource constrained smallholder systems under harsh environmental conditions should be as holistic as possible to ensure sustainability. Sustainability of production systems can be defined as long-term resilience and productivity. We compare the effect of three criteria to define breeding objectives i.e., economic, desired gains and nonmarket value, on annual genetic and monetary gains in production and functional traits for a small-sized nucleus genomic selection breeding program under a developing country conditions. Production traits considered were milk yield (MY), mature body weight (MBW) and fat yield (FY). Functional traits were calving interval $(\mathrm{Cl})$ and production lifetime (PLT). With the economic objective, traits weights were based on economic values. Weights for desired gains and non-market (NM) values breeding objectives were derived iteratively. Economic breeding objectives resulted in undesirable responses in $\mathrm{Cl}, \mathrm{MBW}$ and $\mathrm{FY}$ traits, but had the highest returns on investment. Non-market value objectives achieved more balanced responses between productivity and functional traits. We conclude that breeding objectives based on desired gains or non-market values can be applied to direct selection towards more robust genotypes but with loss in monetary gain. For small-sized genomic selection schemes, more emphasis is required in functional traits since these traits are more difficult to change due to low heritabilities besides the low accuracy in such schemes due to a small reference population. Such approaches can be used to achieve sustainable intensification for developing smallholder dairy systems.
\end{abstract}

Key words: Breeding objectives, sustainability, non-market weights, developing dairy cattle systems 


\subsection{Introduction}

Livestock production in developing countries is going through a phase of rapid intensification as a result of increased demand for animal products (Delgado et al., 1999). Under these dairy cattle production systems, producers seek to intensify production by use of high-yielding genotypes attained through importation of germplasm (Bebe et al., 2003; Ojango et al., 2012). However, statistics show that productivity in most of the best dairy cattle producing countries in Africa has stagnated for the last 10 years (FAOSTAT, 2006). A key cause of poor performance of high-yield dairy breeds under smallholder production systems is genotype by environment mismatch (Wilson, 2009). Recently, various studies have advocated for locally run breeding programs for developing dairy cattle industries (Rica et al., 2004; Okeno et al., 2010). Such programs can benefit in terms of both genetic and monetary gains by adoption of genomic selection (GS) (Kariuki et al., 2014, 2017b). However, the success of such programs will be determined by their ability to meet the producer's "ideal" genotype. This can be achieved through the definition of appropriate breeding objectives.

Successful breeding of highly efficient genotypes is focused on multiple traits. At the genetic level, breeding for the "best" genotype has various challenges. One such challenge is to minimize undesirable correlated responses, particularly in functional traits (Groen et al., 1997; Rauw et al., 1998). Functional traits can be defined as those traits that contribute to robustness of animals in their production systems and relate to health, reproduction and feed utilization efficiency. Undesired responses in functional traits not only negatively impacts the life time performance of animals but also increase the production costs and reduce product quality due to increased use of antibiotics (Groen et al., 1997). These effects are more pronounced and have a larger impact on developing smallholder production systems (Madalena, 2008).

The smallholder systems are mainly dominated by low input-low low-output smallholder farmers (Rege et al., 2011). Low-input generally implies poor quality and insufficient quantities of feed, low hygiene and poor housing and health services; factors that result in low productivity. Increase in demand for animal products is the main driver for genetic improvement of dairy cattle populations in developing countries (FAO, 2012). An important factor to meet the future demand for animal products is sustainability. Sustainability of a production system can be defined in terms of its long-term performance (Olesen et al., 2000). Challenging production environments coupled with a low availability of capital for investment 
for most developing dairy cattle systems limit their success in intensifying production (Rege et al., 2011). As a consequence, smallholder producers, who form the majority of dairy cattle producers in Africa, are mostly unprofitable (TIAPD, 2016). Such farms can benefit from reduced production costs and production losses through use of more robust cows (Groen et al., 1997).

Rate and direction of genetic change through selection is determined by the breeding objective. Weights for breeding goal traits dictate the direction and rate of genetic change for different traits simultaneously. This makes multi-trait selection an appropriate tool to breed the desired animals (Lawrence et al., 2004). Conventionally, derivation of trait weights is based on calculating marginal economic returns i.e., economic values. Economic values reflect the monetary value for unit change in the phenotype for each trait in the objective, holding change in other traits constant (Hazel, 1943). Therefore, the resulting breeding objectives i.e., economic breeding objectives, maximize economic returns from selection.

Functional traits often have tangible economic benefits and intangible benefits, hence it is challenging to derive economic values for them (Olesen et al., 1999). Computation of economic values for functional traits is further limited when formal marketing channels are lacking or are poorly developed, as is the case in developing countries (Sölkner et al., 2008). For situations where formal markets are poorly developed, derived economic values may be unrealistic as market prices do not indicate the "true" value of some marketable traits. As an example, in Kenya (as is the case in many African countries) milk solids do not have a market value (Kahi and Nitter, 2004). Furthermore, even with highly developed marketing systems economic breeding objectives tend to over-emphasis selection on production traits at the expense of functional traits (Groen et al., 1997; Olesen et al., 2000).

An alternative is to make use of non-economic breeding objectives and aim at placing special emphasis on functional traits. Four approaches have been proposed in the literature for derivation of non-economic objectives. First, is the use of restricted selection indices to constrain the response for one or more traits to zero (Kempthorne and Nordskog, 1959; Cunningham et al., 1970; Lin, 2005). Second, is the use of desired gains indices to obtain pre-specified non-zero responses (Yamada et al., 1975; Brascamp, 1984). Third, is the use of iterations to maximize response in the most preferred traits in the breeding objective (Gizaw et al., 2010). Lastly, is the use of non-market (NM) values (Nielsen et al., 2005; Olesen et al., 2000). NM values are based on the premise that some traits have value that cannot be expressed in market prices. Various methodologies for estimating NM values are 
reviewed by (Olesen et al., 1999). One such method is to define the NM value as the monetary value that producers would be willing to forgo in marketable traits in order to improve non-marketable traits (Nielsen et al., 2005).

The aim of this paper was to define a sustainable breeding objective for developing smallholder dairy cattle production systems by placing higher emphasis on functional traits. Specific objective was to determine the effectiveness of noneconomic breeding objectives in incorporating sustainability in developing dairy cattle breeding programs implementing genomic selection. We used the Kenya Holstein-Friesian dairy sector as a working example.

\subsection{Materials and Methods}

\section{Structure of the breeding program and simulation of genetic superiorities}

Genetic gains were simulated for a small-sized closed nucleus program implementing genomic selection. The nucleus was made up of 360 female and 485 male selection candidates (including calves) distributed in 8 one year-long ageclasses. Each year 100 male and 100 female selection candidates were born. The annual survival rates were 0.85 for males and 0.75 for females. 100 elite dams and 10 active sires were selected annually. Candidates were modeled to attain sexual maturity and were available for selection from the $1^{\text {st }}$ year of age onwards. To account for minimal recording in developing dairy cattle industries we fixed the reference population at 15,113 commercial recorded cows.

Annual genetic gains were determined through deterministic simulation based on a pseudo-BLUP selection index with 8 non-overlapping age-classes defined as (Hazel, 1943; Ducrocq and Quaas, 1988):.

$$
\Delta G=\frac{\sum_{j=1}^{\text {no.of age-classes }} i_{j} r_{I H, j} \sigma_{A, j} \frac{n_{j}}{n_{\text {total }}}}{L}
$$

where $\Delta G, i_{j}, r_{I H, j}, \sigma_{A, j}$ and $\frac{n_{j}}{n_{\text {total }}}$ were annual genetic gain, intensity of selection, accuracy, additive genetic standard deviation and the proportion of parents in the $\mathrm{j}^{\text {th }}$ age-class and, $L$ the generation interval. All simulations were implemented in SelAction (Rutten et al., 2002). The program accounts for reduction in variance due to selection and corrects selection intensities for finite population sizes (Bulmer, 1971; Meuwissen, 1991). 
Genomic selection based genetic superiorities were simulated following the procedure of (Dekkers, 2007). For each trait, genetic superiority was simulated by including an "extra" correlated trait with heritability equal to unity in the model. Genetic and phenotypic correlations between the true and "extra" trait were calculated as $r_{g \hat{g}}$ and $h r_{g \hat{g}}$, respectively, where $h$ is the square root of the heritability and $r_{g \hat{g}}$ the accuracy of genomic EBV, which was calculated as (Dekkers, 2007; Daetwyler et al., 2008):

$r_{g \hat{g}}=\sqrt{\frac{\lambda h^{2}}{\lambda h^{2}+1}}$

where $\lambda=n_{P} / n_{G} ; n_{G}$ depends on the size of historic effective base population size $\left(N_{E}\right)$ and the size of the genome $(L)$ in Morgan and was computed as $n_{G}=$ $2 N_{E} L . N_{E}$ was equal to 156 (Muasya et al., 2013) and $L$ was equal to $30 . n_{P}$ was the size of the reference population and $h^{2}$ was equal to the heritability. Genetic and phenotypic correlations between the genomic EBVs were calculated as (Dekkers, 2007):

$r_{\hat{g}_{1} \hat{g}_{2}}=r_{\hat{g}_{1}} r_{\hat{g}_{2}} \rho_{g_{12}}$

where $r_{\hat{g}_{i}}$ is the accuracy of the genomic EBV for the $\mathrm{i}^{\text {th }}$ trait, and $\rho_{g_{12}}$ is the genetic correlation between trait 1 and 2 . Table 5.1 presents the phenotypic heritabilities and genetic and phenotypic correlations between traits used in the study.

Table 5.1 Genetic (above diagonal) and phenotypic (below diagonal) correlations and heritabilities (diagonal) for traits in the breeding goal

\begin{tabular}{llllll}
\hline & ${ }^{1} \mathrm{MY}$ & $\mathrm{PLT}$ & $\mathrm{Cl}$ & $\mathrm{MBW}$ & $\mathrm{FY}$ \\
\hline $\mathrm{MY}$ & $\mathbf{0 . 2 9 ^ { \mathrm { a } }}$ & $-0.34^{\mathrm{e}}$ & $-0.64^{\mathrm{a}}$ & $0.39^{\mathrm{d}}$ & $0.68^{\mathrm{d}}$ \\
$\mathrm{PLT}$ & $-0.06^{\mathrm{e}}$ & $\mathbf{0 . 1 8 ^ { \mathrm { b } }}$ & $-0.71^{\mathrm{b}}$ & 0.00 & $-0.17^{\mathrm{f}}$ \\
$\mathrm{Cl}$ & $0.37^{\mathrm{a}}$ & $-0.01^{\mathrm{b}}$ & $\mathbf{0 . 0 5 ^ { \mathrm { a } }}$ & 0.00 & 0.00 \\
$\mathrm{MBW}$ & $0.20^{\mathrm{d}}$ & 0.00 & 0.00 & $\mathbf{0 . 1 0 ^ { \mathrm { c } }}$ & $0.34^{\mathrm{d}}$ \\
$\mathrm{FY}$ & $0.82^{\mathrm{d}}$ & $-0.01^{\mathrm{f}}$ & 0.00 & $0.18^{\mathrm{d}}$ & $\mathbf{0 . 2 6 ^ { \mathrm { d } }}$ \\
$\sigma_{P}^{2}$ & $1,232,113^{\mathrm{a}}$ & $324^{\mathrm{b}}$ & $5,676^{\mathrm{a}}$ & $2,608^{\mathrm{c}}$ & $469^{\mathrm{d}}$ \\
\hline
\end{tabular}

Sources:

a (Ojango and Pollott, 2001)

b (Abou-Bakr, 2009)

c (Demeke et al., 2004)

d (Ahlborn and Dempfle, 1992)

e (Pritchard- et al., 2013)

${ }^{f}$ (Chauhan and Hayes, 1993)

${ }^{1} \mathrm{MY}=$ milk yields $(\mathrm{kg}), \mathrm{PLT}=$ production lifetime (months), $\mathrm{Cl}=$ calving interval, $\mathrm{MBW}=$ mature body weight, $\mathrm{FY}=$ fat yield $(\mathrm{kg}), \sigma_{P}^{2}=$ phenotypic variance 


\section{Breeding objectives and derivation of trait weights}

To further account for limited recording within developing dairy systems, we defined a breeding objective comprising of 5 most important traits only. The five most important traits in Kenyan dairy farming are milk yield (MY, kg), production lifetime (PLT, months), calving interval ( $\mathbf{C l}$, days), mature body weight (MBW, kg) and fat yield (FY, kg) (Kariuki et al., 2017a). Weights for these traits were derived based on either market values (economic values), desired gains and on NM values.

An economic breeding objective was used as the base for comparison. Economic values in the present study were adopted from (Kahi and Nitter, 2004), who used a profit function for a fixed herd size with payment for milk based on volume. The objective of the present study was to determine the effect of inclusion of desired gains weights and NM values in the breeding objective. Adopted economic values in Kenya shillings (KES) were 18.93 for MY, 0.07 for PLT, 2.65 for $\mathrm{Cl}, 7.95$ for MBW and -2.76 for $F Y$.

NM and desired gains weights were derived using iterations. NM weights were derived using a 2-step approach. In the $1^{\text {st }}$ step weights were derived for two trait objectives. To achieve this, first the maximal response for MY was determined by simulating responses for a breeding objective consisting of MY only. NM weights for the other four traits were subsequently determined iteratively by simulating two-trait breeding objectives, MY being the first trait and $\mathrm{PLT}, \mathrm{Cl}, \mathrm{MBW}$ and $\mathrm{FY}$ the second trait. The NM value for the $2^{\text {nd }}$ trait was derived as the weight that resulted in 5\% decline in annual genetic gain for MY(in trait units) (Olesen et al., 1999; Nielsen et al., 2005). Equation 5.4 presents a prototype for the two-trait breeding objectives used to derive desired gains and NM weights

$\mathrm{H}_{2}=\mathrm{v}_{\mathrm{MY}} \mathrm{MY}+(\mathrm{v}+\mathrm{w})_{\mathrm{T} 2}$ Trait2

where $v$ and $w$ were the economic values and the derived NM values, respectively. In the second, NM weights derived in the $1^{\text {st }}$ step were combined into a single five trait objective.

Desired gains weights were defined as the weights for which the simulated annual genetic gains approximated the desired gains. Desired gains weights were derived by iterating a five-trait objective. Consensus desired gains were taken from (Kariuki et al., 2017a), and were $110.28 \mathrm{~kg}$ for MY, 1.19 months for PLT, -0.89 days for $\mathrm{Cl}$, 0.91 for MBW and $2.33 \mathrm{~kg}$ for FY. Equation 2 presents a prototype of the five-trait breeding objectives

$$
\mathrm{H}_{5}=\mathrm{k}_{\mathrm{MY}} \mathrm{MY}+\mathrm{k}_{\mathrm{PLT}} \mathrm{PLT}+\mathrm{k}_{\mathrm{CI}} \mathrm{CI}+\mathrm{k}_{\mathrm{MBW}} \mathrm{MBW}+\mathrm{k}_{\mathrm{FY}} \mathrm{FY}
$$


where $\mathrm{k}$ is the combination of the market and $\mathrm{NM}$ value i.e. $\mathrm{k}=(\mathrm{v}+\mathrm{w})_{\mathrm{i}}$ or desired gains weight for the $\mathrm{i}^{\text {th }}$ trait. The selection index for both the two and five-traits objectives comprised of all five traits in the breeding objective.

\section{Comparison of genetic gains for five-trait breeding objectives}

Performance of the three alternative breeding objectives was evaluated by comparing annual genetic and monetary gains for individual traits. The breeding objectives were abbreviated as (1) $\mathbf{H}_{\mathbf{E}}=$ the economic objective, (2) $\mathbf{H}_{\mathbf{D G}}=$ the desired gains objective and, (3) $\mathbf{H}_{\mathrm{NM}}=\mathrm{NM}$ value objective. Monetary annual genetic gains were calculated by multiplying the genetic gains in trait units with economic values adopted from Kahi and Nitter (2004) for each trait.

\subsection{Results}

\section{Desired gains and non-market weights and genetic gains from two-trait objectives}

Table 5.2 presents desired gains and NM weights and the corresponding genetic gains. Genetic gains were for a breeding objective fitting MY as the only trait in a five-trait breeding objective, two-trait NM breeding objectives and for five-trait economic and desired gains breeding objectives. As expected, weights were strongly influenced by genetic standard deviations and genetic correlations. Annual genetic gains were similar for breeding objectives with MY only and the economic breeding objectives. Genetic gains for MY and FY were the most affected by genetic correlations as the two traits are highly positively correlated. As a consequence, achieving desired annual genetic gains for these two traits was difficult. We settled for $96 \mathrm{~kg}$ gain for $\mathrm{MY}$ and $0.39 \mathrm{~kg}$ gain for $\mathrm{FY}$ as a compromise compared to the desired $110 \mathrm{~kg}$ gain for $\mathrm{MY}$ and $2.33 \mathrm{~kg}$ gain for $\mathrm{FY}$.

Achieving desired genetic gains and NM genetic gains for $\mathrm{PLT}, \mathrm{Cl}, \mathrm{MBW}$ and $\mathrm{FY}$ resulted in decline in annual gains for MY. MY annual genetic gains for the desired gains and NM objectives were $96 \mathrm{~kg}$ and $131 \mathrm{~kg}$, respectively, compared to $142 \mathrm{~kg}$ achieved gains in the economic objectives. However, economic objective resulted in undesirable genetic gains in all other traits except MY and PLT. These undesirable responses were eliminated by use of non-economic objectives. As an example, comparing the economic and $\mathrm{NM}$ objectives, $\mathrm{Cl}$ improved from +0.21 to 0.4 months, MBW from $-0.17 \mathrm{~kg}$ to $+0.57 \mathrm{~kg}$ and FY from $-0.51 \mathrm{~kg}$ to $+0.26 \mathrm{~kg}$. 


\section{Genetic gains and monetary gains for five- trait breeding objectives}

Annual genetic gains in trait and monetary units for the three alternative five-trait breeding objectives are presented in Table 5.3. $\mathrm{H}_{\mathrm{E}}$ resulted in unfavourable changes in $\mathrm{Cl}, \mathrm{MBW}$ and in FY. Selection on this objective will increase calving intervals and lower milk fat content. $\mathrm{H}_{\mathrm{NM}}$ and $\mathrm{H}_{\mathrm{DG}}$ resulted in genetic gains in all five traits that were in the desired direction, though with loss in milk yield. Genetic gains were for $\mathrm{PLT}, \mathrm{Cl}, \mathrm{MBW}$ and $\mathrm{FY}$ were higher for $\mathrm{H}_{\mathrm{DG}}$ compared to those for $\mathrm{H}_{\mathrm{NM}}$. However, $\mathrm{H}_{\mathrm{NM}}$ had higher genetic gain for $\mathrm{MY}$ which resulted in a higher monetary gain for $\mathrm{H}_{\mathrm{NM}}$ compared to $\mathrm{H}_{\mathrm{DG}}$. $\mathrm{H}_{\mathrm{E}}$ had the highest and $\mathrm{H}_{\mathrm{DG}}$ had the lowest monetary genetic gains. Decline in total monetary gains were $32 \%$ for $\mathrm{H}_{\mathrm{DG}}$ and $17 \%$ for $\mathrm{H}_{\mathrm{NM}}$.

Table 5.2 Comparison of annual genetic gains for two and five-traits breeding objectives based on economic desired gains and NM weights

\begin{tabular}{|c|c|c|c|c|}
\hline \multirow[t]{2}{*}{${ }^{1}$ Objective } & \multicolumn{2}{|c|}{ Weighting } & \multicolumn{2}{|c|}{${ }^{2}$ Annual genetic gains } \\
\hline & $\mathrm{MY}$ & Trait 2 & MY & Trait 2 \\
\hline vMY & 18.93 & & 142.43 & \\
\hline vMY + vPLT & 18.93 & 0.07 & 142.43 & 0.14 \\
\hline$w_{d g} M Y+w_{d g} P L T$ & 1 & 46 & 96.13 & 0.61 \\
\hline$v M Y+\left(v+w_{n m}\right) P L T$ & 18.93 & 599.80 & 131.27 & 0.59 \\
\hline $\mathrm{vMY}+\mathrm{vCI}$ & 18.93 & 2.65 & 142.43 & 0.21 \\
\hline$w_{d g} M Y+w_{d g} C I$ & 1 & -45 & 96.13 & -0.67 \\
\hline $\mathrm{vMY}+\left(\mathrm{v}+\mathrm{w}_{\mathrm{nm}}\right) \mathrm{CI}$ & 18.93 & -444.70 & 131.38 & -0.40 \\
\hline vMY + vMBW & 18.93 & 7.95 & 142.43 & -0.17 \\
\hline$w_{d g} M Y+w_{d g} M B W$ & 1 & 27 & 96.13 & 0.72 \\
\hline$v M Y+\left(v+w_{n m}\right) M B W$ & 18.93 & 340.80 & 131.17 & 0.57 \\
\hline $\mathrm{vMY}+\mathrm{vFY}$ & 18.93 & -2.76 & 142.43 & -0.51 \\
\hline$w_{d g} M Y+w_{d g} F Y$ & 1 & 23 & 96.13 & 0.39 \\
\hline $\mathrm{vMY}+\left(\mathrm{v}+\mathrm{w}_{\mathrm{nm}}\right) \mathrm{FY}$ & 18.93 & 334.24 & 133.68 & 0.26 \\
\hline
\end{tabular}




\subsection{Discussion}

\section{Sustainable intensification of developing dairy cattle production systems}

From an animal breeding perspective sustainability of livestock production systems can be viewed as "the systems' ability to satisfy the future demand for food" (Olesen et al., 2000). For developing tropical dairy production systems, concerns are on the effects of breeding for intensive production on future productivity, product quality and safety, animal health and welfare and, farms' long-term resilience (Thompson and Nardone, 1999). Breeding for increased productivity requires commensurate increase in capital investment to cater for the increase in production costs. Such capital investments may include purchase of extra land, high quality concentrate feeds and machinery and, better trained personnel. However, these extra investments will only be sustainable if the extra revenues generated can pay them back i.e., extra investment must be proportionate to extra revenues. Consequently, care should be exercised when making decisions on genetic improvement, particularly for developing industries.

Decisions on the genetic improvement are pegged on the definition of breeding objectives. The various methods used to define breeding objectives are profit equations, bio-economic modelling and desired gains (Goddard, 1998; Olesen et al., 1999). Each of these criteria have disadvantages (Goddard, 1998; Nielsen et al., 2014). Profit functions are simplistic and therefore lack power to model the complexity of production systems. Bio-economic models can model complex production systems but face challenges in quantifying changes of inter-dependent traits independently. On the other hand, non-economic objectives based on desired gains are not able to economically optimize the production system. It is therefore important to make an appropriate choice of the criteria to use.

In this study, we have investigated the impact of three criteria for defining breeding objectives on annual genetic gains in individual traits and the total monetary genetic gains. Our results show that the emphasis placed on traits when using an economic objective was directly related to their contribution to the monetary gain as dictated by the market prices. As a consequence, MY had the highest economic value while $\mathrm{FY}$, which had no market value, had a negative economic value. The tendency of economic objectives to be highly influenced by market prices coupled with genetic correlations between traits resulted in unfavorable responses in $\mathrm{Cl}$, $\mathrm{MBW}$ and $\mathrm{FY}$. For instance, annual genetic gains in $\mathrm{Cl}$ were positive reflecting a 
decline in fertility and negative gains in FY reflecting a decline in milk quality. This is likely to be detrimental to the long-term performance of farms.

Table 5.3 Annual genetic gains for five-trait breeding objectives

\begin{tabular}{|c|c|c|c|c|c|c|}
\hline \multirow{2}{*}{${ }^{1}$ Breeding objectives } & \multicolumn{5}{|c|}{${ }^{2}$ Annual genetic gains in trait units } & \\
\hline & MY & PLT & $\mathrm{Cl}$ & MBW & FY & \\
\hline $\mathrm{H}_{\mathrm{E}}$ & 142.42 & 0.14 & 0.21 & -0.15 & -0.51 & \\
\hline $\mathrm{H}_{\mathrm{DG}}$ & 96.13 & 0.61 & -0.67 & 0.72 & 0.39 & \\
\hline $\mathrm{H}_{\mathrm{NM}}$ & 118.47 & 0.54 & -0.30 & 0.50 & 0.24 & \\
\hline \multirow[t]{2}{*}{ Desired gains } & 110.28 & 1.19 & -0.89 & 0.91 & 2.33 & \\
\hline & \multicolumn{4}{|c|}{${ }^{3}$ Monetary annual genetic gains } & & Total \\
\hline $\mathrm{H}_{\mathrm{E}}$ & $2,696.14$ & 0.01 & 0.56 & -1.23 & 1.42 & $2,696.90$ \\
\hline $\mathrm{H}_{\mathrm{DG}}$ & $1,826.20$ & 0.04 & 1.78 & 5.72 & -1.08 & $1,826.20$ \\
\hline $\mathrm{H}_{\mathrm{NM}}$ & $2,242.63$ & 0.03 & 0.79 & 3.97 & -0.66 & $2,245.18$ \\
\hline \multicolumn{7}{|c|}{$\begin{array}{l}{ }^{1} \mathrm{H}_{\mathrm{E}}=\mathrm{vMY}+\mathrm{vPLT}+\mathrm{vCI}+\mathrm{vMBW}+\mathrm{vFY} ; \mathrm{H}_{\mathrm{DG}}=\left(\mathrm{v}+\mathrm{w}_{\mathrm{dg}}\right) \mathrm{MY}+\left(\mathrm{v}+\mathrm{w}_{\mathrm{dg}}\right) \mathrm{PLT}+(\mathrm{v}+ \\
\left.\mathrm{w}_{\mathrm{dg}}\right) \mathrm{CI}+\left(\mathrm{v}+\mathrm{w}_{\mathrm{dg}}\right) \mathrm{MBW}+\left(\mathrm{v}+\mathrm{w}_{\mathrm{dg}}\right) \mathrm{FY} ; \mathrm{H}_{\mathrm{NM}}=\mathrm{vMY}+\left(\mathrm{v}+\mathrm{w}_{\mathrm{nm}}\right) \mathrm{PLT}+\left(\mathrm{v}+\mathrm{w}_{\mathrm{nm}}\right) \mathrm{CI}+ \\
\left(\mathrm{v}+\mathrm{w}_{\mathrm{nm}}\right) \mathrm{MBW}+\left(\mathrm{v}+\mathrm{w}_{\mathrm{nm}}\right) \mathrm{FY} \\
{ }^{2} \mathrm{MY}=\text { milk yield }(\mathrm{kg}), \mathrm{PLT}=\text { production lifetime (months), } \mathrm{Cl}=\text { calving interval (days), MBW }= \\
\text { mature bodyweight }(\mathrm{kg}), \mathrm{FY}=\text { fat yield }(\mathrm{kg}), \mathrm{v}=\text { economic value, } \mathrm{w}_{\mathrm{dg}}=\text { weights for desired } \\
\text { gains, } \mathrm{w}_{\mathrm{nm}}=\text { non-market value, } \mathrm{H}_{\mathrm{E}}=\text { economic breeding objective, } \mathrm{H}_{\mathrm{DG}}=\text { desired gains } \\
\text { breeding objective, } \mathrm{H}_{\mathrm{NM}}=\text { non-market value breeding objective } \\
{ }^{3} \text { Currency = Kenya shillings (KES) }\end{array}$} \\
\hline
\end{tabular}

On the other hand, using non-market objectives achieved balanced genetic gains in both production and functional traits as reflected by positive genetic gains for FY and negative gains for $\mathrm{Cl}$ for both desired gains and $\mathrm{NM}$ objectives. However, achievement of desired gains came at a cost, reflected in reduced monetary gains. A frequently used argument against non-economic breeding objectives is that they will result in economically sub-optimal systems (Gibson and Kennedy, 1990). Nielsen et al. (2014) argues that the suitability of a method for defining breeding objectives should be based on its practicability and thus will vary between different production systems. For developing industries, it is debatable whether economic values derived from imperfect market prices can ensure long-term economic optimum. Suitability of non-economic objectives for developing dairy industries can be assessed from the projected long-term economic and animal health and welfare impacts.

Our results show that an overall economic view of the production system can result in erroneous decisions. Comparing only the economic performance of economic and non-economic breeding objectives will not reveal the undesired changes in key traits such as $\mathrm{FY}$ and $\mathrm{Cl}$. It is imperative to consider the genetic changes at individual trait level. Undesired genetic changes will negatively affect the long-term 
economic performance of farms. For such cases, farmers' preferences can be used to correct anomalies that result from imperfect market forces (Nielsen et al., 2014). Our results show that use of desired gains objective resulted in appropriate gains in non-marketable traits. However, in our results, both desired gains and NM objectives resulted in a decline in MY annual genetic gains culminating in decline in monetary gains from KES. 2,696 to KES. 1,826 and KES. 2,245, respectively. Whether this cost justifies the adoption of non-market objectives will depend on the producers' views. However, ultimately producer preferences can be used to reflect the importance of traits for situations where markets are poorly developed. Besides breeding objectives' weights, realized responses from selection programs will be further determined by the accuracy of selection. Genetic gains in individual traits will be determined by the amount of information in the selection index and their heritability. Paucity in implementation of dairy cattle breeding programs in most developing countries has been due to lack of well-established recording systems. Kariuki et al. (2014) have proposed the implementation of small-sized genomic selection schemes. Such schemes have lower accuracies of selection due to the small size of the reference population. Nevertheless, they will generally show faster progress due to the selection of bulls at an earlier age (Kariuki et al., 2014). However, most functional traits are not only more difficult to record but are recorded late in life and tend to have lower heritabilities. Therefore, most functional traits are more difficult to improve by genomic selection compared to production traits. It is therefore, imperative to consider these traits by placing more emphasis on them, such as through use of non-economic objectives, particularly for developing dairy industries.

The intensification process for developing dairy cattle systems should aim at increasing productivity while at the same time minimizing production costs and risks. Minimization of production costs and reduction of risks can be achieved by breeding robust animals by paying more attention to physical strength, disease resilience and fertility. In addition, it will reduce production losses due to inefficiency in production resulting from inadequate feed quality and quantity, decreased product quality (e.g. anti-biotic residues in milk) and high replacement costs due to high mortality rates. This may aid in ensuring the long-term profitability and sustainable intensification \{Wilson, 2009 \#165\}. A fixed approach that focuses solely on the monetary outcome may prove to be more expensive in the long-term. Non-economic objectives based on producer preferences can be utilized in such situations. 


\subsection{Conclusion}

Defining breeding goals is a crucial step for developing dairy cattle industries. We conclude that breeding objectives based on desired gains or non-market values can be applied to direct selection towards more robust genotypes but with loss in monetary gain. For small-sized genomic selection schemes, more emphasis is required in functional traits since these traits are more difficult to change due to low heritabilities besides the low accuracy in such schemes due to a small reference population. Such approaches can be used to achieve sustainable intensification for developing small-holder dairy systems.

\subsection{Acknowledgement}

The authors are grateful to The Netherlands Organization for International Cooperation in Higher Education (NUFFIC), The Hague, The Netherlands for financing this study.

\section{References}

Abou-Bakr, S. 2009. Genetic and phenotypic parameters of some lifetime and longevity traits in Holstein cows of commercial farm in Egypt. Egypt. J. Anim. Prod. 46:11-18.

Ahlborn, G., and L. Dempfle. 1992. Genetic parameters for milk production and body size in New Zealand Holstein-Friesian and Jersey. Livest. Prod. Sci. 31:205-219.

Bebe, B.O., H.M.J. Udo, G.J. Rowlands, and W. Thorpe. 2003. Smallholder dairy systems in the Kenya highlands: breed preferences and breeding practices. Livest. Prod. Sci. 82:117-127.

Brascamp, E.W. 1984. Selection indices with constraints. Anim. Breed. Abstr. 52:645-654.

Chauhan, V.P.S., and J.F. Hayes. 1993. Relationships of first lactation yields with lifetime performance traits in Holstein cows. J. Anim. Breed. Genet. 110:264267.

Cunningham, E.P., R.A. Moen, T. Gjedrem, and E.P. Cunningham1. 1970. Restriction of selection indexes. Biometrics. 26:67-74.

Daetwyler, H.D., B. Villanueva, and J.A. Woolliams. 2008. Accuracy of Predicting the Genetic Risk of Disease Using a Genome-Wide Approach. PLoS One. 3:e3395.

Dekkers, J.C.M. 2007. Prediction of response to marker-assisted and genomic selection using selection index theory. J. Anim. Breed. Genet. 124:331-341. 
Delgado, C., M. Rosegrant, H. Steinfeld, S. Ehui, and C. Courbois. 1999. Livestock to 2020 Revolution - The Next Food Revolution. Washington D.C., USA.

Demeke, S., F.W.C. Neser, S.J. Schoeman, B.S. Demeke, F.W.C. Neser, and S.J. Schoeman. 2004. Estimates of genetic parameters for Boran, Friesian, and crosses of Friesian and Jersey with the Boran cattle in the tropical highlands of Ethiopia : milk production traits and cow weight. J. Anim. Breed. Genet. 121:163-175.

FAO. 2012. Economic growth, hunger and malnutrition. In The State of food insecurity. FAO, Rome, Italy. 15-27.

Gibson, J.P., and B.W. Kennedy. 1990. The use of constrained selection indexes in breeding for economic merit. Theor Appl Genet. 80:801-805.

Gizaw, S., H. Komen, J.A.M. Van Arendonk, and J.A.M. van Arendonk. 2010. Participatory definition of breeding objectives and selection indexes for sheep breeding in traditional systems. Livest. Sci. 128:67-74.

Goddard, M.E. 1998. Consensus and Debate in the Definition of Breeding Objectives. J. Dairy Sci. 81:6-18.

Groen, A.F., T. Steine, J.-J. Colleau', J. Pedersen, J. Pribyl, N. Reinsch, J.-J. Colleau, J. Pedersen, J. Pribyl, N. Reinsch, J.-J. Colleau', J. Pedersen, J. Pribyl, and N. Reinsch. 1997. Economic values in dairy cattle breeding, with special reference to functional traits. Report of an EAAP-working group. Livest. Prod. Sci. 49:1-21.

Hazel, L.N. 1943. The genetic basis for constructing selection indexes. Genetics. 28:476-490.

Kahi, A.K., and G. Nitter. 2004. Developing breeding schemes for pasture based dairy production systems in Kenya I. Derivation of economic values using profit functions. Livest. Prod. Sci. 88:161-177.

Kariuki, C.M., J.A.M. van Arendonk, A.K. Kahi, and H. Komen. 2017a. Multiple criteria decision making process to derive consensus desired gains for a dairy cattle breeding objective for diverse production systems. J. Dairy Sci. Submitted.

Kariuki, C.M., H. Komen, A.K. Kahi, and J.A.M. van Arendonk. 2014. Optimizing the design of small-sized nucleus breeding programs for dairy cattle with minimal performance recording. J. Dairy Sci. 97:7963-7974.

Kariuki, C.M., E.W. Brascamp, H. Komen, A.K. Kahi, and J.A.M. van Arendonk. 2017b. Economic evaluation of progeny-testing and genomic selection schemes for small-sized nucleus dairy cattle breeding programs. J. Dairy Sci. 100:2258-2268.

Kempthorne, O., and A.W. Nordskog. 1959. Restricted selection indices. Biometrics. 
15:10-19.

Lawrence, A.B., J. Conington, and G. Simm. 2004. Breeding and animal welfare: practical and theoretical advantages of multi-trait selection. Anim. Welf. 13:191-196.

Lin, C.Y. 2005. A simultaneous procedure for deriving selection indexes with multiple restrictions. J. Anim. Sci. 83:531-536.

Madalena, F.E. 2008. How sustainable are the breeding programs of the global main stream dairy breeds? - The Latin-American situation. Livest. Res. Rural Dev. 20(2).

Muasya, T.K., K.J. Peters, and A.K. Kahi. 2013. Breeding structure and genetic variability of the Holstein Friesian dairy cattle population in Kenya. Anim. Genet. Resour. 52:127-137.

Nielsen, H.M., P.R. Amer, and T.J. Byrne. 2014. Approaches to formulating practical breeding objectives for animal production systems. Acta Agric. Scand. Sect. A - Anim. Sci. 64:2-12.

Nielsen, H.M., L.G. Christensen, and A.F. Groen. 2005. Derivation of sustainable breeding goals for dairy cattle using selection index theory. J. Dairy Sci. 88:1882-1890.

Ojango, J.M.K., K. Kariuki, N.A. And Baltenweck, A. Njehu, and I. Baltenweck. 2012. Breeding management strategies adopted for dairy production under low input smallholder farming systems of East Africa. Research Report, ILRI pp.

Ojango, J.M.K., and G.E. Pollott. 2001. Genetics of milk yield and fertility traits in Holstein-Friesian cattle on large-scale Kenyan farms. J. Anim. Sci.

Okeno, T.O., I.S. Kosgey, and A.K. Kahi. 2010. Economic evaluation of breeding strategies for improvement of dairy cattle in Kenya. Trop. Anim. Health Prod. 42:1081-1086.

Olesen, I., B. Gjerde, and A.F. Groen. 1999. Methodology for deriving non-market trait values in animal breeding goals for sustainable production systems. In Proceedings of International Workshop EU Concerted Action on Genetic Improvement of Functional Traits in cattle (GIFT). Interbull Bull, Wageningen, The Netherlands. 13-21.

Olesen, I., A.F. Groen, and B. Gjerde. 2000. Definition of animal breeding goals for sustainable production systems. J. Anim. Sci. 78:570-582.

Pritchard-, T., M. Coffey, R. Mrode, E. Wall, T. Pritchard, M. Coffey, R. Mrode, and E. Wall. 2013. Genetic parameters for production, health, fertility and longevity traits in dairy cows. Anim. Anim. Consort. 7:34-46.

Rauw, W.M., E. Kanis, E.N. Noordhuizen-Stassen, and F.J. Grommers. 1998. Undesirable side effects of selection for high production efficiency in farm 
animals: a review. Livest. Prod. Sci. 56:15-33.

Rege, J.E.O., K. Marshall, A. Notenbaert, J.M.K. Ojango, and A.M. Okeyo. 2011. Propoor animal improvement and breeding - What can science do. Livest. Sci. 136:15-28.

Rica, C., B. Vargas, J.A.M. Van Arendonk, and J.A.M. Van Arendonk. 2004. Genetic comparison of breeding schemes based on semen importation and local breeding schemes: Framework and application to Costa Rica. J. Dairy Sci. 87:1496-1505.

Sölkner, J., H. Grausgruber, A.M. Okeyo, P. Ruckenbauer, and M. Wurzinger. 2008. Breeding objectives and the relative importance of traits in plant and animal breeding: A comparative review. Euphytica. 161:273-282.

Thompson, P.B., and A. Nardone. 1999. Sustainable livestock production: methodological and ethical challenges. Livest. Prod. Sci. 61:111-119.

Tegemeo Institute of Agricultural Policy and Development (TIAPD). 2016. Report of a study on assessing the cost of production strutures in dairy stsems in Kenya. Nairobi, Kenya.

Wilson, R.T. 2009. Fit for purpose - the right animal in the right place. Trop. Anim. Health Prod. 41:1081-1090.

Yamada, Y., K. Yokouchi, and A. Nishida. 1975. Selection index when genetic gains of individual traits are of primary concern. Japan J. Genet. 50:33-41. 


\section{6}

General discussion 


\subsection{Introduction}

Intensification of production in smallholder dairy farms is driven by the rapidly growing human population (Delgado et al., 1999). In these systems, intensification has been based on crossbreeding Bos indicus and Bos taurus breeds (Bebe et al., 2003; Ojango et al., 2012). Bos indicus genotypes confer adaptability while Bos taurus breeds confer productivity genes to the crossbred commercial cows. Crossbreeding systems require maintenance and selection within the different lines/breeds used to produce the crossbreds. In addition, the genetic contribution of the different pure breeds to the crossbred should be clearly defined. Lack of genetic improvement of Bos indicus genotype and a clear crossbreeding plan has resulted in heterogeneous crosses. In addition, continuous use of exotic bulls has gradually resulted in the genetic shift of the commercial cow population towards pure Bos taurus breeds, which has a negative impact on the intensification process due to presence of unfavorable genotype by environment interaction (Ojango and Pollott, 2002; Okeno et al., 2010; McClintock et al., 2007). It is therefore imperative to design sustainable intensification at the farm level to ensure stable dairy productivity in the future.

The aim of this thesis was to design a breeding program for developing smallholder dairy cattle production systems. Dairy sectors in developing countries are characterized by diverse production systems and minimal participation of commercial producers in pedigree and performance recording. In my thesis, I accounted for heterogeneity among producers in defining consensus desired gains for breeding objective traits. Individual preferences were determined using the Analytical Hierarchical Process. Group and consensus preferences were determined using the Weighted Goal Programming procedure and expressed as desired gains (Chapter 2). Second, to account for the limited pedigree and performance records, I studied the opportunities for implementation of a small-sized nucleus breeding program. The breeding program was optimized by comparing genetic and economic performances of progeny testing (PT) and genomic selection (GS) methods. GS out-performed PT in both genetic and monetary gains (Chapter 3 and 4). Last, to account for challenging production environments and poorly developed pricing systems, desired genetic gains weights in functional and production traits without a market value were obtained by use of non-market value weights (Chapter 5).

Two key issues have to be addressed to attain sustainable intensification. First, is to determine the appropriate genotype for the local production realities. Second, is to 
develop this genotype through breeding. In this thesis, approaches to achieve these goals are presented. In this Chapter, the technical factors that determine the successful implementation of suggestions presented in this thesis are discussed. In particular, I discuss (a) establishing a reference population (b) controlling inbreeding (c) choice of local genotype to improve and (d) sustainability of the breeding program.

\subsection{Establishing the reference population}

GS utilize linkage disequilibrium (LD) between genome-wide dense markers and QTL to estimate breeding values (GEBV) for selection candidates (Meuwissen et al., 2001). A reference population, i.e. a proportion of the population with genotypic and phenotypic information, is required for estimation of marker effects. Therefore, the successful implementation of a GS scheme requires the establishment a sufficiently large reference population to allow accurate genetic evaluation. From the classical breeder equation, response to selection is determined by genetic standard deviation, intensity and accuracy of selection (Falconer and Mackay, 1996). Accuracy is of importance to producers as it is a measure of the reliability of the selection decision. Accuracy of GEBV is determined by the extent of LD between markers and QTL (which is largely determined by the effective population), heritability and the number of loci affecting the trait, and the size of the reference population (Daetwyler et al., 2008; Goddard, 2009). Limited pedigree and performance recording in Kenya presents a challenge to the implementation of GS. In Chapter 2 of this thesis, it has been shown that as a starting point, a GS scheme can be initiated based on a small reference population of between 2,500 and 5,000 commercial recorded cows. Kosgey et al. (2011) reported that annually between 1,200 and 2,600 pedigree and performance records were delivered to the Dairy Recording Service of Kenya (DRSK) between $1994-2008$. This indicates the availability of the minimal number of pedigree and performance recorded commercial cows that can be genotyped to give a head-start to a GS scheme. However, accuracy will be low. Strategies to increase the reference population are necessary.

The first strategy to increase the size of the reference population is to use records from across generations. For situations with few recorded animals, the size of the reference population can be increased over time by accumulating genotypic and phenotypic records across generations (Boichard et al., 2015). Muir (2007) showed that information up to three previous generations positively impacts accuracy. Benefits of across generation phenotypic and genotypic information are four-fold. 
First, is the increase in accuracy due to a larger reference population (Meuwissen et al., 2001; Bastiaansen et al., 2012). Second, is the effect of historical information on long-term response to selection. Long-term response to selection is influenced by the effects of the rate of inbreeding, $\Delta F$, and selection on genetic variance. Rate of inbreeding expressed per year will be higher in GS schemes compared to PT schemes due to shorter generation intervals. Higher $\Delta F$ will increase homozygosity at both QTL and marker loci hence reducing genetic variance and long-term response. On the other hand, selection on markers will result in markers getting fixed before QTL for loci with incomplete LD, thus creating new unfavorable LD (Muir, 2007; Hayes et al., 2009). Unfavorable LD reduces the long-term response in GS schemes. Third, is the effect of family relationships in the reference population on LD explained (Habier et al., 2007; Bastiaansen et al., 2012). Closely related animals explain the same part of the variation, reducing the amount of variation captured. Use of across generations information minimizes family relationships in the reference population which increases the reliability of GEBV (Habier et al., 2007; Muir, 2007; Pszczola et al., 2012). Last, is estimation of variance of low frequency QTL. Capturing variance of low frequency QTL alleles positively impacts the long-term response of GS (Jannink, 2010). Re-estimation of prediction equations by continuous updating the reference population can aid in capturing low-frequency QTL alleles (Muir, 2007; Hayes et al., 2009).

The impact of information from previous generations for the Kenyan situation can be approximated. Following Muir, (2007) use can be made of information up to 3 past generations to improve accuracy in the present generation. I assume presently there are available an average of 1,900 cows with phenotypic information that can be genotyped to establish a reference population (Kosgey et al., 2011). Since cattle have overlapping generations, each year the information submitted for evaluation will include repeated records for dams in their $2^{\text {nd }}$ and higher lactations and new records for $1^{\text {st }}$ lactation dams. For simplicity, the effect of repeated records is ignored. Increase in the size of the reference population due to accumulation of information across generations is determined by the number of new $1^{\text {st }}$ lactation information collected annually. The number of $1^{\text {st }}$ lactation information is determined by the replacement rate which we fixed at $25 \%$ (Chapter 5 ). The number of accumulated unique records at year $t=N+[R R *(t-1)]$ where, $N$ is the size of the reference population in year 0 and $R R$ is the replacement rate. The number of accumulated unique records in 10 years $=3,325$; a 1.75-fold increase in the size of the reference population compared to progeny testing where the number of test daughters produced is constant. This above calculation 
demonstrates the gain that can be achieved by use of across generations information. Disadvantage of this strategy is that it takes time for information to accumulate unless historic material is available which enables going back in time.

Besides use of across-generation information, the second strategy is to recruit more producers to participate in recording and minimize drop-out rate. Despite the long presence of farmer based pedigree and performance recording organizations in Kenya, participation of producers has been low with high dropout rate (Kosgey et al., 2011). Key factors contributing to producers' reluctance to record are lack of tangible benefits and unmet expectations (Wasike et al., 2011). Therefore, producers are more likely to actively participate in pedigree and performance recording if they derive a direct benefit from it. Such benefits in developed countries include access to markets (by satisfying government marketing policies such as product traceability), access to subsidies, benefits from membership to a breed society and use of records as a management tool. For developing dairy industries such incentives are generally lacking. It is therefore, important to device incentives for the producers for their recording efforts.

Currently, pedigree and performance recording in Kenya is externally driven, i.e. not an initiative of the farmers but of governmental and non-governmental organizations. As a consequence, ownership of the recording schemes by farmers is lacking, resulting in their collapse shortly after the withdrawal of funding agencies (Kahi et al., 2005). However, opportunities exist for re-structuring pedigree and performance recording in such a way that farmers do not only derive direct and sustainable benefits but also have a sense of ownership of the recording system. As an example, there is a revived motivation among farmers to record due to the prospects for higher prices for cows and heifers with own or dam performance history (personal observation). Such approaches, that demonstrate the value of recording for the farmer, can improve the participation of farmers in recording. Therefore, there is need to develop tools to translate recording into farm support tools. To be successful, such tools must translate records to improved management and incomes and be easy to adopt.

\subsection{Controlling inbreeding}

Inbreeding results in inbreeding depression and increased risk of expression of monogenic recessive disorders. Inbreeding in a population is measured by the coefficient of inbreeding, $F$, which is determined by the population size and the selection strategy. $F$ expresses the average degree of relationship within a population while $\Delta F$ determines the accumulation of inbreeding in the 
population. $\Delta F$ per year is expected to be large in small-sized GS breeding scheme due to small nucleus size and shorter generation intervals \{Muir, 2007 \#201\}. GS schemes derive their main advantage from selection at younger ages resulting in shorter generation intervals (Chapter 3 and 4). Strategies are needed to avoid increased inbreeding. Here I discuss strategies to minimize inbreeding in smallsized genomic schemes.

Contribution of co-selection of sibs to inbreeding is lower in GS schemes as molecular selection is superior to phenotypic selection at estimating Mendelian sampling variance (Daetwyler et al., 2007). With Mendelian sampling variances explained, sibs will have different breeding values, which lowers their chances of co-selection. On the other hand, the optimal contribution selection criteria can be used to constrain the rate of inbreeding (Meuwissen and Sonesson, 1998). Optimal contribution selection uses the numerator relationship matrix, $\mathbf{A}$, to estimate the co-ancestries among candidates. Selection and mating in subsequently based on co-ancestries such that inbreeding is constrained at a pre-determined level. Estimation of co-ancestry based on $\mathbf{A}$ assumes independent loci i.e., not linked to any other loci under selection (Meuwissen and Sonesson, 1998; Woolliams et al., 2015). This assumption is not valid with GS as selection is based on LD. Therefore, application of optimal contribution selection in GS schemes requires estimation of co-ancestry be based on genomic relationships rather than pedigree relationships (Sonesson et al., 2012). Optimal contribution selection can be implemented in GS schemes by replacing $\mathbf{A}$ with a genomic relationship matrix, G (Woolliams et al., 2015).

Application of optimal contribution selection might be limited by the small number of selection candidates as the scheme may not have much room to choose from to meet the required number of parents. Therefore, the ultimate goal should be to increase the nucleus size. The small nucleus size in the Kenya dairy sector results from minimal participation of producers in pedigree and performance recording (Chapter 3). Schaeffer (2006) first illustrated the possibility to re-organize the structure of dairy cattle breeding programs when selection is on GEBV so that $\mathrm{Al}$ companies own nucleuses and have more control on quality of data collected. For the Kenya situation, it is possible to re-organize the breeding structure so as to increase the nucleus size. This is because with GS the size of the nucleus is independent of the number of commercial recorded cows (CRC), unlike with PT. As an illustration, to test an extra bull in PT with 15 daughter records and assuming 0.5 sex ratio, 0.60 conception rate and 0.75 survival rate, requires an extra 200 CRC. However, with GS extra bulls can be tested without the need for extra information from CRC This presents two possibilities for increasing the nucleus size: (a) 
recruiting bull dams from the CRC population (as these dams are not used for production of test daughters) and (b) recruit bull dams from non-recorded dams (as GS allows the evaluation of animals without own performance records), as illustrated in Figure 6.1. However, recruitment of CRC will be more effective when the genetic gap between the nucleus and the CRC is small, i.e. at the start of the program. This also is the time when the reference population is expected to be at its smallest size since interventions such as those discussed earlier will over time increase the size of the reference population. Recruited CRC should be of a competitive level. Therefore, GS allows an easy and practical approach to overcome inbreeding for small-sized programs in the short-term.

PT

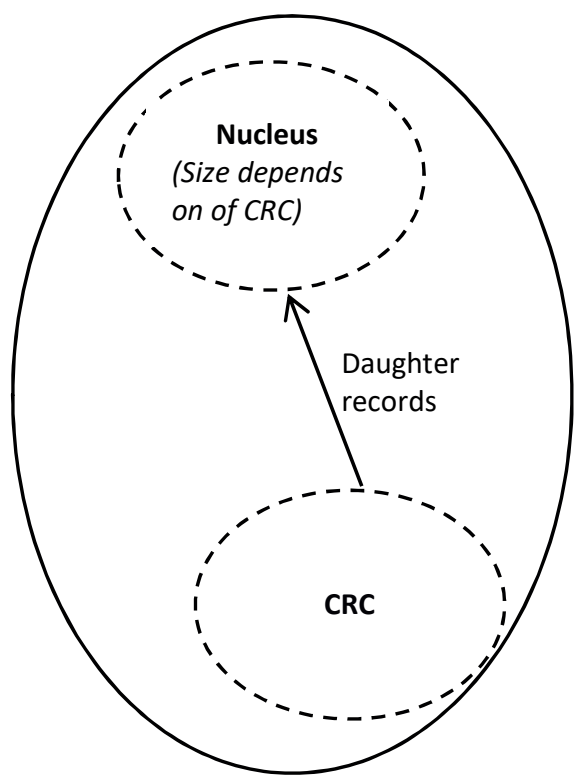

GS

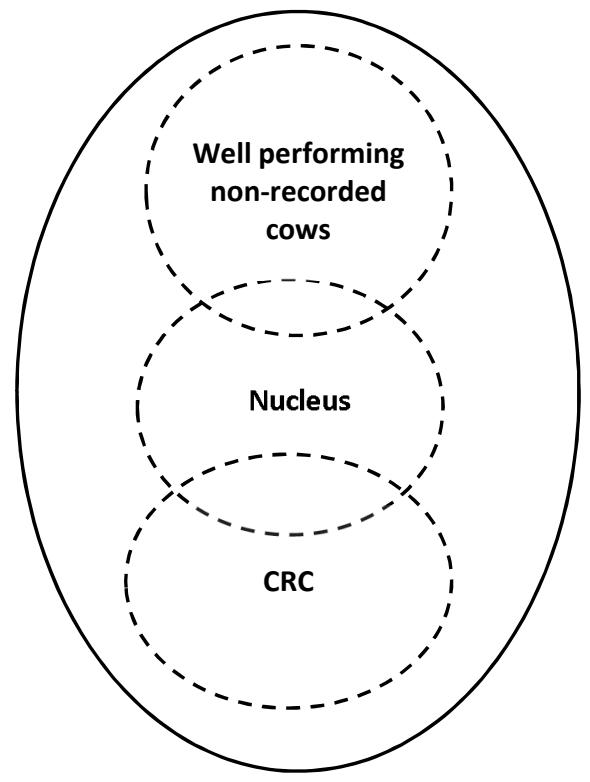

Figure 6.1. Illustration of change of breeding structure for GS schemes to increase the size of nucleus. The nucleus in GS can be expanded by contracting bull dams from commercial recording herds (CRC) and non-recording herds with well performing cows since it is possible to evaluated animals with no own performance record.

\subsection{What genotype to improve}

Sustainable intensification under tropical production environment requires a balance between productivity and adaptability in commercial cows (Chapter 5 ). 
Historically, intensification in Kenya has relied on crossbreeding Bos taurus and Bos indicus breeds (Bebe et al., 2003). Crossbred cows have been shown to have better production and economic performance compared to pure-bred Bos taurus cows under smallholder production system (Vaccaro, 1990; McClintock et al., 2007). Superior performance of crossbred cows is attributed to better adaptability and heterosis (Cunningham and Syrstad, 1987). However, lack of genetic improvement efforts for Bos indicus has resulted in the increased use of Bos taurus bulls on commercial farms. The overall outcome has been sub-optimal performance due to genotype by environment mismatch (McClintock et al., 2007). To ensure sustainable intensification it is imperative to maintain adaptability in the commercial cows. Adaptability can be maintained in two ways: (a) by maintaining a Zebu line as a source of adaptability genes for the production of crossbred commercial cows or (b) inter se mating and selection to develop of adapted synthetic breed. To make a decision on the approach to adopt it is necessary to consider the advantages and disadvantages of each approach.

\subsubsection{Crossbreeding approach}

Crossbreeding aims at exploiting heterosis and combining desired qualities from two or more breeds/ lines (Falconer and Mackay, 1996). To achieve the most from crossbreeding, selection need to be done within the various breeds contributing to the crossbreeds. This implies that the current crossbreeding in Kenya can benefit from selection within the Bos indicus breeds combined with use of Bos taurus semen for the production of crossbred cows. Currently, maintenance and selection within the Bos indicus genotypes has been neglected. The comparatively low performance of Bos indicus cows is the main reason for this neglect. However, medium to low heritability estimates have been reported for reproductive traits in Bos indicus breeds (Nonato and Lobo, 1998). This indicates potential for selective breeding in these breeds.

Figure 6.2 illustrates the design of a crossbreeding scheme utilizing GS for a Bos indicus breed. The objective of the scheme is to produce F1 and/ or F2 elite bulls which are used to improve the commercial herds. In Chapter 3 of this thesis the design of a small sized GS nucleus breeding scheme is illustrated. Here the nucleus is expanded to incorporate crossbreeding. This is achieved by further selecting "crossbreeding" dams (CD) that are mated with Bos taurus bulls to produce F1 and F2 elite bulls. For production of F1 elite sires, CD are selected from the local nucleus and mated with elite Bos taurus bulls. Young bulls produced can be further evaluated and the required number selected or used directly as elite sires. To 
produce F2 elite sires that are 25\% Bos indicus and 75\% Bos taurus, CD are first used to produce F1 bull dams, which are then mated with elite Bos taurus bulls. The F1 crossbred cows can be subjected to further evaluation and selection or used directly to produce F2 elite sires by crossing again with Bos taurus bulls. The crossbred elite sires (F1 or F2) are used to produce semen that is dispensed to commercial herds through the existing Al structures.

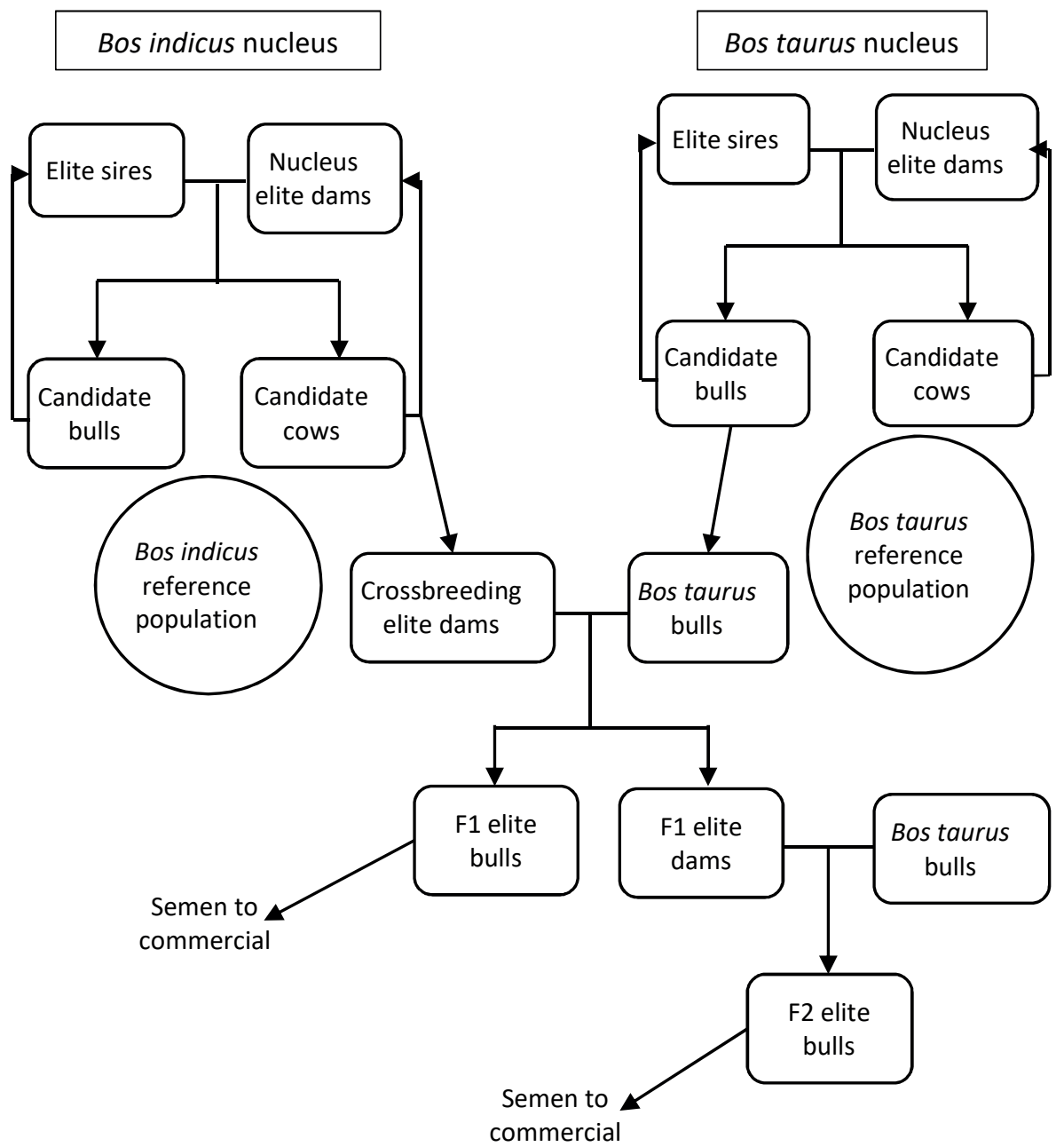

Figure 6.2. Illustration of a crossbreeding structure using Bos indicus and Bos taurus breeds. B. indicus genotype is maintained and improved in a local nucleus scheme. Elite crossbreeding dams are mated with $B$. taurus bulls to produce 0.5:0.5 B. taurus:B. indicus $F 1$ elite sires that can be used for semen production. F1 dams can also be mated with $B$. taurus bulls to produce 0.75:0.25 $B$. taurus:B. indicus $\mathrm{F} 2$ bulls for semen production. 
Implementation of such a scheme is feasible in Kenya. First, government owned nucleuses keeping Bos indicus cattle are already present in Kenya for the Sahiwal and Boran breeds which can be utilized, particularly the well adapted Sahiwal breed which has relatively well developed dairy characteristics (Ilatsia et al., 2007). Second, dairy farms practicing routine recording can be used to establish a Bos taurus nucleus (Chapter 3). Advantages of crossbreeding are (a) it enables the use of heterosis that will have a positive impact on production and (b) it makes it possible to complement one breed with the other in a structured way to reap the maximum benefits from both breeds. In addition, of female reproductive technologies such as multiple ovulation and embryo transfer can be used to enhance the reproductive capacity of nucleus cows (Kosgey et al., 2005). Disadvantages are that it is a complex and expensive breeding structure requiring the maintenance and selection of not one but two populations. Alternatively, the maintenance of a Bos taurus population can be avoided by importation of these germplasm. However, it will not be possible to control the breeding objective in the exporting country, which may again result in unintended responses.

\subsubsection{Development of a synthetic dairy breed}

A synthetic breed is developed by inter se mating of crossbred male and female animals. Development of stable synthetic breeds adapted to tropical environments has been achieved in Africa e.g. the Bonsmara beef cattle and Dorper sheep breeds (Milne, 2000; ILRI and SLU, 2009). The first step in developing a synthetic breed is to determine which established breeds to use to develop the synthetic breed. The choice of established breeds is based on the traits required in the synthetic breed. For dairy cattle in Kenya, adaptation and production traits are essential for sustainable intensification (Chapter 5). The Holstein-Friesian and Ayrshire breeds have been choice breeds for dairy traits (Bebe et al., 2003). The Bos indicus are essential for adaptation. Second, is to determine the genetic contribution of each established breed to the synthetic breed. This should be based on the economic performance of the synthetic breed on commercial farms. The highly heterogeneous crosses that have resulted from indiscriminate crossing of Bos taurus and Bos indicus cattle provides a base upon which the production, adaptation and economic performance of different levels of crossing can be evaluated. Genetic markers can be used to determine the breed proportions in the crosses and the performance of different levels of crossing compared (Ojango et al., 2014). Once the appropriate level of crossing is established, a nucleus can be established. The design of a GS nucleus scheme illustrated in Chapter 3 can be 
adopted for further development of the synthetic breed. Appropriate crosses are first introduced in the nucleus. These are then subjected to continuous genetic improvement through evaluation and selection. Elite selected sires are then used to produce semen for dissemination to commercial producers.

Development of a synthetic breed has several advantages. First, the presence of crossbred cows on commercial farms provides a platform for testing the "best" combination of breeds in the synthetic breed, which gives a head-start to the breeding program. Second, it is possible to involve the producers in the genetic improvement process through provision of performance and pedigree data for genetic improvement since farmer's rear crosses on their farms. Direct involvement of producers in the breeding process is likely to increase the chances of acceptance of the synthetic breed. Criteria described earlier in this chapter can be used to increase the size of the reference population and minimize inbreeding. Lastly, LD is expected to be relatively high in the crosses for the first few generations, which increases the genetic variance explained by markers and the response to GS (Dekkers and van der Werf, 2007). Disadvantage of this strategy is that the presence of the desired breed proportions in a cow does not indicate a competitive cow, posing the danger of recruitment of an initial parent population of low genetic merit. Furthermore, it will take a long time before the synthetic breed is stabilized and to establish a reference population for the synthetic breed to allow for further genetic improvement.

A crossbreeding approach, though expensive and complicated, allows for maintenance and improvement of indigenous genotypes. These genotypes play a crucial role in pastoral production systems. Therefore, a crossbreeding approach will have a larger socio-economic impact compared to development of a synthetic breed. In addition, it will also aid in the maintenance of biodiversity through continued use these genotypes.

\subsection{Towards a sustainable breeding program}

Sustainability of a breeding program in Kenya will be determined by its long-term ability to create and disseminate genetic superiority profitably. Creating genetic superiority implies a cost to the breeding program, which must be recovered through sale of semen to commercial farms. Therefore, the sustainability of the breeding program will ultimately be determined by the willingness of producers to purchase semen from the program over a longer period of time. To create demand for semen, the program must satisfy the needs at the farm level i.e., the genetic 
superiority created must result in maximal profitability at commercial farms. As illustrated in Chapter 2 and 5, the long-term profitability at commercial farms will be determined by production and functional traits. Reduction in operating costs at the farm level is equally important for the smallholder system as revenue generation through sale of milk and animals. Production traits will give high returns but require an increase of inputs. Functional traits on the other hand are likely to affect direct farm costs such as replacement costs and health care costs. Small holder farmers are expected to benefit more from cost reduction resulting from selection on functional traits.

The large number of smallholder dairy cattle producers and the demand for milk in Kenya reflects a market for semen whose demands are currently met by the unplanned use of Bos taurus semen; and haphazard trial and error crossbreeding. High potential exists for tapping into this market by providing the most appropriate genetic product. For the predominantly low input production and pricing systems in Kenya, the long-term profit maximization at the farm level is more likely to be achieved by breeding a balanced genotype that is well adapted to perform optimally in the system (Chapter 5). A local breeding program is the most suited approach to achieve such a genotype, as discussed in the previous section. By providing the appropriate genetic change in commercial farms, the breeding program can capture the local Kenyan semen market. Maintaining relevance to producers will ensure the long-term sustainability of the program.

It will be essential for the breeding program to generate quick returns on investment. This implies that a program that starts to generate revenues earlier will have a competitive advantage compared to a program that takes long to start selling semen. Genomic selection can offer this advantage, preferably in combination with crossbreeding or the development of a synthetic breed. However, as discussed earlier, present structures in Kenya need to be exploited to fast-track both of these approaches. Lastly, the program will need to be competitive to survive in the market. This requires a prudent business plan besides provision of appropriate germplasm.

\section{References}

Bastiaansen, J.W.M., A. Coster, M.P.L. Calus, J.A.M. van Arendonk, and H. Bovenhuis. 2012. Long-term response to genomic selection: effects of estimation method and reference population structure for different genetic architectures. Genet. Sel. Evol. 44:3.

Bebe, B.O., H.M.J. Udo, G.J. Rowlands, and W. Thorpe. 2003. Smallholder dairy 
systems in the Kenya highlands: breed preferences and breeding practices. Livest. Prod. Sci. 82:117-127.

Boichard, D., V. Ducrocq, and S. Fritz. 2015. Sustainable dairy cattle selection in the genomic era. J. Anim. Breed. Genet. 132:135-143.

Cunningham, E.P., and O. Syrstad. 1987. Crossbreeding Bos indicus and Bos taurus for milk production in the tropics. FAO, Rome, Italy.

Daetwyler, H.D., B. Villanueva, P. Bijma, and J.A. Woolliams. 2007. Inbreeding in genome-wide selection. J. Anim. Breed. Genet. 124:369-376.

Daetwyler, H.D., B. Villanueva, and J.A. Woolliams. 2008. Accuracy of Predicting the Genetic Risk of Disease Using a Genome-Wide Approach. PLoS One. 3:e3395.

Dekkers, J.C.M., and J.H.J. van der Werf. 2007. Stategies, limitations and opportunities for marker-assisted selection in livestock. In Marker-assisted selection - current status and future perspectives in crops, livestock, forestry and fish. E.P. Guimaraes, J. Ruane, B.D. Scherf, A. Sonnino, and J.D. Dargie, editors. FAO, Rome, Italy. 167-184.

Delgado, C., M. Rosegrant, H. Steinfeld, S. Ehui, and C. Courbois. 1999. Livestock to 2020 Revolution - The Next Food Revolution. IFRI Discussion Paper 28. Washington D.C., USA.

Falconer, D.S., and T.F.C. Mackay. 1996. Introduction to quantitative genetics. 4th Ed. Pearson Education Ltd., Edinburgh Gate, Harlow, Essex CM20 2JE, England.

Goddard, M. 2009. Genomic selection : prediction of accuracy and maximisation of long term response. Genetica. 136:245-257.

Habier, D., R.L. Fernando, and J.C.M. Dekkers. 2007. The Impact of Genetic Relationship Information on Genome-Assisted Breeding Values. Genetics. 177:2389-2397.

Hayes, B.J., P.J. Bowman, A.J. Chamberlain, and M.E. Goddard. 2009. Genomic selection in dairy cattle: Progress and challenges. J. Dairy Sci. 92:433-443.

Ilatsia, E.D., T.K. Muasya, W.B. Muhuyi, and A.K. Kahi. 2007. Milk production and reproductive performance of Sahiwal cattle in semi-arid Kenya. Trop. Sci. 47:120-127.

ILRI, and SLU. 2009. Bonsmara. Anim. Genet. Train. Resour.

Jannink, J.L. 2010. Dynamics of long-term genomic selection. Genet. Sel. Evol. 42:35.

Kahi, A.K., T.O. Rewe, and I.S. Kosgey. 2005. Sustainable community- based organizations for the genetic improvement of livestock in developing countries. Outlook Agric. 34:261-270. 
Kosgey, I.S., A.K. Kahi, and J.A.M. van Arendonk. 2005. Evaluation of Closed Adult Nucleus Multiple Ovulation and Embryo Transfer and Conventional Progeny Testing Breeding Schemes for Milk Production in Tropical Crossbred Cattle. J. Dairy Sci. 88:1582-1594.

Kosgey, I.S., S.M. Mbuku, A.M. Okeyo, J. Amimo, J. Philipsson, and J.M. Ojango. 2011. Institutional and organizational frameworks for dairy and beef cattle recording in Kenya: a review and opportunities for improvement. Anim. Genet. Resour. 48:1-11.

McClintock, S., R. Ouma, I. Baltenweck, A.M. Okeyo, A.E. McClintock, and J.E.O. Rege. 2007. Continuous sexed dairy F1 production to alleviate poverty: Combining the economic and the genetics. In Proc. Assoc. Advmt. Anim. Breed. Genet. 17: 41-44.

Meuwissen, T.H.E., B.J. Hayes, and M.E. Goddard. 2001. Prediction of total genetic value using genome-wide dense marker maps.Genetics 157: 1819-1829.

Meuwissen, T.H.E., and A.K. Sonesson. 1998. Maximizing the Response of Selection with a Predefined Rate of Inbreeding : Overlapping Generations. J. Anim. Sci. 76:2575-2583.

Milne, C. 2000. The history of the Dorper sheep. Small Rumin. Res. 36:99-102.

Muir, W.M. 2007. Comparison of genomic and traditional BLUP-estimated breeding value accuracy and selection response under alternative trait and genomic parameters. J. Anim. Breed. Genet. 124:342-355.

Nonato, R., and B. Lobo. 1998. Genetic parameters for reproductive traits of zebu cows in the semi-arid region of Brazil. Livest. Prod. Sci. 55:245-248.

Ojango, J.M.K., K. Kariuki, A. Njehu, and I. Baltenweck. 2012. Breeding management strategies adopted for dairy production under low - input smallholder farming systems of East Africa. Research Report. ILRI, Nairobi, Kenya.Ojango, J.M.K., A. Marete, D. Mujibi, J. Rao, J. Poole, J.E.O. Rege, C. Gondro, W.M.S.P. Weerasinghe, J.P. Gibson, and A.M. Okeyo. 2014. A novel use of high density SNP assays to optimize choice of different crossbred dairy cattle genotypes in smallholder systems in East Africa. In 10th World Congress of Genetics Applied to Livestock Production. Vancouver, BC, Canada. August 17-22, 2014.

Ojango, J.M.K., and G.E. Pollott. 2002. The relationship between Holstein bull breeding values for milk yield derived in both the UK and Kenya. Livest. Prod. Sci. 74:1-12.

Okeno, T.O., I.S. Kosgey, and A.K. Kahi. 2010. Economic evaluation of breeding strategies for improvement of dairy cattle in Kenya. Trop. Anim. Health Prod. 42:1081-1086. 
Pszczola, M., T. Strabel, H.A. Mulder, and M.P.L. Calus. 2012. Reliability of direct genomic values for animals with different relationships within and to the reference population. J. Dairy Sci. 95:389-400.

Schaeffer, L.R. 2006. Strategy for applying genome-wide selection in dairy cattle. J. Anim. Breed. Genet. 123:218-223.

Sonesson, A.K., J.A. Woolliams, and T.H.E. Meuwissen. 2012. Genomic selection requires genomic control of inbreeding. Genet. Sel. Evol. 44:27.

Vaccaro, L.P. de. 1990. Survival of European dairy breeds and their crosses with zebus in the tropics. Anim. Breed. Abstr. 58:475-494.

Wasike, C.B., T.M. Magothe, A.K. Kahi, and K.J. Peters. 2011. Factors that influence the efficiency of beef and dairy cattle recording system in Kenya: A SWOT - AHP analysis. Trop. Anim. Health Prod. 43:141-152.

Woolliams, J.A., P. Berg, B.S. Dagnachew, and T.H.E. Meuwissen. 2015. Genetic contributions and their optimization. J. Anim. Breed. Genet. 132:89-99. 
Summary 
Smallholder dairy cattle farmers that want to intensify their production import semen from breeding programs in temperate regions to improve their herd performance. Continuous importation of semen has resulted in a shift towards higher-yielding temperate genotypes. However, within the smallholder systems these genotypes perform below their potential, exhibit higher mortalities and increase strain on available resources, in a system that is already resource deficient. Two key reasons necessitate the establishment of local breeding programs for sustainable intensification of dairy cattle productivity for smallholder systems. Firstly, there is a difference in breeding objectives for developed and developing dairy cattle industries due to differences in production systems and markets. Secondly, there is unfavourable genotype by environment (GxE) interaction between temperate and tropical regions. Sustainable intensification of the smallholder dairy systems in developing countries can be optimized by addressing these challenges through appropriate breeding programs.

Lack of successful local breeding programs in developing countries is attributed to absence of extensive pedigree and performance recording systems. Therefore, the aim of this thesis was to optimize the design of a breeding program for a situation where (a) there is limited pedigree and performance recording and (b) adaptation and health traits play a crucial role to the productivity and resilience of farms. The design of a breeding program was divided into three major phases (1) the definition of a breeding objective, (2) the comparison of small-scale progeny testing (PT) and genomic selection (GS) schemes in terms of genetic gains and economic benefits and (3) the optimization of the breeding program that balances productivity with sustainability.

Chapter 2 dealt with determination of breeding objective traits. The dairy industry in Kenya is characterized by diverse production and marketing systems. To define a breeding objective, a desired genetic gains approach was used to account for this diversity among the different systems. Analytic Hierarchy Process (AHP) was used to determine individual preference values for milk yield (MY), calving interval $(\mathrm{Cl})$, production life time (PLT), mature body weight (MBW), and fat yield (FY). The classical classification of production systems into large scale and smallholder systems did not adequately capture the differences among producers. These differences were better explained when classification was based on productivity at the individual animal level, with high (HIP) and low intensity producers (LIP) and processors being the main important categories. High intensity producers had highest preferences for PLT and MY, while LIP had highest preference for $\mathrm{Cl}$ and PLT; processors preferred MY and FY the most. Highest disagreements between the groups were observed for FY, PLT, and MY. Individual and group preferences were 
aggregated into consensus preferences using Weighted Goal Programming. Desired gains, as a percentage of the population means for individual traits, were obtained as a product of consensus preferences and approximate genetic gains. These were $2.42 \%$ for $\mathrm{MY}, 0.22 \%$ for $\mathrm{Cl}, 2.51 \%$ for PLT, $0.15 \%$ for $\mathrm{MBW}$ and $0.87 \%$ for $\mathrm{FY}$. The consensus breeding goal derived in this study can be used in the establishment and acceptability of a local breeding scheme for the highly diverse production and marketing circumstances in Eastern Africa.

In Chapter 3 I optimized the utilization of the available limited phenotypic records by optimizing the design of small-sized nucleus programs supported by a few commercial herds with reliable pedigree and performance recording. Optimization was achieved by determining the effect of five selection strategies on genetic superiorities. The five strategies were defined as only nucleus records on dams' performance (DP), progeny records in addition to nucleus records (PT), only genomic information (GS), dam performance records in addition to genomic information (GS+DP), and progeny records in addition to genomic information (GS+PT). Alternative PT, GS, GS+DP and GS+PT schemes differed in the number of progeny per sire and size of reference population. The maximum number of progeny records per sire was 30, and the maximum size of the reference population was 5000. Overall, GS schemes had higher responses and lower accuracies compared to other strategies; the higher response being due to shorter generation intervals. Compared to similar sized progeny testing schemes, genomic selection schemes will have lower accuracies but these are offset by higher responses per year.

Adoption of a selection strategy will be determined by the economic outcome. In Chapter $4 \mathrm{I}$ investigated the economic performance of progeny testing (PT) and genomic selection (GS) strategies over a 20 years investment period. Genetic superiorities were for a nucleus program with 453 male and 360 female animals distributed in 8 non-overlapping age classes. A population of commercial recorded cows (CRC), of sizes 12,592 and 25,184 , was used to produce test daughters in PT or to create a reference population in GS. Economic performance was defined as gross margins, calculated as discounted revenues minus discounted costs following a single generation of selection. Revenues were calculated as cumulative discounted expressions (CDE, kg) x 0.32 (Euro per $\mathrm{kg}$ of milk) x 100,000 (size commercial population). Genetic superiorities were deterministically simulated using pseudo-BLUP index and CDE determined using gene flow. GS schemes had higher cumulative genetic gain in the commercial cow population and higher gross margins compared to PT schemes. Gross margins were between 3.2 and 5.2-fold higher for GS, depending on size of the CRC. The increase in gross margin was 
mostly due to a decreased generation interval and lower running costs in GS schemes. I also evaluated the benefits of storing and selling semen instead of keeping live bulls. Semen storage resulted in an increase in gross margins in PT schemes but gross margins remained lower than those of GS schemes. These results show that implementation of small-sized genomic selection breeding schemes can be economically viable for developing countries.

Intensification of production in smallholder dairy cattle production systems is driven by increasing demand for animal products. Sustainable intensification under these systems requires emphasis on both production and functional traits. Poorly developed pricing systems coupled with unfavourable correlations between production and functional traits may compromise health, welfare and ultimately productivity of cows, particularly for the resource poor systems in challenging tropical environments. Sustainable intensification therefore requires special emphasis on functional traits. In Chapter 5 I compared the effect of three methods to define breeding objectives i.e., economic, desired gains and non-market value, on responses in production and functional related traits. With economic breeding objective, traits weights were based on economic values. Weights for desired gains (DG) and non-market (NM) value weights were derived iteratively. Economic breeding objectives resulted in undesirable responses in calving interval $(\mathrm{Cl})$, fat yield (FY) and mature body weight (MBW), but had the highest returns on investment. DG and NM -based breeding objectives achieved more balanced responses between productivity and functional traits. I conclude that breeding objectives based on desired gains or non-market values can be applied to direct selection towards more robust genotypes but with loss in monetary gain. For smallsized genomic selection schemes, more emphasis is required in functional traits since these traits are more difficult to change due to low heritabilities besides the low accuracy in such schemes due to a small reference population. Such approaches can be used to achieve sustainable intensification for developing smallholder dairy systems.

In Chapter 6 I discuss the technical challenges and solutions to the implementation of breeding programs in developing dairy sectors. In particular, I discuss (a) establishing a reference population (b) controlling inbreeding (c) choice of local genotype to improve and (d) sustainability of the breeding program. A sizable reference population can be established by use of information across generations and recruitment of more producers to participate in routine pedigree and performance recording. To reduce the drop-out rate of producers from the recording scheme requires development of tools that will improve the management and profitability of farms. Effects of inbreeding can be minimized by 
use of optimal contribution selection and by increasing the size of the nucleus. The size of the nucleus can be increased by recruiting cows from the commercial recorded population and other competitive cows in the commercial population. 


\section{Training and Supervision Plan}


EDUCATION AND TRAINING

year

The Basic Package

WIAS Introduction Course

2013

Course on philosophy of science and/or ethics

2015

\section{Scientific Exposure}

\section{International conferences}

65th Eurpean Association of Animal Production (EAAP) conference,

Copenhagen, Denmark, 25th - 29th August, 2014

Animal Production Society of Kenya (APSK) scientific conference,

Kisumu, Kenya, 27-29th April, 2016

67th European Association of Animal Production (EAAP)

conference, Belfast, UK, 29th August - $2^{\text {nd }}$ September, 2016

\section{Seminars and workshops}

WIAS Science Day, 2nd February, 2016

WGS PhD Workshop Carousel, 8th April, 2016

\section{Presentations}

Optimizing the design of small-sized nucleus breeding programs for dairy cattle with minimal performance recording, EAAP,

Copenhagen, Denmark, 27th August, 2014 (oral)

Defining desired genetic gains for breeding goal traits for Holstein-

Friesian cattle breeding program in Kenya, WIAS Science Day, $2^{\text {nd }}$

February, 2016

Economic evaluation of alternative selection strategies for smallsized nucleus dairy cattle breeding programs, Animal Production Society of Kenya, Kisumu, Kenya, $27^{\text {th }}-29^{\text {th }}$ April, 2016

Defining desired genetic gains for breeding goal traits for the Kenya Holstein-Friesian cattle breeding objective, EAAP, Belfast, UK, 29 ${ }^{\text {th }}$ Aug $-2^{\text {nd }}$ Sep, 2016 (Oral)

\section{In-Depth Studies}

\section{Disciplinary and interdisciplinary courses}

EGS-ABG Animal Breeding Graduate Course (in Addis Abba,

Ethiopia)

Tropical Farming Systems with Livestock, WIAS course

Introduction to theory and implementation of genomic selection, 


\section{Advanced statistics courses}

Statistics for Life Sciences

2016

MSc level courses

ABG-30806: Modern Statistics for the Life Sciences

2012

Professional Skills Support Courses

Essentials of Scientific Writing and Presenting

2016

Research Skills Training

Preparing own $\mathrm{PhD}$ research proposal

2013

Introduction to ASREML

Didactic Skills Training

Lecturing

ANSC 241: Animal Breeding [Chuka University, Kenya]

2013

ANSC 372: Agricultural Experimentation [Chuka University, Kenya] 2013

ANSC 241: Animal Breeding [Chuka University, Kenya]

2014 


\section{Curriculum Vitae}

Charles Mbogo Kariuki was born on $20^{\text {th }}$ January, 1979 to Mr Benjamin K. Ngai and Mrs Nicera M. Kariuki in Embu, Kenya. He joined Ena Primary school, Embu for nursery class in 1985. Mr Kariuki completed primary education in 1992 from St. Peters Primary School, Ishiara, Embu. In 1993 he joined Kangaru School, Embu for secondary education and completed secondary education in 1992. In 1998 he joined Egerton University from where he graduated with a BSc. in Animal Production in 2004 and MSc. in Animal Production (Breeding option) in 2010. In 2010 he joined Chuka University College as an Assistant Lecturer. In 2012 he joined Wageningen University to pursue a PhD in Animal Breeding and graduated in 2017. The following is a list of his publications in refereed journals:

Kariuki, C.M., E.D. Ilatsia, I.S. Kosgey, A.K. Kahi. 2010. Direct and maternal (co)variance components, genetic parameters and annual trends for growth traits of Dorper sheep in semi-arid Kenya. Trop. Anima. Health Prod. 42:473-481.

Kariuki, C.M., E.D. Ilatsia, C.B. Wasike, I.S. Kosgey, A.K. Kahi. 2010. Genetic evaluation of growth of Dorper sheep in semi-arid Kenya using random regression models. Small Rumin. Res. 93:126-134.

Kariuki, C.M., H. Komen, A.K. Kahi, J.A.M. van Arendonk. 2014. Optimizing the design of small-sized nucleus breeding programs for dairy cattle with minimal performance recording. J. Dairy Sci. 97:7963-7974.

Kariuki, C.M., E.W. Brascamp, H. Komen, A.K. Kahi, J.A.M. van Arendonk. 2017. Economic evaluation of progeny-testing and genomic selection schemes for small-sized nucleus dairy cattle breeding programs in developing countries. J. Dairy Sci. 100:2258-2268.

Kariuki, C.M., J.A.M. van Arendonk, A.K. Kahi, H. Komen. 2017. Multiple criteria decision making process to derive consensus desired gains for a dairy cattle breeding objective for diverse production systems. J. Dairy Sci. (In press) http://doi.org/10.3168/jds.2016-11454. 
Acknowledgements 
I am grateful to Prof. dr. Johan van Arendonk for agreeing to have me as a PhD candidate at WIAS, Wageningen University. Johan, during the period we interacted, I was most impressed at how keen you were with my work and your willingness to be of assistance despite been extremely busy. My heartfelt gratitude for agreeing to see me through graduation even after you stopped working with the university. Your influence on me goes beyond science. Your humility and kindness has had a big impact on me.

I am grateful to Prof. dr. Hans Komen for agreeing to be my supervisor. Your challenging questions helped me to think in much broader ways. Your contribution to the writing of this thesis cannot be over emphasized. I was also very impressed and challenged by your cooking prowess for the few evenings you invited Simion and me for dinner. Maybe it is time for me to break from our traditions and learn a few cooking tricks!

I am grateful to Prof. dr. Alexander Kahi who has steered me to heights I only dreamt of. I have known and admired you Kahi from my days as an undergraduate student at Egerton University. It was you who encouraged and enabled me to enroll not only for the PhD but also the MSc program in Animal Breeding. It has been a challenging and highly fulfilling endeavor. Many of your students would say the same. Thank you for Prof. (as well always referred to you) for being there for us.

I am grateful to the staff at ABG group of Wageningen University for the encouraging and challenging working environment. I wish in particular to thank Pim who contributed a lot to the writing of the fourth chapter of this thesis. Your challenging questions and guidance Pim helped me write a high quality paper. Thank you Piter and Henk for always taking time to respond to my questions. Thank you Lisette and Ada for making life so very smooth for me. You are the best organized and friendliest secretariat I ever known. But most impressive was your willingness to be of assistance even when you had too much work to do. Kudos! I am grateful to my fellow PhD students for the time we had together. In one way or another you made my stay in Wageningen memorable. I am particularly grateful to my office mates over the years; Gus, Panya, Britt, Simion, Anche, Matthieu, Carolia, Merina, Sonia, Maria and Zhou. I was the quietest, I admit. But it was great having you as my office mates. I enjoyed the talks and jokes. At least you pushed me to say a few words every day:-

I am grateful to my wife Cherop and sons Müngai and Müthure for always being so patient with me. It was difficult for you guys (and me too) that I was away from home for so long periods. I thank you for standing with me during those difficult 
moments and your encouragement. Am also grateful to my parents and siblings who have stood with me this many years.

I am also grateful to NUFFIC, The Hague, The Netherlands who financed this study. It is my hope this work contributes not only to knowledge and science but more directly to the productivity and profitability of smallholder dairy cattle farms in developing countries and to the achievement of the NUFFIC vision for a better world for humanity. 
The research described in this thesis was financed by NUFFIC, The Hague, The Netherlands.

I acknowledge Chuka U niversity for granting me a paid study-leave during the period of the study.

This thesis was printed by Digiforce / Proefschriftmaken.nl, De Limiet 26, 4131 NC, Vianen, The Netherlands 